\title{
OLFML2A Downregulation Inhibits Glioma Proliferation through Suppression of Wnt/ $\beta$-catenin Signaling
}

\section{Shize Ma}

Lanzhou University Second Hospital https://orcid.org/0000-0003-4660-1314

\section{Lei Duan}

Lanzhou University Second Hospital

\section{Huateng Dong}

Gansu Provincial Maternity and Child-Care Hospital

\section{Xiaodong Ma}

Lanzhou University Second Hospital

\section{Xinyu Guo}

Lanzhou University Second Hospital

Jianli Liu

Lanzhou University

\section{Guoqiang Li}

Lanzhou University Second Hospital

\section{Yue Yu}

Lanzhou University Second Hospital

\section{Yanlong Xu}

Lanzhou University Second Hospital

\section{Guoqiang Yuan}

Lanzhou University Second Hospital

\section{Xingkun Zhao}

Lanzhou University

\section{Guopeng Tian}

Lanzhou University Second Hospital

\section{Shijia Zhai}

Lanzhou University Second Hospital

\section{Yawen Pan}

Lanzhou University Second Hospital

\section{Yinian Zhang ( $\nabla$ ery_zhangyinian@lzu.edu.cn )}

Lanzhou University Second Hospital https://orcid.org/0000-0002-5942-994X 
Research

Keywords: Olfactomedin-like 2A (OLFML2A), glioma, amyloid precursor protein (APP), proliferation, apoptosis, Wnt/ $\beta$-catenin signaling

Posted Date: December 16th, 2020

DOl: https://doi.org/10.21203/rs.3.rs-126643/v1

License: (c) (i) This work is licensed under a Creative Commons Attribution 4.0 International License.

Read Full License 


\section{Abstract}

Background: Glioma is a highly heterogeneous and lethal tumor with extremely poor prognosis. Through analysis of TCGA data, we found that OLFML2A was significantly upregulated in glioma tissues and positively correlated with glioma grade and worse prognosis. However, the molecular function of OLFML2A and its underlying mechanism in glioma remain unclear.

Methods: The expression of OLFML2A in glioma was determined by immunohistochemistry (IHC). Celigo assay, MTT assay and flow cytometry were utilized to evaluate the effects of OLFML2A on glioma proliferation and apoptosis. Gene chip microarray analysis and ingenuity pathway analysis were used to investigate the potential regulatory mechanisms of OLFML2A, which were further assessed by q-PCR, western blotting and IHC. An animal transplanting glioma model and spectral computed tomography scan were used to verify OLFML2A expression in vivo.

Results: In this study, we found that the expression of OLFML2A was significantly upregulated in glioma specimens and positively correlated with pathological grades in glioma patients. Moreover, Kaplan-Meier survival analysis of TCGA data revealed that glioma patients with higher expression of OLFML2A had shorter overall survival. Importantly, when we knocked down the expression of OLFML2A in glioma cells, cell proliferation was inhibited, and apoptosis was promoted. Mechanistically, downregulation of OLFML2A inhibited Wnt/ $\beta$-catenin signaling by directly reducing the level of stabilized $\beta$-catenin and upregulating the expression of amyloid precursor protein (APP) to indirectly suppress $\beta$-catenin, leading to repression of MYC, CD44 and CSKN2A2 expression. Furthermore, we found that OLFML2A downregulation clearly suppressed the growth of subcutaneous glioma and intracranial transplantation of glioma by inhibiting Wnt/ $\beta$-catenin pathway-dependent cell proliferation.

Conclusion: Our data indicate the oncogenic effect of OLFML2A in glioma through regulation of Wnt/ $\beta$ catenin signaling, which may provide a novel therapeutic target for glioma.

\section{Background}

Glioma is characterized by extremely poor outcomes[1]. In particular, glioblastoma (GBM), a World Health Organization (WHO) grade IV tumor, is the most common and aggressive malignant brain tumor in humans, and even with radical surgery, radiation therapy and chemotherapy, the median survival time is less than 12 months[2]. Studies over the past two decades have partly characterized the genetic basis of tumorigenesis in glioma[3, 4]. Based on these findings, the molecular classification standard of central nervous system tumors was established by the WHO in 2016[5]. However, glioma is a highly heterogeneous tumor[6], and there are many specific molecules that can be used for its classification. Thus, identifying the molecules that regulate glioma progression may contribute to the development of reliable therapeutic targets for glioblastoma.

Olfactomedin-like 2A (OLFML2A) belongs to subfamily $₫$ of olfactomedin domain-containing (OLFM) proteins[7], also known as photomedins-1, which were first identified and characterized in the mouse 
retina[8]. In normal human tissue, OLFML2A is predominantly detected in the photoreceptor layer of the retina but is not expressed in neuronal tissues[9]. Currently, the function of OLFML2A is still generally poorly understood. Recent studies have shown that OLFML2A is highly expressed in triple-negative breast cancer (TNBC) and positively related to cell growth, proliferation and migration[10]. In acute myeloid leukemia, the high expression of OLFML2A is associated with extramedullary infiltration and predicts a poor prognosis[11]. Consistent with these findings, Dr. Dai showed that OLFML2A was also overexpressed in liver hepatocellular carcinoma (LIHC) and many other cancers, such as breast cancer and leukemia, using the Oncomine dataset compared to normal samples[12]. Ultimately, Kyoto Encyclopedia of Genes and Genomes (KEGG) pathway and process enrichment analysis suggested that OLFML2A regulates the tumorigenesis of LIHC through angiogenesis, negative regulation of DNA-binding transcription factor activity, regulation of neuron differentiation, positive regulation of apoptotic process, and autophagy via the Wnt, Notch, and hypoxia signaling pathways[12]. The above observations suggest that OLFML2A may be involved in many cancers. However, the detailed regulatory mechanisms have not yet been thoroughly validated, and the underlying molecular mechanisms need to be clarified. Moreover, the role of OLFML2A in glioma has not been reported.

Therefore, to better understand the function of OLFML2A and identify new markers for targeted glioma therapy, in the present study, in vitro and in vivo assays and bioinformatics analyses were performed to elucidate the function and mechanisms of OLFML2A in glioma progression.

\section{Materials And Methods Cell culture}

Human glioblastoma cell lines (U87MG and U251) were purchased from GeneChem (Shanghai, China) and were cultured in DMEM (HyClone, USA) supplemented with $10 \%$ fetal bovine serum (Sigma, USA) and $1 \%$ penicillin and streptomycin (Beyotime). All cells were cultured in a humidified incubator at $37^{\circ} \mathrm{C}$ with $5 \% \mathrm{CO}_{2}$.

\section{Lentiviral transduction}

Cells were seeded in 6-well plates at $5 \times 10^{4}$ cells/well and incubated at $37{ }^{\circ} \mathrm{C}$ until $30 \%$ confluence was reached. According to the multiplicity of infection, an appropriate amount of lentivirus was added to the culture medium of glioma cells for transduction, and the cells were cultured for another $14 \mathrm{~h}$. The medium containing the lentivirus was then removed, and the cells were cultured in normal medium for 58 h. The expression of GFP was observed under a fluorescence microscope 3 days after infection, and glioma cells with infection efficiency $>80 \%$ were selected for subsequent analysis.

All lentiviruses were purchased from GeneChem (Shanghai, China). The forward sequences of the shRNAs targeting OLFML2A in U251 and U87MG cells were as follows: sh-OLFML2A-1: 
TCTATGTCACCAACTACTA and sh-OLFML2A-2: GCCAAACAAACATTCACTA. The forward sequence of the shRNA targeting OLFML2A in C6 cells was as follows: AGGCCGGTGGAGTAATATGTA. To increase the efficiency of RNA interference, four shRNAs targeting amyloid precursor protein (APP) were designed, and the four plasmids carrying the different shRNAs were mixed in equal proportion for lentivirus packaging. The forward sequences of the shRNAs targeting APP in U87MG cells were as follows: psc10391: cCCTGTTCATTGTAAGCACTT; psc10392: gcAGACACAGACTATGCAGAT; psc11434: cCCAAAGTTTACTCAAGACTA; and psc11435: gcCATCTTTGACCGAAACGAA.

\section{Immunohistochemistry (IHC)}

All glioma specimens were routinely sectioned in paraffin, and immunohistochemical staining was performed. Specimens were cut into 5- $\mu \mathrm{m}$ sections. The slides were subjected to antigen retrieval. Sections were incubated with primary antibodies (anti-OLFML2A antibody, Abcam, ab75882, 1:200; antiKi-67 antibody, Abcam, ab15580, 1:200; anti-APP antibody, Abcam, ab32136, 1:300; anti- $\beta$-catenin antibody, CST, CST\#8480, 1:50; anti-P-ß-catenin (Ser33/37/Thr41) antibody, CST, CST\#9561, 1:200; antiGSK-3 $\beta$ antibody, CST, CST\#12456, 1:800; and anti-P-GSK-3 $\beta$ antibody, CST, CST\#9323, 1:50) overnight at $4{ }^{\circ} \mathrm{C}$ and then visualized using a DAB detection kit according to the manufacturer's protocol. Sections were counterstained with hematoxylin and observed under a BX-53 microscope (Olympus, Tokyo, Japan). The degree of immunostaining in the sections was reviewed and scored independently by 2 observers based on both the percentage of positively stained tumor cells and the staining intensity. The staining intensity was graded into four categories on a scale from 0 to 3 (intensity score): no staining (0), lightbrown staining (1), brown staining (2) and dark-brown staining (3). Protein staining was evaluated using the following formula: overall staining score = intensity score $\times$ percentage score.

\section{Cell proliferation analysis by Celigo assay}

Cell proliferation was analyzed using a Celigo assay as described in a previous work[13]. Briefly, cells were cultured in 96-well plates at a density of 1000 cells/well and treated with the indicated shRNAs or control shRNA (shCtrl). The medium was changed every other day. The cells were imaged with a Celigo Imaging Cytometer for 5 consecutive days. For each experimental well of a 96-well plate, Celigo scans of four visual fields at each time point (40 × magnification) were performed, and the images were analyzed with the corresponding software. Each assay was conducted in triplicate. After 5 days of consecutive measurements, a cell growth curve was plotted to reflect cell proliferation.

\section{3-(4,5-Dimethylthiazol-2-yl)-2,5-diphenyl tetrazolium bromide (MTT) assay}

MTT and dimethyl sulfoxide (DMSO) solutions (Sigma-Aldrich, St. Louis, MO, USA) were used to determine the cell proliferative ability. Specific cells $\left(2 \times 10^{4}\right)$ were seeded into 96 -well plates. Sterile MTT 
solution $(10 \mu \mathrm{L})$ was added to the 96 -well plate after cell culturing for $24 \mathrm{~h}, 48 \mathrm{~h}$ and $72 \mathrm{~h}$. After incubation for $4 \mathrm{~h}$ at $37^{\circ} \mathrm{C}$, the medium was removed, and $150 \mu \mathrm{L}$ DMSO was added to each well. The absorbance at $490 \mathrm{~nm}$ was measured on a microplate reader (SpectraMax i3X, MOLECULAR, California, USA).

\section{Quantitation of apoptosis by flow cytometry}

An Annexin-V-APC apoptosis detection kit (eBioscience, Cat. No. 88-8007) was used for cell apoptosis analysis according to the manufacturer's instructions. First, glioma cells were infected with a lentivirus expressing OLFML2A or a scrambled shRNA sequence (Scr-shRNA). After incubation for another 4 days, the cells were harvested, washed with PBS buffer, and resuspended in staining buffer at a final density of $1 \times 10^{6}-1 \times 10^{7} / \mathrm{ml}$. Then, $5 \mu \mathrm{L}$ Annexin-V-APC was added to $100 \mu \mathrm{L}$ cell suspensions and incubated at room temperature for 10-15 min. Signals were detected with a FACSCalibur (Becton-Dickinson, USA).

\section{Animal studies}

All animals were purchased from the Animal Experiment Center of Gansu College of Traditional Chinese Medicine (Lanzhou, China) and housed in a standardized specific pathogen-free animal facility. All experimental procedures were approved by the Institutional Animal Care and Use Committee of Lanzhou University Second Hospital.

For the tumor xenograft implantation model, 4-week-old mice were randomly divided into two groups ( $n=10$ per group) and implanted with $1 \times 10^{6}$ U87MG cells previously transfected with OLFML2A shRNA lentivirus or negative control. Cells were mixed with Matrigel (50\% volume) and implanted subcutaneously into the right flank areas of the nude mice (BALB/c). Tumor volume was determined using an external caliper every 3-4 days and calculated using the formula (Length $\left.\times W i d t h^{2}\right) / 2$. Mice were sacrificed 50 days after transplantation, at which time tumors were excised and subjected to subsequent analyses.

For the orthotropic model, $1 \times 10^{6}$ C6-OLFML2A-shRNA cells and control cells were injected into the right corpus striatum of the brains of 6-week-old Wistar rats using a stereotactic frame. Spectral computed tomography (HD750 CT scanner; GE Healthcare, Little Chalfont, UK) was performed to record tumor growth at 14 days and 19 days after injection. The scanning parameters were consistent with those reported in previous work[14]. Rats were monitored and sacrificed when neurological signs appeared or after 35 days.

\section{Gene chip microarray analysis}


Total RNA was extracted using an RNAiso Plus kit (TaKaRa Biotechnology Co., Ltd., Dalian, China) and examined using a NanoDrop 2000 Spectrophotometer (Thermo Scientific, MA, USA) and an Agilent Bioanalyzer 2100 (Palo Alto, CA, USA)[15]. Only samples of sufficient quality were used in subsequent gene chip experiments. The RNA quality control standards were as follows: $1.7<A 260 / A 280<2.2$ on the NanoDrop 2000 and an RNA integrity number $(\mathrm{RIN})>=7.0$ and a $28 \mathrm{~S} / 18 \mathrm{~S}$ ratio $>0.7$ on the Agilent 2100 Bioanalyzer. The microarray was processed as described in previous work[16]. Briefly, amplified RNA ( aRNA) was prepared from total RNA using a GeneChip 3' IVT Express Kit (Affymetrix, Santa Clara, CA, USA). DNA was synthesized, after which double-stranded template DNA was synthesized. Biotin-labeled aRNA was obtained by transcription in vitro. Then, aRNA was purified, fragmented, labeled and hybridized with an Affymetrix GeneChip ${ }^{\circledR}$ Human Transcriptome Array 2.0 (Affymetrix, Santa Clara, CA, USA). After hybridization, the chips were washed and stained. Finally, raw intensity data were analyzed using Affymetrix Expression Console software after the images and raw data were scanned. Genes that were up- or downregulated with fold changes $>2.0$ or $<2.0$ were analyzed using Affymetrix Transcriptome Analysis Console Software.

\section{Ingenuity pathway analysis (IPA)}

IPA of differentially expressed genes (DEGs) was conducted with Qiagen's Ingenuity Pathway Analysis algorithm (www.qiagen.com/ingenuity, Qiagen, Redwood City, CA, USA). Canonical pathway analysis, functional analysis, regulatory effect analysis, and interaction network analysis were performed. The activation z-score and overlapping p-value were calculated as described in a previous work[17].

\section{Quantitative real-time PCR (qRT-PCR)}

Cells in the exponential growth phase were collected, and an RNAiso Plus kit (TaKaRa Biotechnology Co., Ltd., Dalian, China) was used for cell lysis to extract total RNA. A NanoDrop-2000 spectrophotometer (Thermo Scientific, MA, USA) was used to measure the purity and concentration of RNA. According to the manufacturer's protocol, total RNA was reverse transcribed using the Prime Script RT kit (TaKaRa Biotechnology Co., Ltd.) for 15 min at $37^{\circ} \mathrm{C}$ and 20 seconds at $85^{\circ} \mathrm{C}$. Subsequently, PCR amplification was performed using SYBR ${ }^{\circledR}$ Premix Ex Taq ${ }^{\mathrm{TM}}$ Master Mix (TaKaRa Biotechnology Co., Ltd.) and the BioRad CFX96 Real-time PCR system (Bio-Rad Laboratories, Inc., Hercules, CA, USA). The primers used are illustrated in Table 1. PCR was performed with a final volume of $10 \mu \mathrm{L}$ and the following cycles: initial denaturation step at $95^{\circ} \mathrm{C}$ for $10 \mathrm{~min}$, followed by 40 cycles at $95^{\circ} \mathrm{C}$ for 10 seconds, $60^{\circ} \mathrm{C}$ for 30 seconds, and $72{ }^{\circ} \mathrm{C}$ for 30 seconds. As the reaction progressed, a fluorescence signal was obtained. After amplification, a melting curve analysis was performed, which was used to determine the dissociation characteristics of the PCR products. The $2^{-\Delta \Delta C q}$ method was used to calculate the mRNA expression level relative to the expression level of the internal reference gene GAPDH. Each sample was run in triplicate. 
Table 1

Primer sequences used in this study.

\begin{tabular}{|c|c|c|}
\hline Gene & forward primer $5^{\prime}-3^{\prime}$ & reverse primer 5'-3' \\
\hline GAPDH & TGACTTCAACAGCGACACCCA & САCCCTGTTGCTGTAGCCAAA \\
\hline$O L F M L 2 A$ & AACAGGCAGTAGAGTCAA & TTACAAGATTCCTACCAACAG \\
\hline$A P P$ & CTGATGCGGAGGAGGATGAC & TCTCTGTGGCTTCTTCGTAGG \\
\hline Wnt3 & GGACGGAGAAGCGGAAGGA & GCGAGTTGGGTCTGGGTCAT \\
\hline Wnt5a & TCGACTATGGCTACCGCTTTG & CACTCTCGTAGGAGCCCTTG \\
\hline Wnt5b & CTGGTGGTCATTAGCTTTG & ATGTGCTCCTGGTACAATT \\
\hline$M Y C$ & TGTCCGTCCAAGCAGAGG & CGCACAAGAGTTCCGTAGC \\
\hline$C D 44$ & AGGCTGAGACAGGAGGTTA & ССТCССTTATTTCTATCGTG \\
\hline CSNK2A2 & TGGAGTTTGGGCTGTATGTT & TCGTATCGCAGAAGTTTGTC \\
\hline LEF1 & AGAGCGAATGTCGTTGCTGA & TCGTTTTCCACCTGATGCAGA \\
\hline FZD3 & CAAATCTGGGTGTTGGGTT & TGAGAAAGGCTGGGCATC \\
\hline LRP6 & TGGGGAAACTATGACTAATG & CTGACAAAGAACTTGGGTG \\
\hline$L R P 1$ & AGGGCGTAGGTTCCTTTCTC & CATTGGTCACCACGTCTTCA \\
\hline DVL3 & TACTGCGGGAGATTGTGC & GAACTGGTGATGGAGGAGC \\
\hline SOX4 & ACTTCGAGTTCCCGGACTACT & TGAAAACCAGGTTGGAGATGC \\
\hline MAPЗK7 & CCGGTGAGATGATCGAAGCC & GCCGAAGCTCTACAATAAACGC \\
\hline AKT3 & AATGGACAGAAGCTATCCAGGC & TGATGGGTTGTAGAGGCATCC \\
\hline MDM2 & GAATCATCGGACTCAGGTACATC & TCTGTCTCACTAATTGCTCTCCT \\
\hline$R A R G$ & ATGCTGCGTATCTGCACAAG & AGGCAAAGACAAGGTCTGTGA \\
\hline$B T R C$ & AGTTCTGCACTTGCGTTTC & ACTCACTACCAGCCTGTCC \\
\hline TGFBR2 & GTGCCAACAACATCAACC & GACTGCCACTGTCTCAAACT \\
\hline ACVR1C & GCACCTTCCAACAGCATCAC & ATCCAGAGGCGGTCACATC \\
\hline$A C V R 2 B$ & AGACACGGGAGTGCATCTACT & GCCTATCGTAGCAGTTGAAGTC \\
\hline$P P P 2 R 2 B$ & ACCAGGGACTACTTGACCG & TCACGCTTGGTGTTTCTGT \\
\hline
\end{tabular}

\section{Western blot analysis}


Cells were lysed using RIPA (Beyotime Institute of Biotechnology) buffer on ice for 30 min and were centrifuged at $12,000 \times \mathrm{g}$ for $45 \mathrm{~min}$ at $4{ }^{\circ} \mathrm{C}$. The protein concentrations were analyzed by the BCA protein assay kit (Solarbio, China). The samples were subjected to SDS-PAGE and transferred to PVDF membranes. Membranes were blocked with TBST containing $5 \%$ bovine serum albumin (BSA, Solarbio, China) for $2 \mathrm{~h}$ at room temperature and then incubated with primary antibodies against the following antigens: OLFML2A (1:500, Abcam, ab85458, UK); GAPDH (1:1000, Abcam, ab8245, UK); APP (1:500, Abcam, ab32136, UK); $\beta$-catenin (1:500, CST, CST\#8480, USA); P- $\beta$-catenin (Ser33/37/Thr41) (1:500, CST,

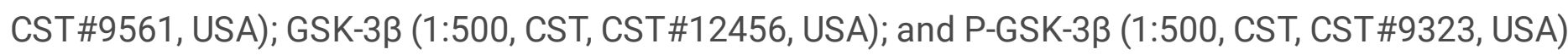
overnight at $4{ }^{\circ} \mathrm{C}$. The membranes were then washed three times with TBST and incubated with horseradish peroxidase-conjugated secondary antibody for $2 \mathrm{~h}$ at room temperature. The blots were visualized with an enhanced chemiluminescence (ECL) kit (Solarbio, China) and scanned by Chemlmager 5500 V2.03 software. The relative integrated density values (IDVs) were calculated using Fluor Chen 2.0 software based on GAPDH as an internal control.

\section{Statistics and data analysis}

All data are presented as the means \pm standard deviation (SD). Statistical analyses were performed using Prism 8 (GraphPad Software, San Diego, CA, USA). Two-tailed Student's t-test was used to assess the significance of the differences between two groups. One-way ANOVA was used to assess the significance of the differences among multiple groups. Survival curves were analyzed using the Kaplan-Meier method and assessed by the log-rank test. P-values $<0.05$ were considered to be statistically significant.

\section{Results}

\section{OLFML2A overexpression is correlated with glioma progression and poor prognosis}

By analyzing datasets from The Cancer Genome Atlas (TCGA), we found that OLFML2A expression was significantly upregulated in glioma tissues compared with normal brain tissue and that OLFML2A expression was positively correlated with glioma grades (Fig. 1a-b). Kaplan-Meier survival analysis of TCGA data revealed that glioma patients with higher expression of OLFML2A had shorter overall survival (Fig. 1c). Real-time PCR showed that OLFML2A expression was upregulated in four different glioma cell lines (Fig. 1d). These findings suggested that OLFML2A is overexpressed in human glioma.

To determine the clinical relevance of OLFML2A in glioma patients, OLFML2A was examined in 69 paraffin-embedded, archived glioma tissues by IHC. As expected, OLFML2A was significantly upregulated in glioma tissues (Fig. 1e). Furthermore, OLFML2A levels were positively correlated with pathological grades in glioma patients (Fig. 1f). Collectively, these findings confirmed the results of TCGA analysis and suggested a potential association between OLFML2A upregulation and the progression of glioma. 


\section{OLFML2A expression was efficiently inhibited by lentiviral- based shRNA in human Glioma cell lines}

A positive correlation between OLFML2A expression and glioma grade suggests that OLFML2A may be involved in glioma development and progression. To examine the causal role of OLFML2A in gliomas, a lentiviral-based shRNA strategy was employed to knock down OLFML2A in the human glioma cell lines U251 and U87MG. First, lentivirus expressing shRNA specifically targeting human OLFML2A (OLFML2AshRNA) or Scr-shRNA was generated. Then, U251 and U87MG cells were infected with the lentivirus expressing OLFML2A-shRNA or Scr-shRNA to evaluate the knockdown efficiency. Cells were harvested, and total RNAs/proteins were collected. Then, quantitative fluorescent PCR and western blotting were performed to determine OLFML2A expression at both the mRNA and protein levels. The OLFML2A protein was barely detected in cells treated with OLFML2A-shRNA (Fig. 2b); similarly, OLFML2A mRNA expression was significantly reduced (Fig. 2a). These results showed that the lentiviral-based shRNA strategy could efficiently inhibit OLFML2A expression at both the protein and mRNA levels.

\section{OLFML2A knockdown leads to reduced proliferation of glioma cells in vitro}

The glioma cells U251 and U87MG express high levels of OLFML2A protein. To determine whether OLFML2A is required for the proliferation of these cell lines, we generated U251 and U87MG cells with lentivirus-delivered OLFML2A shRNA knockdown as previously described. Then, Celigo assays were performed to monitor cell growth for 5 days. As shown in Figure 3a-f, silencing OLFML2A decreased the total cell numbers and slowed the growth rate of U251 and U87MG cells. The MTT assay was used to further evaluate the effect of OLFML2A knockdown on the proliferation ability of U251 and U87MG cells. As indicated in Figure 3g-j, the cell proliferation rate of the OLFML2A-shRNA group was markedly reduced compared with that of the control group.

\section{Suppression of OLFML2A leads to increased apoptosis of glioma cells}

Resisting cell death, another hallmark of cancers, is essential for tumors. The reduction in cell number induced by OLFML2A knockdown may be attributed to cell proliferation inhibition and increased cell apoptosis. To further investigate whether OLFML2A promotes the proliferation of glioma cells by regulating cell apoptosis, we used Annexin-V staining to assess apoptosis in OLFML2A-knockdown and control U251 cells. OLFML2A knockdown significantly induced apoptosis in U251 cells (Fig. 4a-b). Similar results were observed in U87MG cells following OLFML2A silencing by shRNA (Fig. 4c-d). These results suggest that OLFML2A inhibits apoptosis in glioma cells. 


\section{Disruption of multiple critical cell cycle regulation pathways involved in cancer development by OLFML2A knockdown}

The results above showed that OLFML2A is critical for tumor development in human glioma cell lines. However, the mechanisms underlying OLFML2A-mediated glioma development and its downstream pathways have not been systematically explored. Here, global gene expression profiling of U87MG cells infected with lentivirus expressing either Scr-shRNA or OLFML2A-shRNA was performed using a microarray platform, and 1911 genes showing significant differential expression were identified (based on |fold change| $\geq 2.0$ and FDR<0.05), of which 658 were upregulated and 1253 were downregulated (Fig. $5 a-b$ and Supplementary Document 1-2). Then, functional analysis using IPA was performed, and the DEGs were found to be enriched in cancer, cell cycle, cell death and cell survival, cellular growth and proliferation, suggesting that OLFML2A was significantly (based on a $\mathrm{P}<0.001$ threshold) involved in proliferation and cell cycle regulation processes (Fig. 5c).

Canonical pathway analysis using IPA was conducted to further explore potential signaling pathways, and 136 pathways were identified (Supplementary Document 3-Canonical Pathways.xlsx), of which 117 were inhibited and 19 were activated following OLFML2A gene suppression (based on |Z-score|>0 and $P<0.05)$. Of note, among the inhibited signaling pathways, those involved in cell proliferation and cell cycle regulation, such as Cyclins and Cell Cycle Regulation, Estrogen-mediated S-phase Entry, and Glioblastoma Multiforme Signaling, were significantly inhibited (based on $\mid Z$-score|>2 and P<0.05) (Fig. $5 d)$. In addition, Cell Cycle Regulation by BTG Family Proteins (Z-score囚-1.633), TGF- $\beta$ Signaling (Z-score 囚-1.387), Wnt/ $\beta$-catenin Signaling (Z-score邓-1.342) and Antiproliferative Role of Somatostatin Receptor 2 (Z-score $\-1.265)$, which are important signaling pathways in glioma proliferation and cell cycle regulation, were also inhibited (Fig. 5d). Furthermore, Apoptosis Signaling (Z-score『1.508), Cell Cycle: G1/S Checkpoint Regulation (Z-score=1.291) and Cell Cycle: G2/M DNA Damage Checkpoint Regulation (Z-

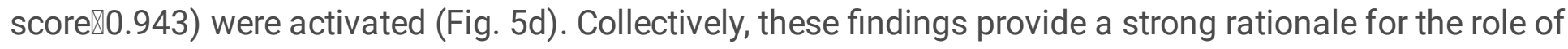
OLFML2A as a crucial molecule that regulates the proliferation of glioma cells.

\section{OLFML2A knockdown suppresses the Wnt/ $\beta$-catenin pathway in glioma cells}

Based on previous studies, activation of the $\mathrm{Wnt} / \beta$-catenin pathway has been reported in glioma and is essential for glioma growth, proliferation, cell cycle regulation and apoptosis[18]. Importantly, IPA data showed that Wnt/ $\beta$-catenin signaling was one of the inhibited pathways enriched in the OLFML2Aassociated gene signatures (Fig. $5 \mathrm{~d}$ ). The expression of 21 molecules involved in the $\mathrm{Wnt} / \beta$-catenin pathway was altered (Fig. 6a). We validated the expression levels of the 21 molecules by real-time PCR, and we found that the expression levels of Wnt ligands (Wnt3, Wnt5a, Wnt5b), the transcription factor LEF1 and Wnt-downstream genes (MYC, CD44, CSKN2A2) were decreased when OLFML2A was downregulated (Fig. $6 \mathrm{c}$ ). The changes in the remaining molecules were generally consistent with the 
results of chip detection (Fig. 6c) These data preliminarily confirmed that Wnt activity was suppressed with OLFML2A downregulation. Further, we found that the mRNA levels of the Wnt target genes MYC, CD44 and CSKN2A2 were significantly and positively correlated with the OLFML2A mRNA levels in GBM patients by analyzing TCGA data (Fig. $6 \mathrm{~d}$ ). Accumulating studies have demonstrated that the regulation of $\beta$-catenin and GSK-3 $\beta$ phosphorylation determines the activation of the Wnt/ $\beta$-catenin pathway[18]. Next, we detected the phosphorylation of $\beta$-catenin and GSK-3 $\beta$ in U87MG cells. The results showed that the Thr41/Ser37/Ser33 phosphorylation levels of $\beta$-catenin were significantly increased with OLFML2A downregulation. Conversely, the stabilized $\beta$-catenin level was decreased when OLFML2A was downregulated. Additionally, we observed that phosphorylation of GSK-3 $\beta$ was significantly decreased and total GSK-3 $\beta$ was elevated with OLFML2A downregulation. Therefore, our study indicated that high levels of OLFML2A expression may activate the $\mathrm{Wnt} / \beta$-catenin pathway to promote cell proliferation and inhibit cell apoptosis.

\section{APP acts as an intermediate molecule to mediate the downstream regulatory effects of OLFML2A in glioma}

To further clarify the regulatory mechanism of OLFML2A on the Wnt/ $\beta$-catenin pathway and cell proliferation, interaction network analysis based on IPA was performed, which confirmed that APP is an important intermediate molecule that mediates the downstream regulatory effects of OLFML2A (Fig. 7a). It has been reported that APP is a negative regulator of the Wnt/ $\beta$-catenin signaling pathways[19]. Our study showed that OLFML2A knockdown leads to increased expression of APP (Fig. 7b-c). Furthermore, we found that the expression of APP was significantly downregulated in GBM tissues compared with normal brain tissue by analyzing TCGA data (Fig. 7d). Additionally, we demonstrated that downregulation of APP partly increases the proliferation of OLFML2A-knockdown U87MG cells (Fig. 7e-f). These data further suggest that APP is a functional regulator that mediates the downstream regulatory effects of OLFML2A through the Wnt/ $\beta$-catenin pathway in glioma.

\section{Downregulation of OLFML2A leads to the repression of glioma cell proliferation in vivo}

We used a xenograft model to test whether OLFML2A knockdown reduces tumor growth in vivo. U87MG cells infected with Scr-shRNA or OLFML2A-shRNA were transplanted into immunocompromised nude mice. Significantly, OLFML2A knockdown led to 7.66- and 6.6-fold decreases in the volume and weight of tumors, respectively (Fig. 8a-C) $(n=10)$. The IHC staining of Ki-67 showed the proliferation states of subcutaneous glioblastoma tissues, in which the positive rate of Ki-67 in the OLFML2A-shRNA groups was significantly lower than that in the control groups (Fig. 8d). In addition, the expression level of APP was consistent with the results in vitro (Fig. 8e). Moreover, IHC assays indicated that the phosphorylation level of $\beta$-catenin was significantly elevated while stabilized $\beta$-catenin was markedly decreased in the 
OLFML2A-shRNA groups (Fig. 8e). These results confirmed that OLFML2A functioned as an oncogene in glioblastoma by regulating the Wnt/ $\beta$-catenin pathway via APP in vivo.

To further verify the effects of OLFML2A on glioma growth in immunocompetent animals, we transplanted C6-OLFML2A-shRNA cells and control cells into the right striatum of Wistar rats and found that the downregulation of OLFML2A strongly suppressed the growth of intracranial glioma by CT scan. The tumor volume in the OLFML2A-shRNA group was significantly smaller than that in the control group on days 14 and 19 after transplantation (Fig. 9a). Likewise, gross observation also demonstrated that the downregulation of OLFML2A slowed the growth of orthotopic glioblastoma (Fig. 9b). In addition, the proliferative state was alleviated after OLFML2A knockdown, as demonstrated by Ki-67 staining (Fig. 9c).

\section{Discussion}

Glioma is a very aggressive and heterogeneous tumor that lacks effective targeted therapy and has a relatively poor prognosis[20]. It is urgent to identify additional targets to develop potential diagnostic and therapeutic strategies. Here, we first analyzed a publicly available genomic database (TCGA) and identified OLFML2A as a putative molecule involved in glioma tumorigenesis. Our results indicated that OLFML2A was upregulated in glioma, negatively correlated with the prognosis of glioma patients and positively correlated with tumor grade. We found that the level of OLFML2A was correlated with glioma proliferation and apoptosis. Downregulation of OLFML2A expression dramatically suppressed the growth of glioma cells both in vitro and in vivo. Moreover, silencing OLFML2A significantly promoted the apoptosis process of glioma cells. Furthermore, we confirmed that activation of the Wnt/ $\beta$-catenin pathway was involved in OLFML2A-regulated glioma cell proliferation in vitro and in vivo. Finally, we demonstrated that APP is an important intermediate molecule that mediates the downstream regulatory effects of OLFML2A in glioma. Overall, OLFML2A regulated glioblastoma mainly through $\mathrm{Wnt} / \beta$-catenin signaling by targeting APP. Our results suggest that OLFML2A promotes the progression of glioblastoma and may be a potential novel prognostic factor for glioblastoma. Importantly, OLFML2A might be a promising target gene for glioma treatment.

OLFML2A is a member of the OLF family[7]. Data obtained over the past several years demonstrate that OLF family proteins play important roles in neurogenesis, neural crest formation, dorsal ventral patterning, cell-cell adhesion, cell cycle regulation, and tumorigenesis and may act as modulators of critical signaling pathways (Wnt, BMP)[7]. Human OLFML2A genes are located on chromosome 9q33.3 and encode secreted glycoproteins also known as photomedin-1 [9]. The biological functions of proteins that possess the OLF domain remain elusive[7, 9, 21]. In the field of cancer research, the tumorigenic function of OLFM4 has been verified in many tumors[22, 23]. Intriguingly, the tumorigenic function of OLFML2A is also gradually emerging. The expression of OLFML2A was negatively correlated with the biological progression and clinical features of TNBC, LIHC and leukemia[10-12]. Moreover, as previously reported, the Wnt/ $\beta$-catenin pathway is a potential regulatory target of OLFML2A, through which OLFML2A regulates several malignant biological processes in LIHC[12]. Consistent with previous studies, our study indicated that OLFML2A acts as an oncogene that exerts an important effect on glioma 
progression. Moreover, based on pathway enrichment analysis by IPA, the Wnt/ $\beta$-catenin pathway was found to be altered after downregulation of OLFML2A.

Extensive studies have shown that aberrant Wnt/ $\beta$-catenin signaling plays a key role in the development of glioma, including cell proliferation, cell apoptosis and cell invasion[24]. In the classical Wnt/ $\beta$-catenin pathway, Wnt ligands interact with the receptor protein Frizzled (Fzd) and coreceptor low-density lipoprotein receptor related protein 5/6 (LRP5/6) receptor and then activate Dishevelled (Dvl), which in

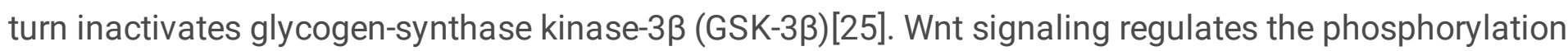
of GSK-3 $\beta$, consequently preventing the phosphorylation and degradation of $\beta$-catenin. $\beta$-Catenin is phosphorylated by the serine/threonine kinases casein kinase 1 (CK1) and GSK-3 $\beta$. In the absence of Wnt, the signaling pool of $\beta$-catenin is maintained at a low level through degradation. When the Wnt signaling pathway is abnormally activated, the phosphorylation and degradation of $\beta$-catenin are inhibited. Stabilized $\beta$-catenin enters the nucleus and associates with T-cell factor/lymphoid enhancer binding factor (TCF/LEF) transcription factors, leading to the transcription of Wnt target genes, such as MYC, CD44, cyclin D1 and PPAR delta[25]. In our study, we found that the expression levels of Wnt ligands (Wnt3, Wnt5a, Wnt5b), the transcription factor LEF1 and Wnt-downstream genes (MYC, CD44) were decreased when OLFML2A was downregulated. Furthermore, Thr41/Ser37/Ser33 phosphorylation levels of $\beta$-catenin were significantly increased with OLFML2A downregulation. Conversely, the stabilized $\beta$-catenin level was decreased when OLFML2A was downregulated. Additionally, phosphorylation of GSK$3 \beta$ was significantly decreased while total GSK-3 $\beta$ was elevated with OLFML2A downregulation. Overall, our study indicates that high levels of OLFML2A expression may activate the Wnt/ $\beta$-catenin pathway to promote cell proliferation and inhibit cell apoptosis.

Interaction network analysis based on IPA confirmed that APP is an important intermediate molecule that mediates the downstream regulatory effects of OLFML2A in glioma. It has been confirmed that the aberrant cleavage of APP is a central process in the pathogenesis of Alzheimer's disease (AD)[25-27]. Over the last decade, there has been increasing evidence suggesting that the Wnt/ $\beta$-catenin pathway is dysfunctional in AD brains[28]. Accumulating evidence has shown that the processing of APP and the formation of amyloid- $\beta$ are associated with the canonical Wnt/ $\beta$-catenin pathway[25, 29]. For instance, Chen et al. reported that APP appears to downregulate $\beta$-catenin expression by increasing its degradation[30]. Additionally, Zhang et al. verified that APP overexpression in N2a cells led to alterations in the subcellular distribution of $\beta$-catenin by physically binding to it, preventing its translocation into the nucleus and precluding the transcription of Wnt target genes[19]. Therefore, these findings indicate a reciprocal regulation between APP and the Wnt/ $\beta$-catenin signaling pathway. The results of the interaction network analysis are consistent with the function of APP as a Wnt/ $\beta$-catenin pathway suppressor. In our study, we found that APP was expressed at low levels in glioma tissue. The expression level of APP was negatively correlated with OLFML2A, and OLFML2A knockdown led to increased levels of APP. Moreover, downregulation of APP partially attenuated the inhibitory effect of OLFML2A knockdown on cell proliferation. Hence, we concluded that downregulation of OLFML2A inhibited Wnt/ $\beta$ catenin signaling by directly reducing the level of stabilized $\beta$-catenin and upregulating the expression of APP to indirectly reduce $\beta$-catenin. 


\section{Conclusion}

In summary, our results suggest that OLFML2A is frequently upregulated in human glioma tissues and acts as an oncogene to promote cell proliferation during the progression of glioblastoma in vitro and in vivo. Mechanistically, OLFML2A regulates the $W n t / \beta$-catenin signaling pathway by suppressing the level of stabilized $\beta$-catenin, leading to repression of MYC, CD44 and CSKN2A2 expression. These findings indicate that OLFML2A may become a promising diagnostic biomarker and a potential therapeutic target for glioma patients.

\section{Abbreviations}

OLFML2A: Olfactomedin-like 2A; APP: amyloid precursor protein; TCGA: The Cancer Genome Atlas; LGG: Low grade glioma; TNBC: Triple-negative breast cancer; LIHC: liver hepatocellular carcinoma; IHC: immunohistochemistry; DEGs: differentially expressed genes; IPA: Ingenuity pathway analysis;

\section{Declarations}

\section{Ethics approval and consent to participate}

This study was performed with approval from the Ethics Committee at the Lanzhou University second hospital (No. 2019A-077 and No. D2019-117). Written informed consent was obtained from all patients and data was analyzed anonymously. All Animal experiments complied with the national guidelines for the care and use of laboratory animals.

\section{Consent for publication}

Not applicable.

\section{Availability of data and materials}

All data generated or analyzed during this study are included either in this article or in the supplementary information files. If absent are available from the corresponding author upon reasonable request.

\section{Competing interests}

The authors declare that they have no competing interests.

\section{Funding}


The article was supported by National Natural Science Foundation of China (8177050431), Cuiying Scientific and Technological Innovation Program of Lanzhou University Second Hospital (CY2017-MS04) and Cuiying Scientific and Training Program for Undergraduates of Lanzhou University Second Hospital (CYXZ-10, CYXZ2019-08).

\section{Authors' contributions}

MSZ , DL, PYW and ZYN designed the research, analyzed data and wrote the manuscript; MSZ, DLهDHT, MXD, GXY, LJL, LGQ, YY, XYL, YGQ, ZXK, TGP and ZSJ performed the experiments. All authors have read and approved the final version of the manuscript.

\section{Acknowledgements}

We thank the 69 glioma patients from Lanzhou University second hospital for providing clinical samples.

\section{Authors' information}

${ }^{1}$ Department of Neurosurgery and Laboratory of Neurosurgery, Lanzhou University Second Hospital, Lanzhou, Gansu, China

2 Second Clinical School, Lanzhou University, Lanzhou, Gansu, China

${ }^{3}$ Department of Pediatric Neurology, Gansu Provincial Maternity and Child-Care Hospital, Lanzhou, Gansu, China.

${ }^{4}$ Department of Radiology, Lanzhou University Second Hospital, Cuiyingmen No.82, Chengguan District, Lanzhou 730030, China

\section{References}

1. Weller M, Wick W, Aldape K, Brada M, Berger M, Pfister SM, et al. Glioma. Nat Rev Dis Primers. 2015;1:15017.

2. Jackson CM, Choi J, Lim M. Mechanisms of immunotherapy resistance: lessons from glioblastoma. Nat Immunol. 2019;20(9):1100-9.

3. D'Angelo F, Ceccarelli M, Tala, Garofano L, Zhang J, Frattini V, et al. The molecular landscape of glioma in patients with Neurofibromatosis 1. Nat Med. 2019;25(1):176-87.

4. Molinaro AM, Taylor JW, Wiencke JK, Wrensch MR. Genetic and molecular epidemiology of adult diffuse glioma. Nat Rev Neurol. 2019;15(7):405-17. 
5. Louis DN, Perry A, Reifenberger G, von Deimling A, Figarella-Branger D, Cavenee WK, et al. The 2016 World Health Organization Classification of Tumors of the Central Nervous System: a summary. Acta Neuropathol. 2016;131(6):803-20.

6. Qazi MA, Bakhshinyan D, Singh SK. Deciphering brain tumor heterogeneity, one cell at a time. Nat Med. 2019;25(10):1474-6.

7. Tomarev SI, Nakaya N. Olfactomedin domain-containing proteins: possible mechanisms of action and functions in normal development and pathology. Mol Neurobiol. 2009;40(2):122-38.

8. Furutani Y, Manabe R, Tsutsui K, Yamada T, Sugimoto N, Fukuda S, et al. Identification and characterization of photomedins: novel olfactomedin-domain-containing proteins with chondroitin sulphate-E-binding activity. Biochem J. 2005;389(Pt 3):675-84.

9. Perez-Ibave DC, Gonzalez-Alvarez R, de La Luz Martinez-Fierro M, Ruiz-Ayma G, Luna-Munoz M, Martinez-De-Villarreal LE, et al. Olfactomedin-like $2 \mathrm{~A}$ and B (OLFML2A and OLFML2B) expression profile in primates (human and baboon). Biol Res. 2016;49(1):44.

10. Wu C, Chen M, Zhang Q, Yu L, Zhu J, Gao X. Genomic and GeneChip expression profiling reveals the inhibitory effects of Amorphophalli Rhizoma in TNBC cells. J Ethnopharmacol. 2019;235:206-18.

11. Lv C, Sun L, Guo Z, Li H, Kong D, Xu B, et al. Circular RNA regulatory network reveals cell-cell crosstalk in acute myeloid leukemia extramedullary infiltration. J Transl Med. 2018;16(1):361.

12. Bai KH, He SY, Shu LL, Wang WD, Lin SY, Zhang QY, et al. Identification of cancer stem cell characteristics in liver hepatocellular carcinoma by WGCNA analysis of transcriptome stemness index. Cancer medicine. 2020.

13. Vinci M, Gowan S, Boxall F, Patterson L, Zimmermann M, Court W, et al. Advances in establishment and analysis of three-dimensional tumor spheroid-based functional assays for target validation and drug evaluation. BMC Biol. 2012;10:29.

14. Liu J, Zhou J, Li J, Zhang L, Zhang P, Liu B. Evaluation of rat C6 malignant glioma using spectral computed tomography. Exp Ther Med. 2017;14(2):1037-44.

15. Calvano SE, Xiao W, Richards DR, Felciano RM, Baker HV, Cho RJ, et al. A network-based analysis of systemic inflammation in humans. Nature. 2005;437(7061):1032-7.

16. Irizarry RA, Bolstad BM, Collin F, Cope LM, Hobbs B, Speed TP. Summaries of Affymetrix GeneChip probe level data. Nucleic Acids Res. 2003;31(4):e15.

17. Krämer A, Green J, Pollard J, Jr., Tugendreich S. Causal analysis approaches in Ingenuity Pathway Analysis. Bioinformatics. 2014;30(4):523-30.

18. Zhang K, Zhang J, Han L, Pu P, Kang C. Wnt/beta-catenin signaling in glioma. J Neuroimmune Pharmacol. 2012;7(4):740-9.

19. Zhang N, Parr CJC, Birch AM, Goldfinger MH, Sastre M. The amyloid precursor protein binds to $\beta$ catenin and modulates its cellular distribution. Neurosci Lett. 2018;685:190-5.

20. Cuddapah VA, Robel S, Watkins S, Sontheimer H. A neurocentric perspective on glioma invasion. Nat Rev Neurosci. 2014;15(7):455-65. 
21. Zeng LC, Han ZG, Ma WJ. Elucidation of subfamily segregation and intramolecular coevolution of the olfactomedin-like proteins by comprehensive phylogenetic analysis and gene expression pattern assessment. FEBS Lett. 2005;579(25):5443-53.

22. Liu W, Li H, Hong SH, Piszczek GP, Chen W, Rodgers GP. Olfactomedin 4 deletion induces colon adenocarcinoma in Apc(Min/+) mice. Oncogene. 2016;35(40):5237-47.

23. Grover PK, Hardingham JE, Cummins AG. Stem cell marker olfactomedin 4: critical appraisal of its characteristics and role in tumorigenesis. Cancer Metastasis Rev. 2010;29(4):761-75.

24. He L, Zhou H, Zeng Z, Yao H, Jiang W, Qu H. Wnt/ß-catenin signaling cascade: A promising target for glioma therapy. J Cell Physiol. 2019;234(3):2217-28.

25. Toledo EM, Colombres M, Inestrosa NC. Wnt signaling in neuroprotection and stem cell differentiation. Prog Neurobiol. 2008;86(3):281-96.

26. Esteve P, Rueda-Carrasco J, Inés Mateo M, Martin-Bermejo MJ, Draffin J, Pereyra G, et al. Elevated levels of Secreted-Frizzled-Related-Protein 1 contribute to Alzheimer's disease pathogenesis. Nat Neurosci. 2019;22(8):1258-68.

27. Zhou R, Yang G, Guo X, Zhou Q, Lei J, Shi Y. Recognition of the amyloid precursor protein by human Y-secretase. Science. 2019;363(6428).

28. Boonen RA, van Tijn P, Zivkovic D. Wnt signaling in Alzheimer's disease: up or down, that is the question. Ageing research reviews. 2009;8(2):71-82.

29. Magdesian MH, Carvalho MM, Mendes FA, Saraiva LM, Juliano MA, Juliano L, et al. Amyloid-beta binds to the extracellular cysteine-rich domain of Frizzled and inhibits Wnt/beta-catenin signaling. $J$ Biol Chem. 2008;283(14):9359-68.

30. Chen Y, Bodles AM. Amyloid precursor protein modulates beta-catenin degradation. J Neuroinflammation. 2007;4:29.

\section{Figures}


A

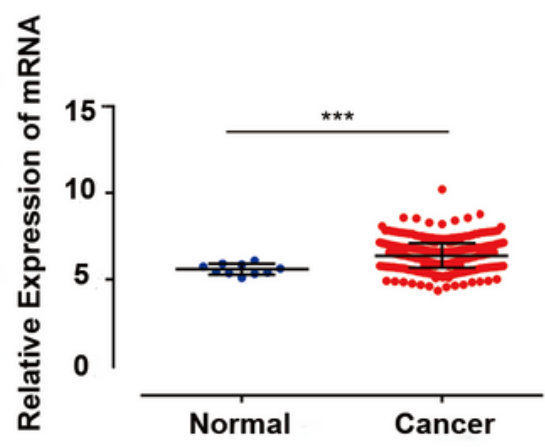

C

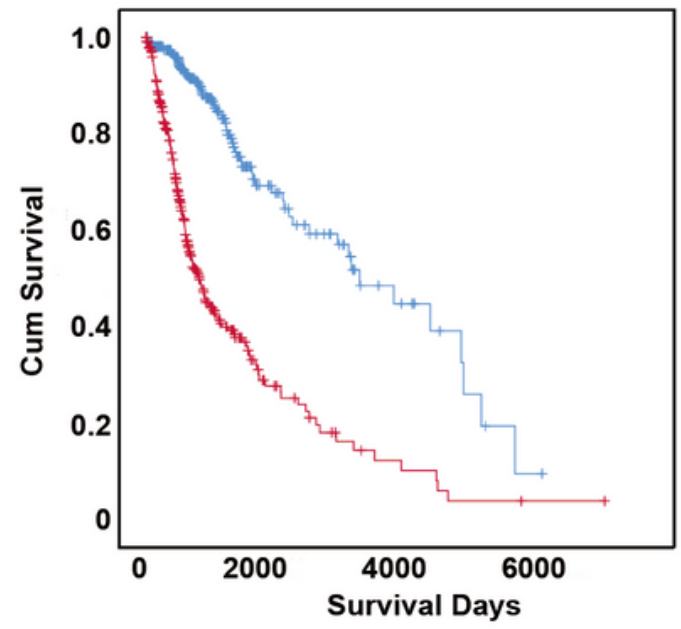

B

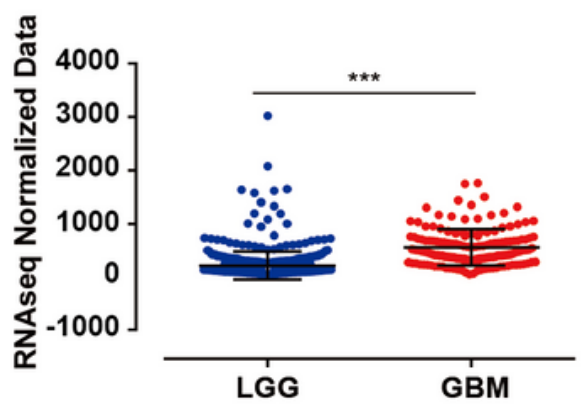

D
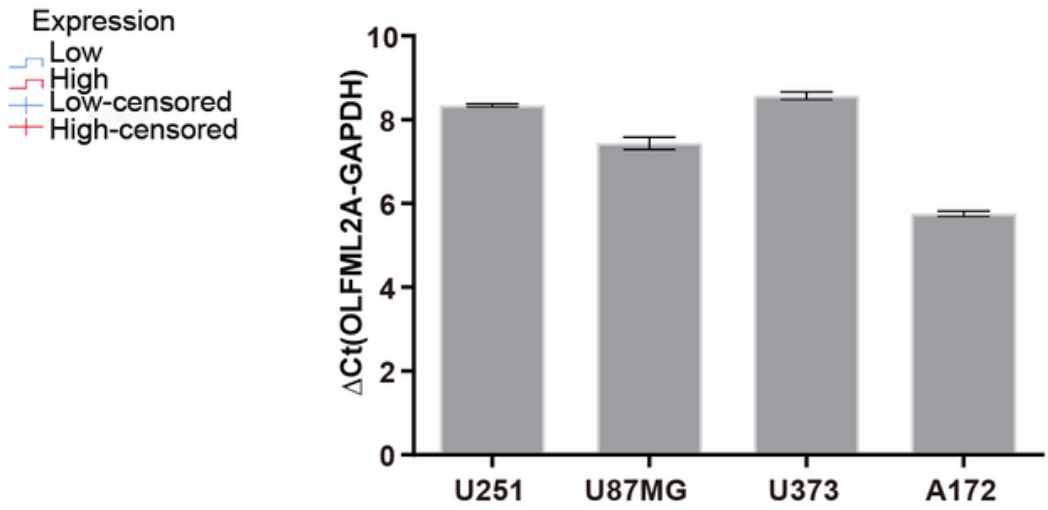

E

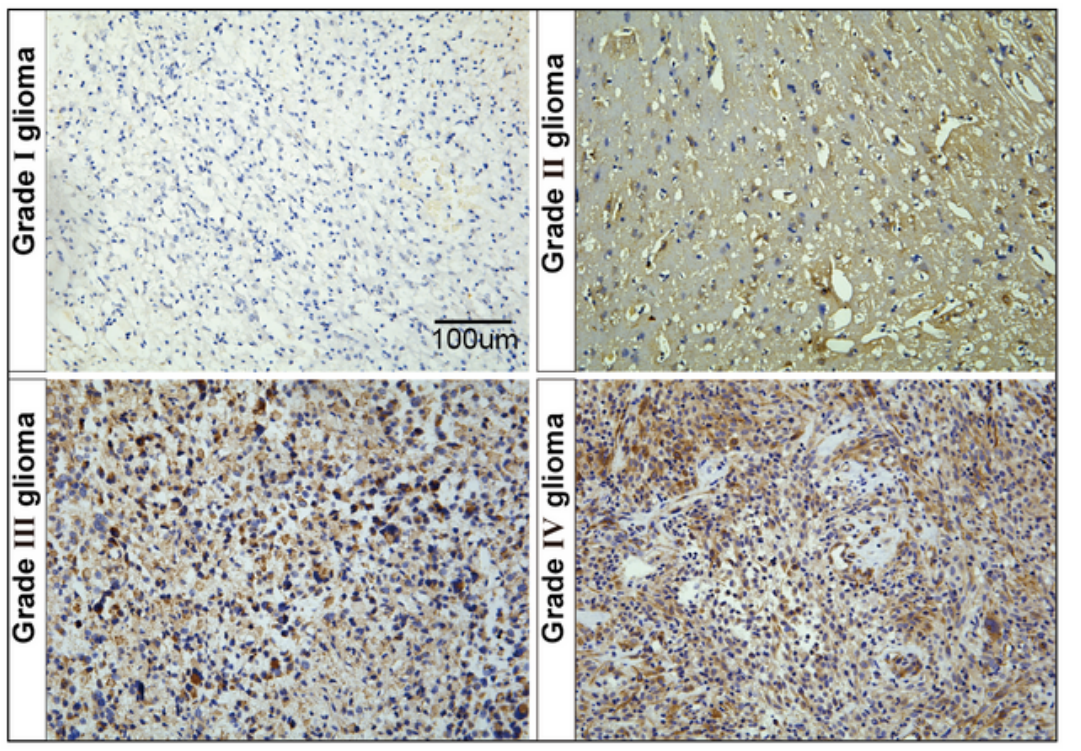

F

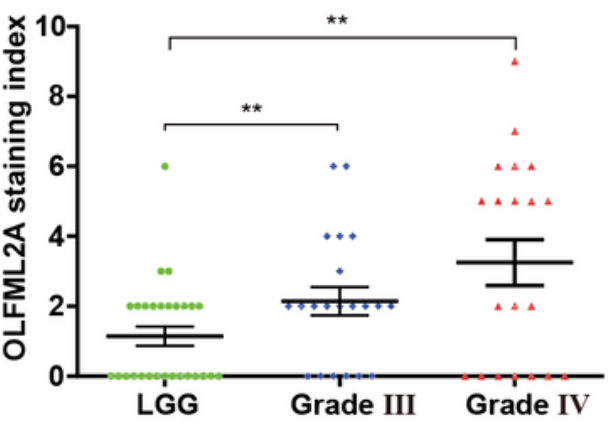

Figure 1

OLFML2A is elevated in gliomas and correlated with tumor grade and prognosis. a. Expression profile of OLFML2A mRNA in primary glioma tissues $(n=548)$ and normal brain tissues ( $n=10$; Mann-Whitney $U$ test; $\star \star \star p<0.001$; TCGA). b. Expression profile of OLFML2A mRNA in low-grade glioma (LGG) samples $(n=515)$ and glioblastoma (GBM) samples ( $n=152$; Mann-Whitney U test; ${ }^{\star \star *} p<0.001$; TCGA). c. KaplanMeier survival curves comparing glioma patients with low and high OLFML2A expression levels $(n=664$; 
$p<0.001 ;$ TCGA). Higher and lower expression was based on the median value of OLFML2A mRNA. $d$. Real-time PCR analysis of OLFML2A expression in four human glioma cell lines. e-f.

Immunohistochemistry (IHC) analysis of OLFML2A in 69 specimens with low- and high-grade gliomas. Scale bar $=100 \mu \mathrm{m}$. The score was calculated according to the degree of cell staining and the proportion of positive cells. The staining index is shown as the product value of two scores. $(* \star p<0.01)$

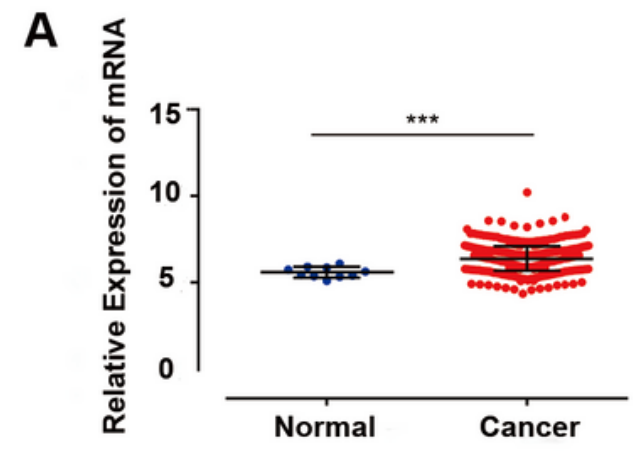

C

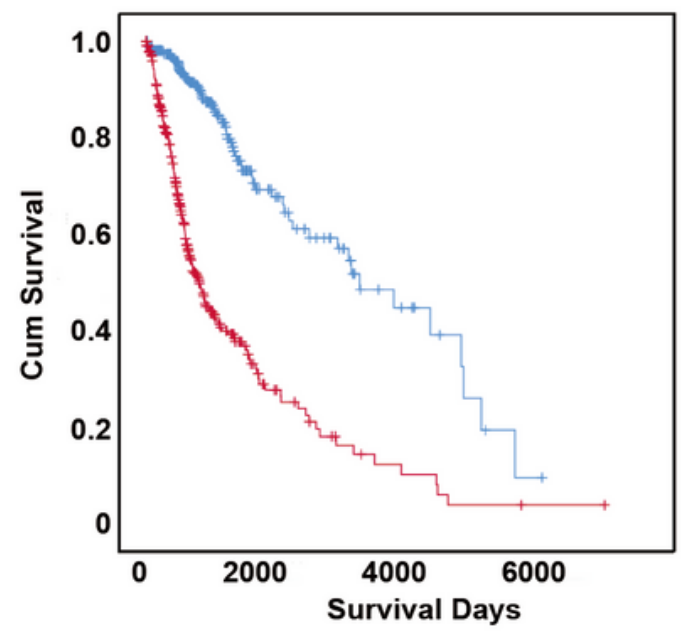

B

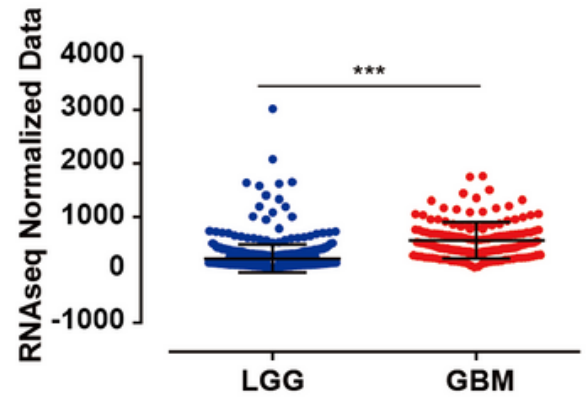

D

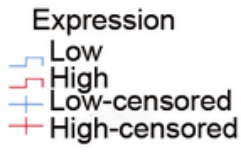

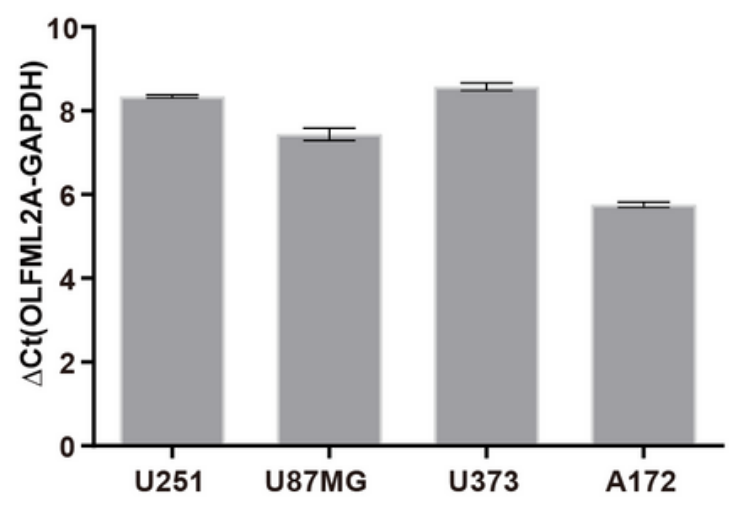

E

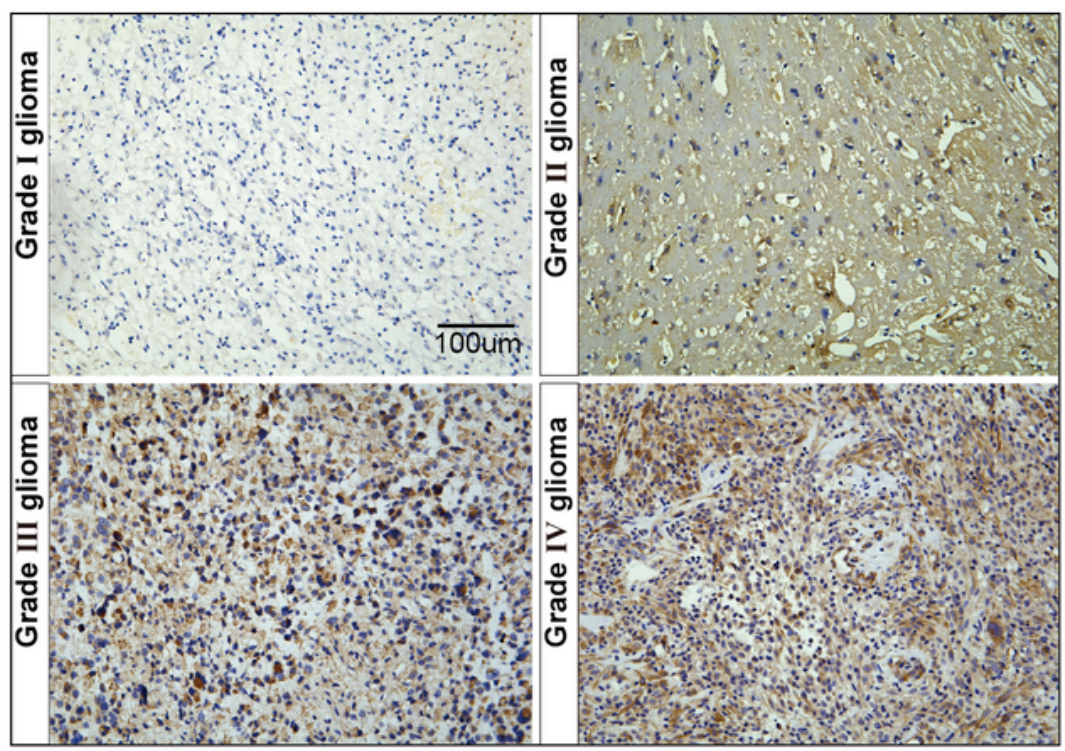

$\mathbf{F}$

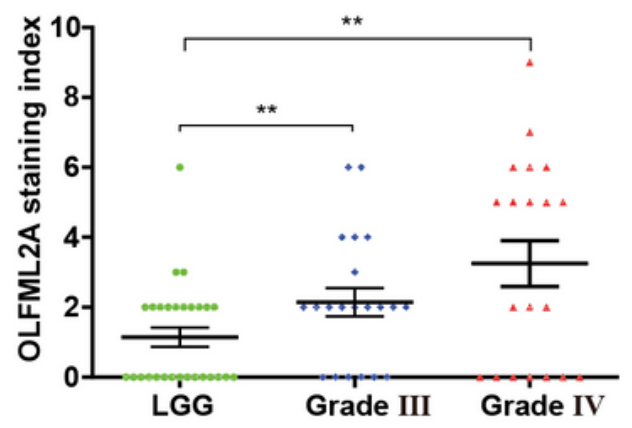

Figure 1 
OLFML2A is elevated in gliomas and correlated with tumor grade and prognosis. a. Expression profile of OLFML2A mRNA in primary glioma tissues $(n=548)$ and normal brain tissues $(n=10$; Mann-Whitney $U$ test; $\star \star \star x p<0.001$; TCGA). b. Expression profile of OLFML2A mRNA in low-grade glioma (LGG) samples $(n=515)$ and glioblastoma (GBM) samples ( $n=152$; Mann-Whitney $U$ test; $* \star * p<0.001$; TCGA). c. KaplanMeier survival curves comparing glioma patients with low and high OLFML2A expression levels $(n=664$; $p<0.001 ;$ TCGA). Higher and lower expression was based on the median value of OLFML2A mRNA. $d$. Real-time PCR analysis of OLFML2A expression in four human glioma cell lines. e-f. Immunohistochemistry (IHC) analysis of OLFML2A in 69 specimens with low- and high-grade gliomas. Scale bar $=100 \mu \mathrm{m}$. The score was calculated according to the degree of cell staining and the proportion of positive cells. The staining index is shown as the product value of two scores. $(\star \star p<0.01)$ 


\section{A}

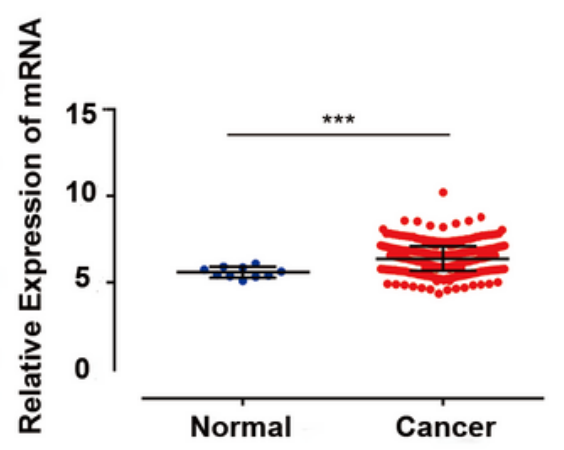

C

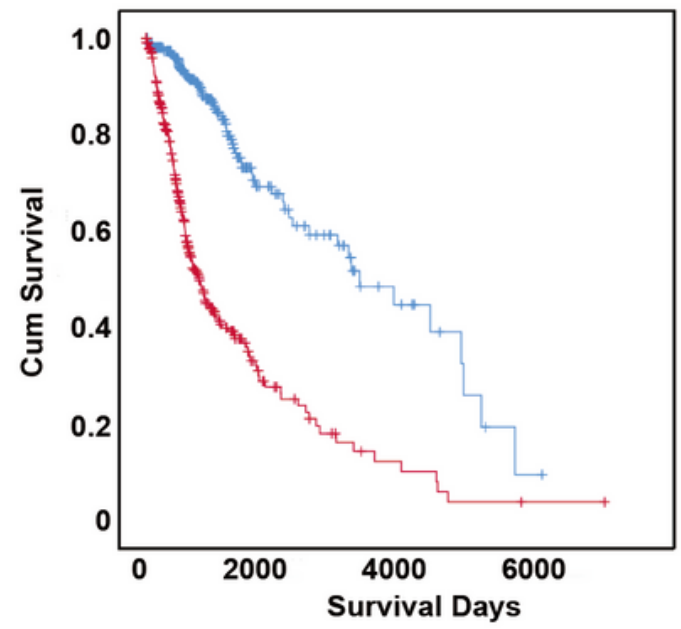

B

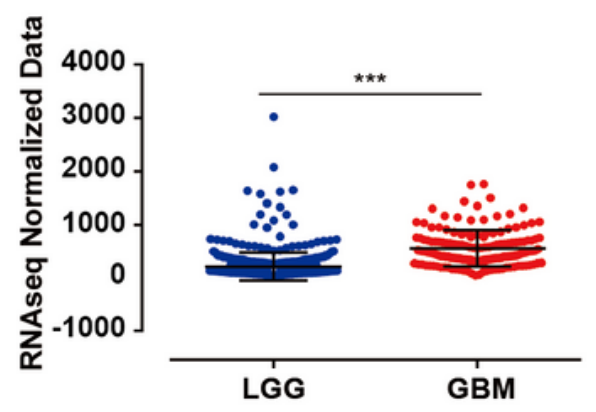

D
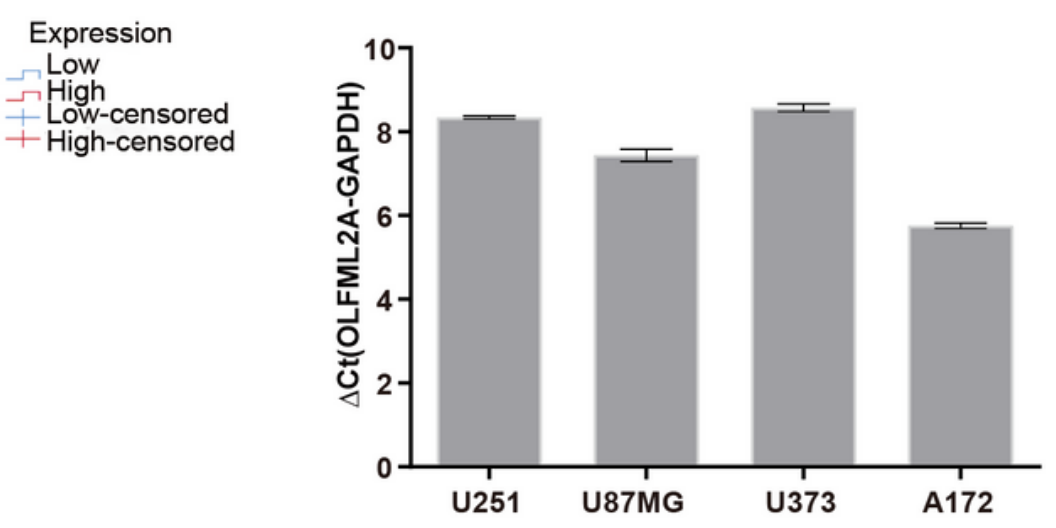

E

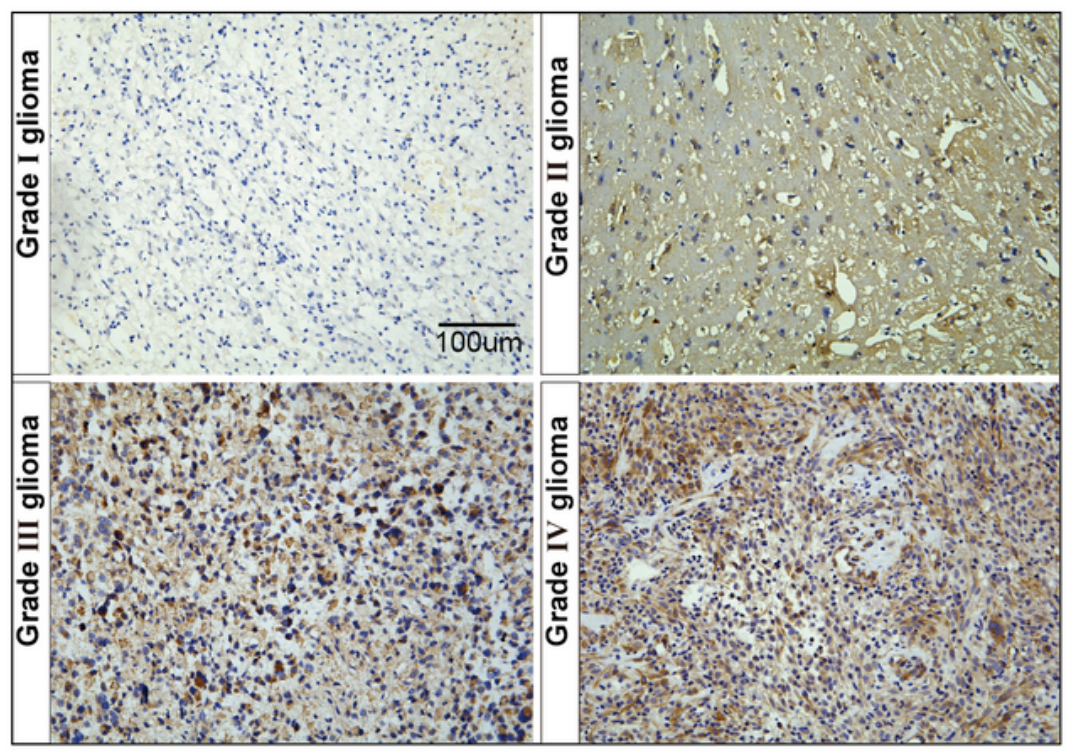

$\mathbf{F}$

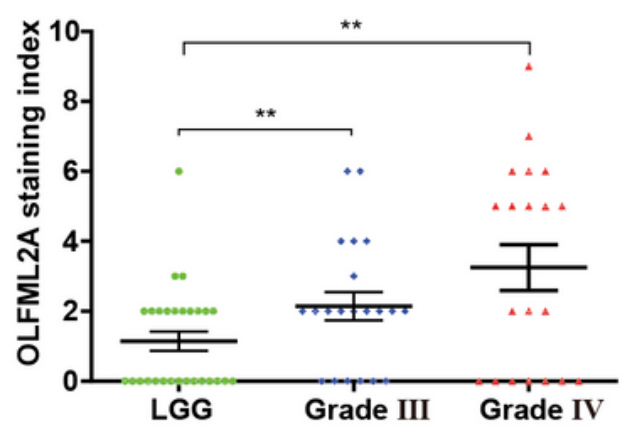

\section{Figure 1}

OLFML2A is elevated in gliomas and correlated with tumor grade and prognosis. a. Expression profile of OLFML2A mRNA in primary glioma tissues $(n=548)$ and normal brain tissues $(n=10$; Mann-Whitney $U$ test; $\star \star \star * p<0.001 ; T C G A)$. b. Expression profile of OLFML2A mRNA in low-grade glioma (LGG) samples $(n=515)$ and glioblastoma (GBM) samples ( $n=152$; Mann-Whitney U test; $* \star \star p<0.001$; TCGA). c. KaplanMeier survival curves comparing glioma patients with low and high OLFML2A expression levels $(n=664$; 
$p<0.001 ;$ TCGA). Higher and lower expression was based on the median value of OLFML2A mRNA. $d$. Real-time PCR analysis of OLFML2A expression in four human glioma cell lines. e-f.

Immunohistochemistry (IHC) analysis of OLFML2A in 69 specimens with low- and high-grade gliomas. Scale bar $=100 \mu \mathrm{m}$. The score was calculated according to the degree of cell staining and the proportion of positive cells. The staining index is shown as the product value of two scores. $(* \star p<0.01)$

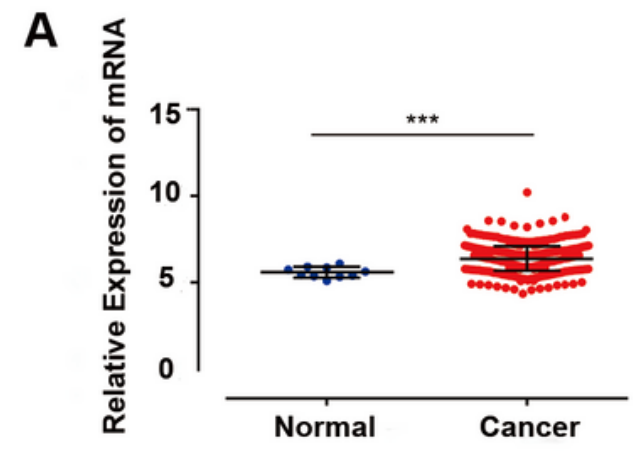

C

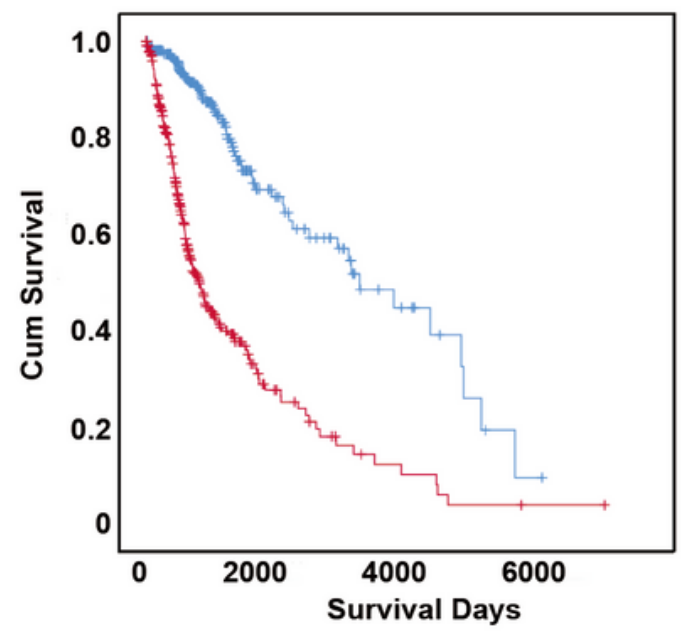

B

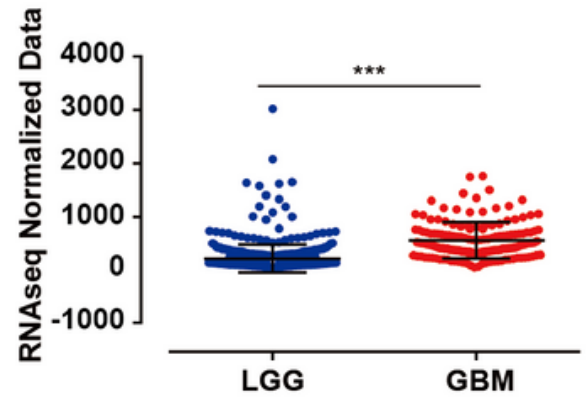

D

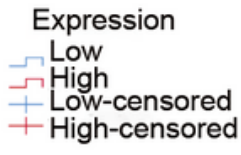

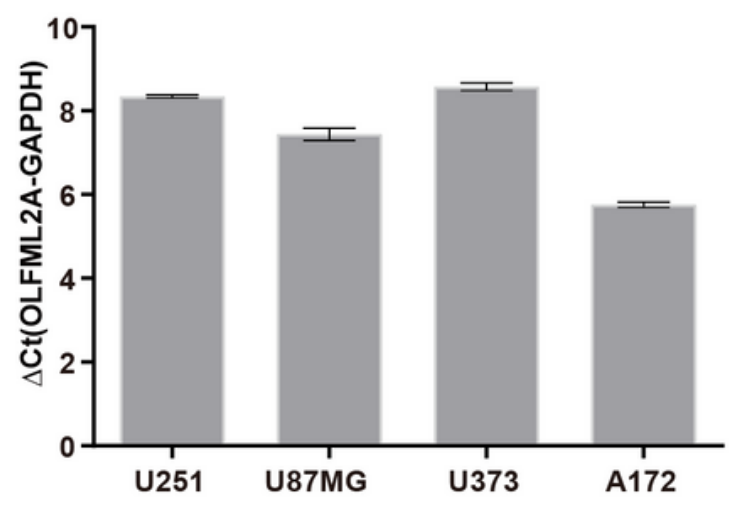

E

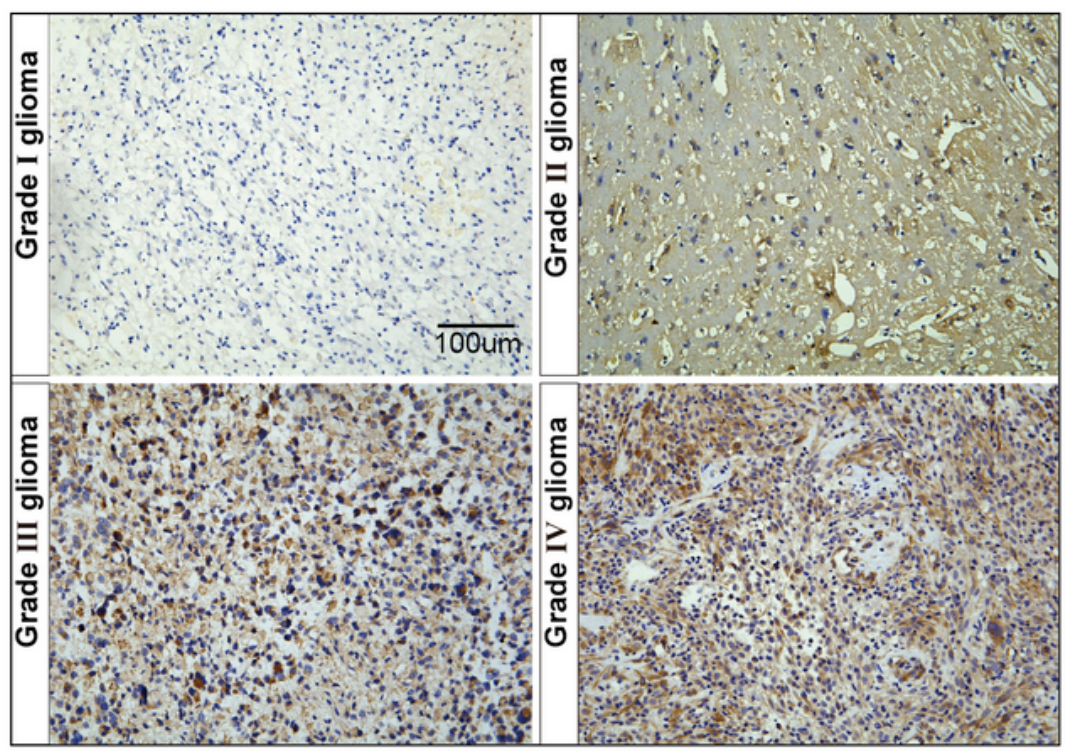

$\mathbf{F}$

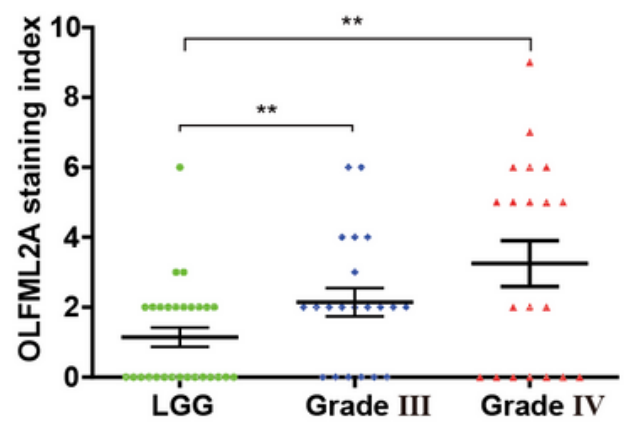

Figure 1 
OLFML2A is elevated in gliomas and correlated with tumor grade and prognosis. a. Expression profile of OLFML2A mRNA in primary glioma tissues $(n=548)$ and normal brain tissues $(n=10$; Mann-Whitney $U$ test; $\star \star \star x<0.001 ; T C G A$ ). b. Expression profile of OLFML2A mRNA in low-grade glioma (LGG) samples $(n=515)$ and glioblastoma (GBM) samples ( $n=152$; Mann-Whitney $U$ test; ${ }^{\star \star \star} p<0.001$; TCGA). c. KaplanMeier survival curves comparing glioma patients with low and high OLFML2A expression levels $(n=664$; $p<0.001 ;$ TCGA). Higher and lower expression was based on the median value of OLFML2A mRNA. $d$. Real-time PCR analysis of OLFML2A expression in four human glioma cell lines. e-f. Immunohistochemistry (IHC) analysis of OLFML2A in 69 specimens with low- and high-grade gliomas. Scale bar $=100 \mu \mathrm{m}$. The score was calculated according to the degree of cell staining and the proportion of positive cells. The staining index is shown as the product value of two scores. $(* \star p<0.01)$

A

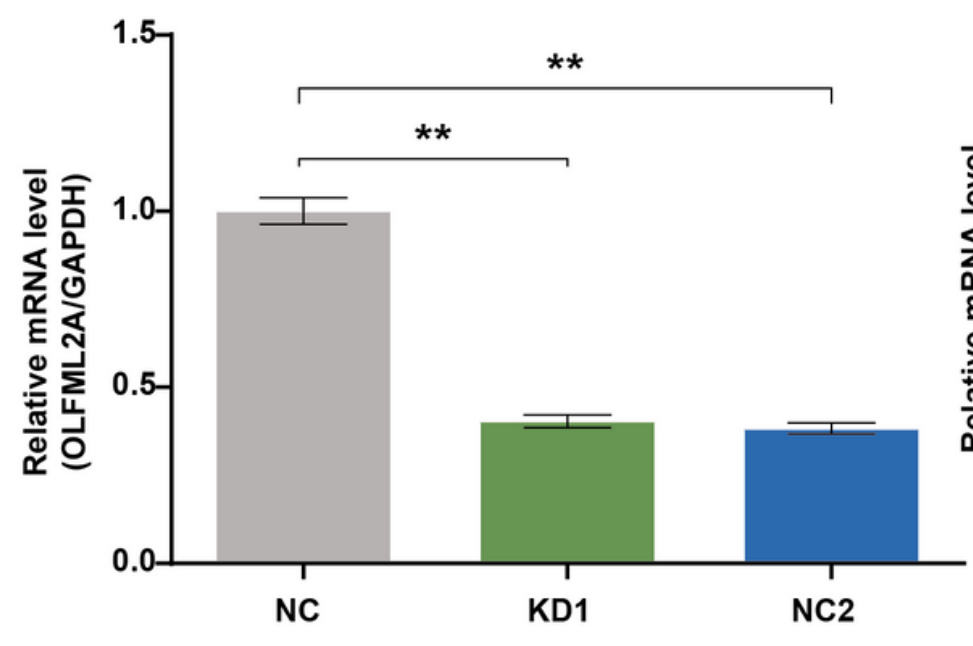

C

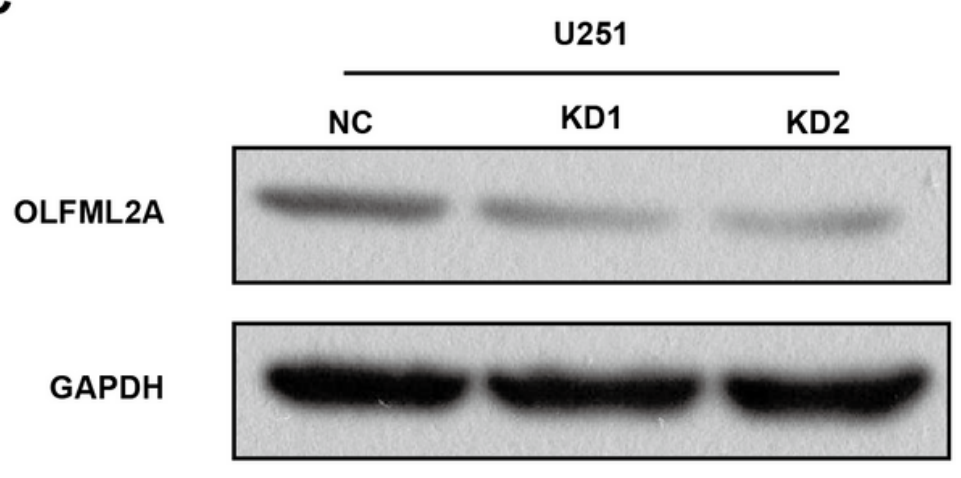

B
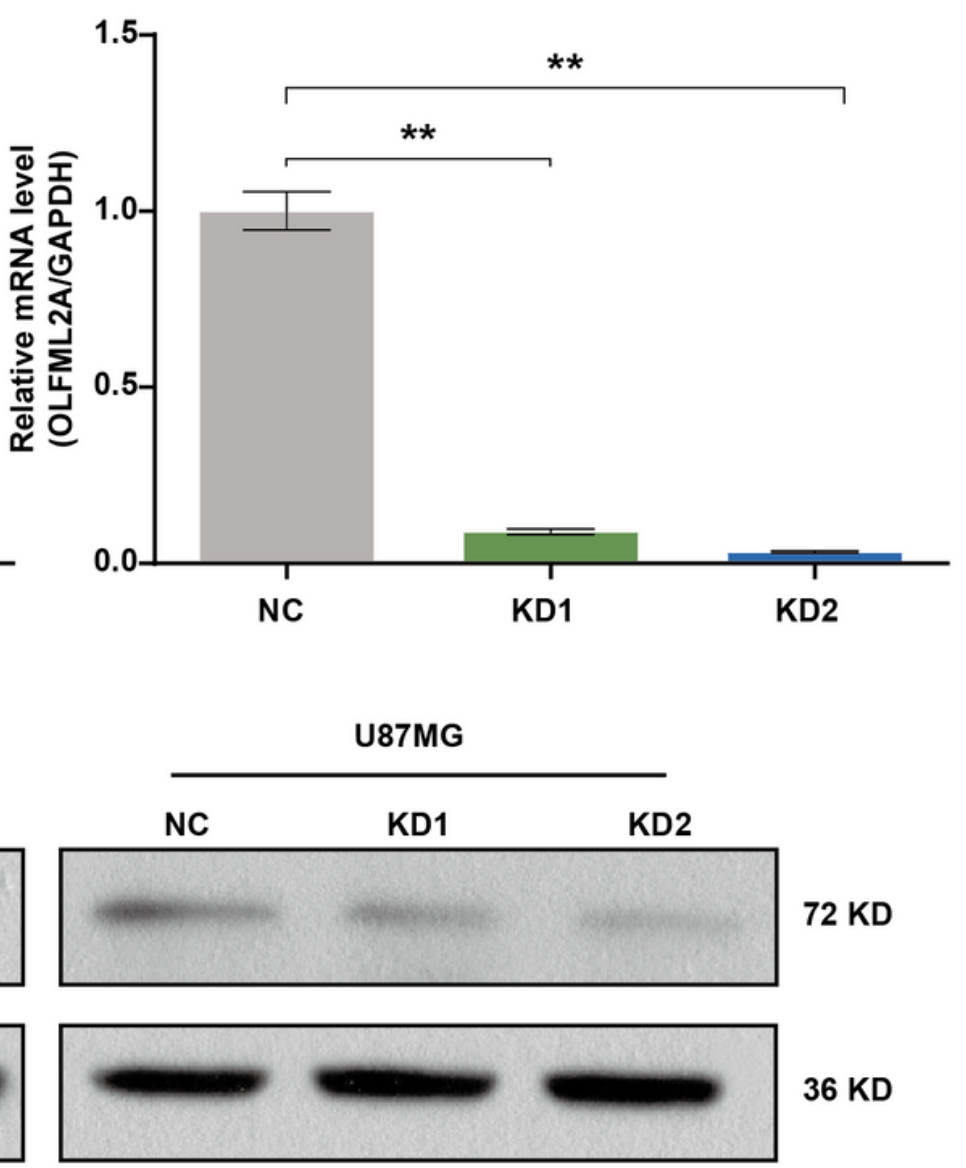

Figure 2

OLFML2A expression was efficiently inhibited by lentiviral-based shRNA in human glioma cell lines. a-b. OLFML2A mRNA levels were assessed by quantitative RT-PCR in U251 (a) and U87MG (b) cells. c. OLFML2A protein content in glioma cell lines was assessed by western blotting. ${ }^{*} p<0.01$. (NC, cells infected with negative control lentivirus expressing Scr-shRNA; KD1 and KD2, cells infected with OLFML2A-knockdown lentivirus expressing OLFML2A-shRNA-1 and OLFML2A-shRNA-2, respectively.) 
A

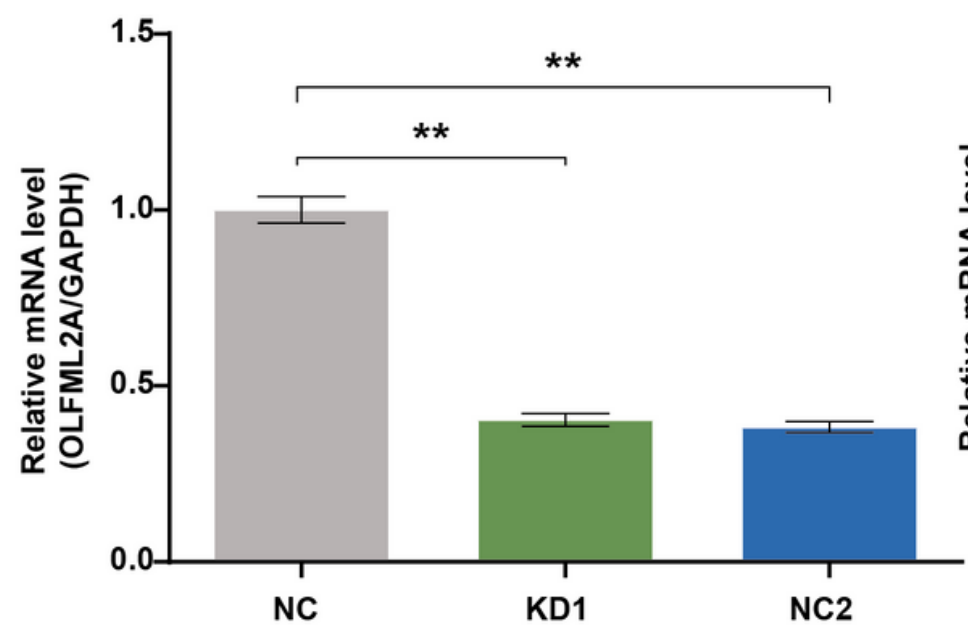

C

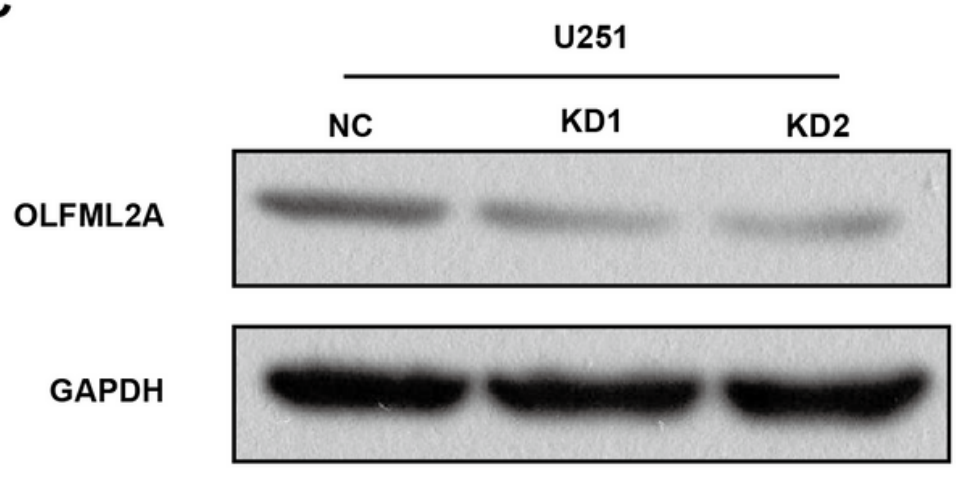

B
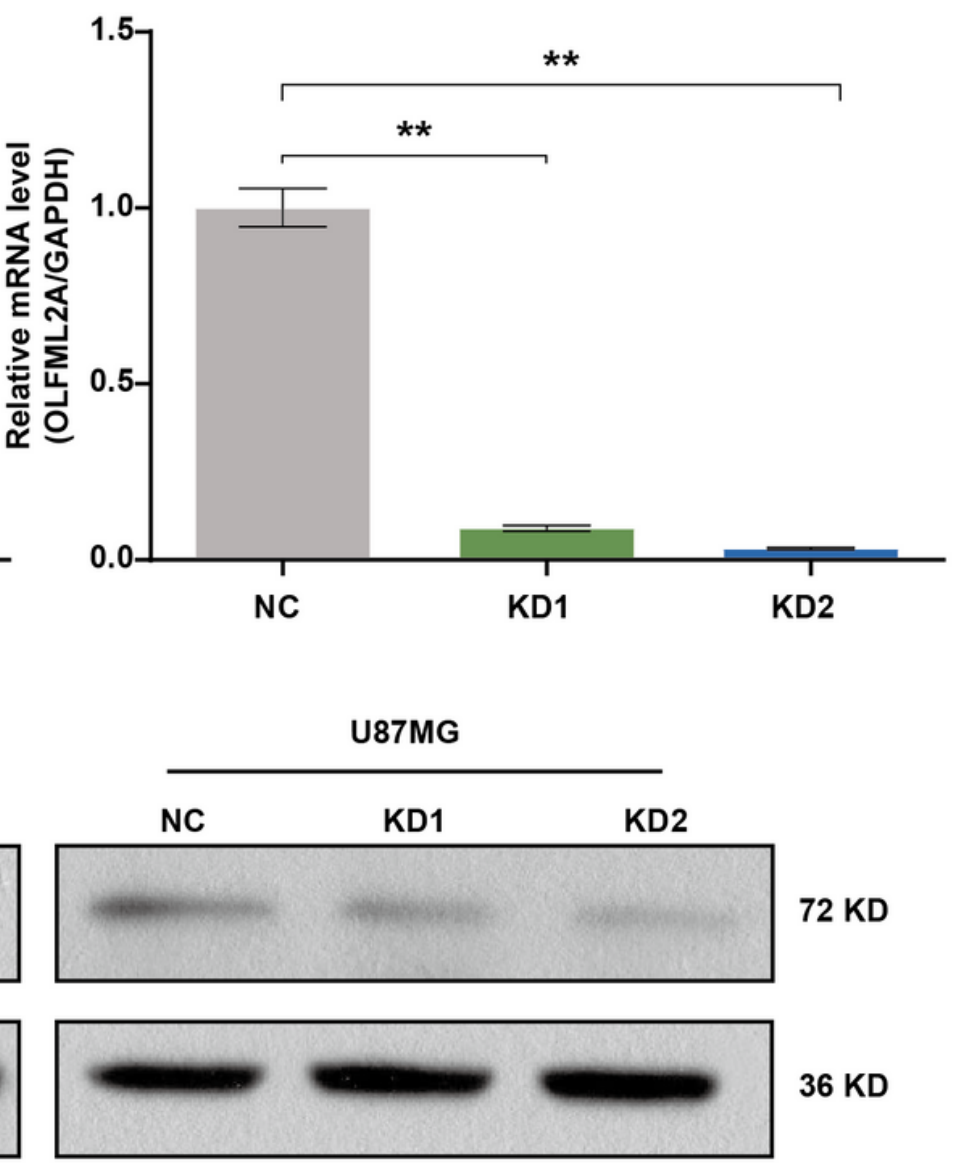

Figure 2

OLFML2A expression was efficiently inhibited by lentiviral-based shRNA in human glioma cell lines. a-b. OLFML2A mRNA levels were assessed by quantitative RT-PCR in U251 (a) and U87MG (b) cells. c. OLFML2A protein content in glioma cell lines was assessed by western blotting. ${ }^{\star *} p<0.01$. (NC, cells infected with negative control lentivirus expressing Scr-shRNA; KD1 and KD2, cells infected with OLFML2A-knockdown lentivirus expressing OLFML2A-shRNA-1 and OLFML2A-shRNA-2, respectively.) 
A

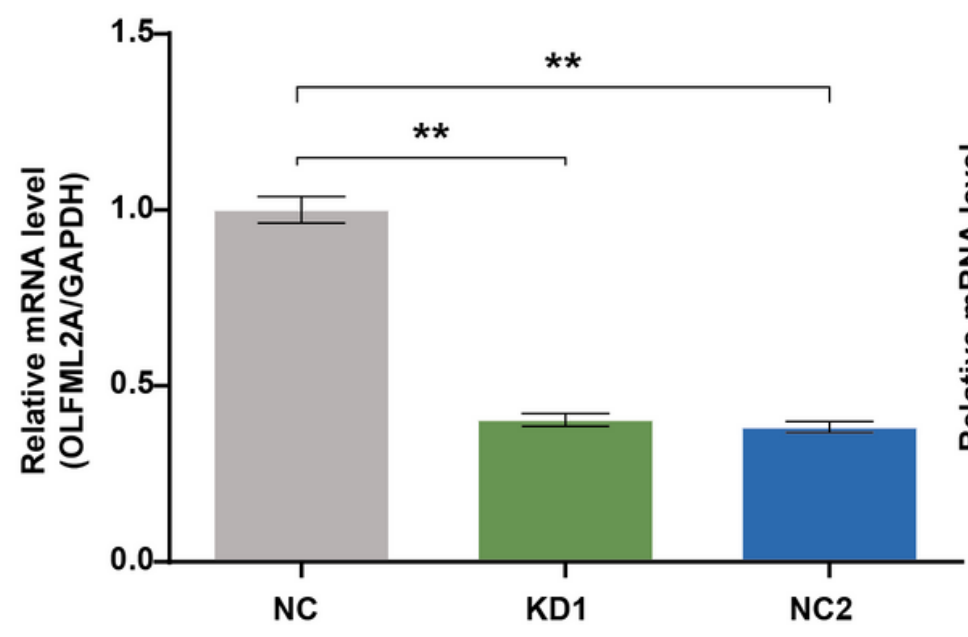

C

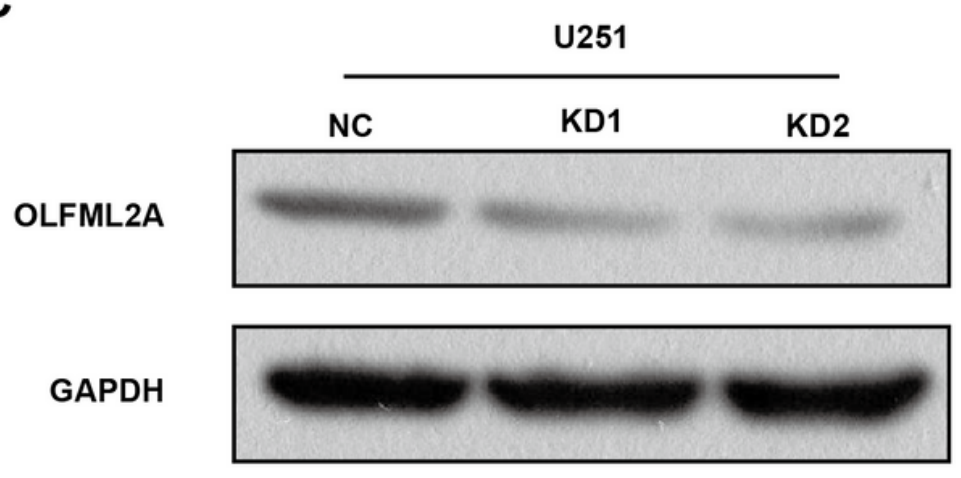

B
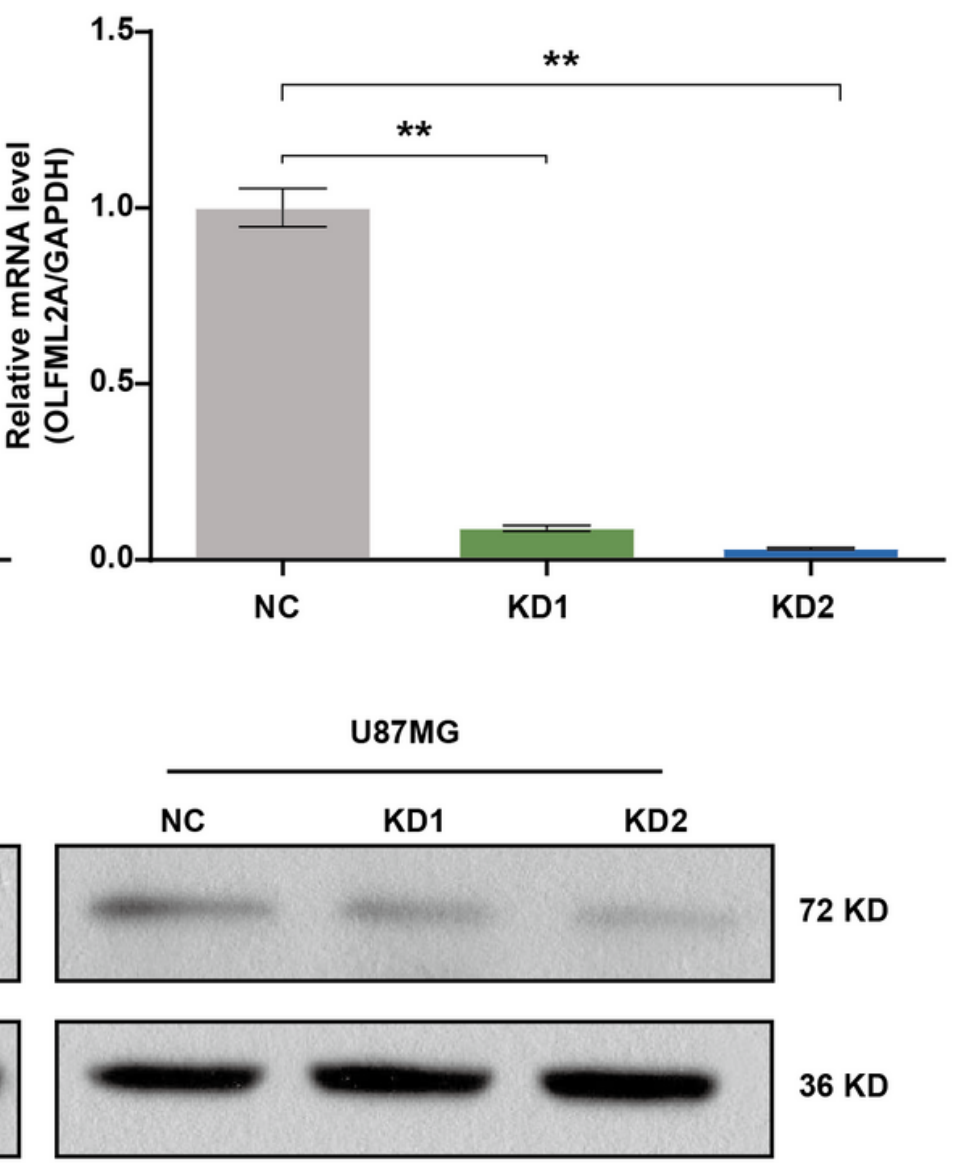

Figure 2

OLFML2A expression was efficiently inhibited by lentiviral-based shRNA in human glioma cell lines. a-b. OLFML2A mRNA levels were assessed by quantitative RT-PCR in U251 (a) and U87MG (b) cells. c. OLFML2A protein content in glioma cell lines was assessed by western blotting. ${ }^{\star *} p<0.01$. (NC, cells infected with negative control lentivirus expressing Scr-shRNA; KD1 and KD2, cells infected with OLFML2A-knockdown lentivirus expressing OLFML2A-shRNA-1 and OLFML2A-shRNA-2, respectively.) 
A

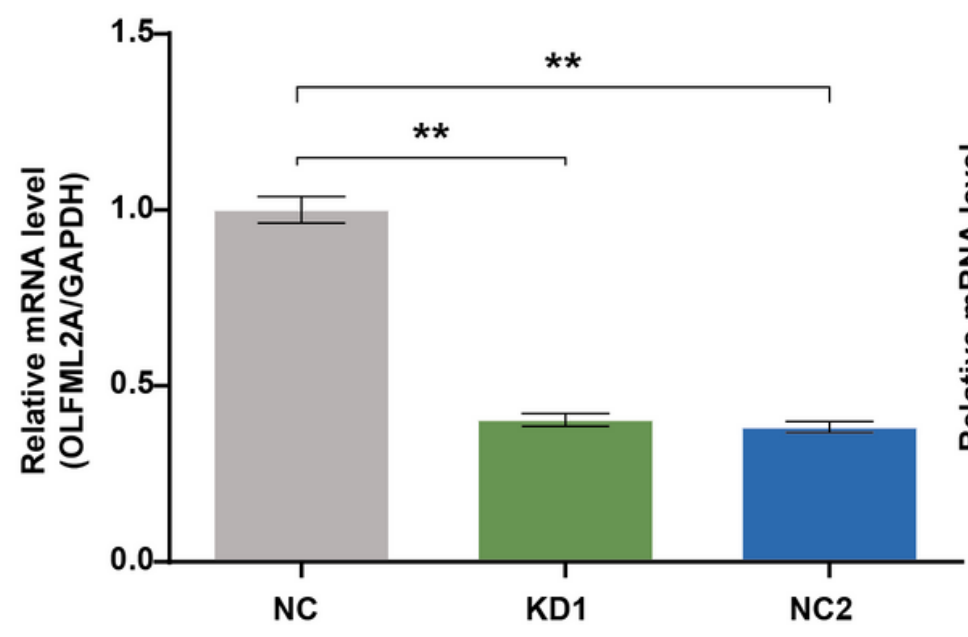

C

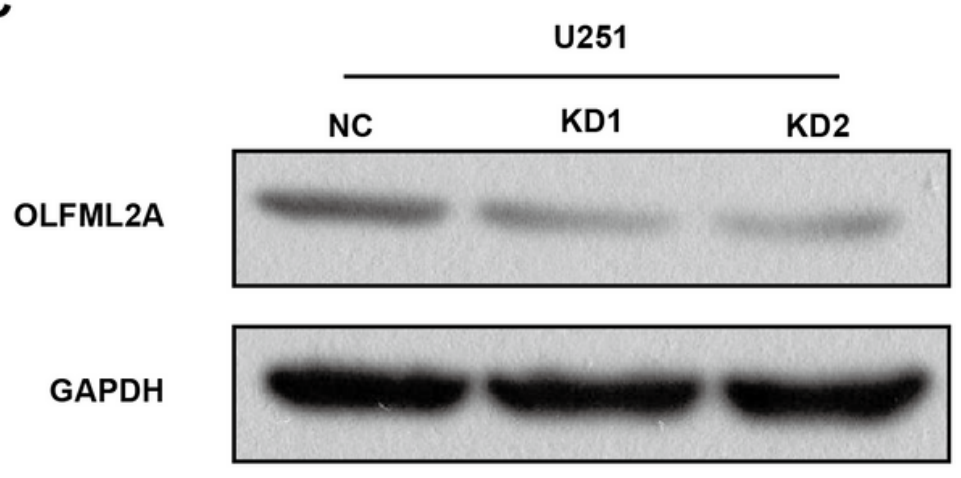

B
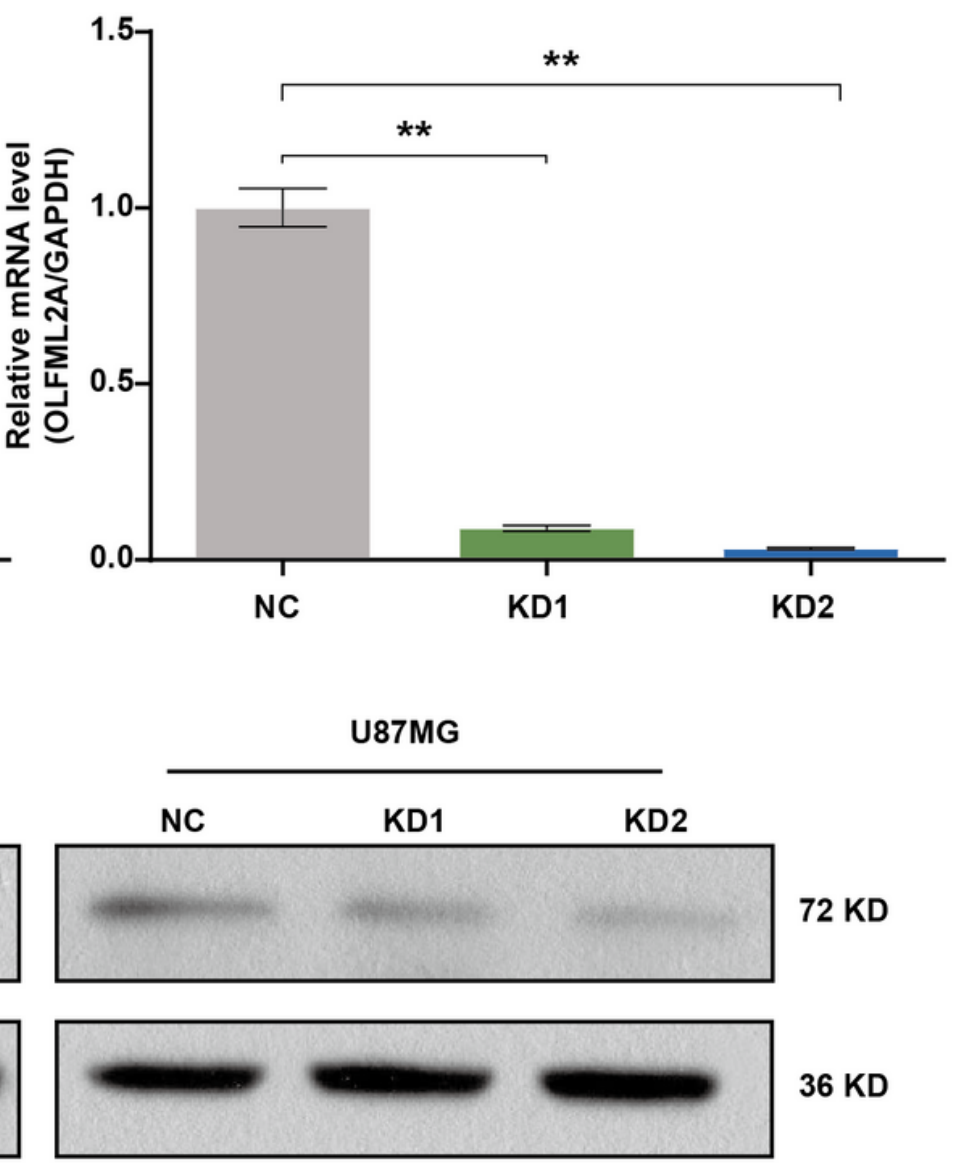

Figure 2

OLFML2A expression was efficiently inhibited by lentiviral-based shRNA in human glioma cell lines. a-b. OLFML2A mRNA levels were assessed by quantitative RT-PCR in U251 (a) and U87MG (b) cells. c. OLFML2A protein content in glioma cell lines was assessed by western blotting. ${ }^{\star *} p<0.01$. (NC, cells infected with negative control lentivirus expressing Scr-shRNA; KD1 and KD2, cells infected with OLFML2A-knockdown lentivirus expressing OLFML2A-shRNA-1 and OLFML2A-shRNA-2, respectively.) 

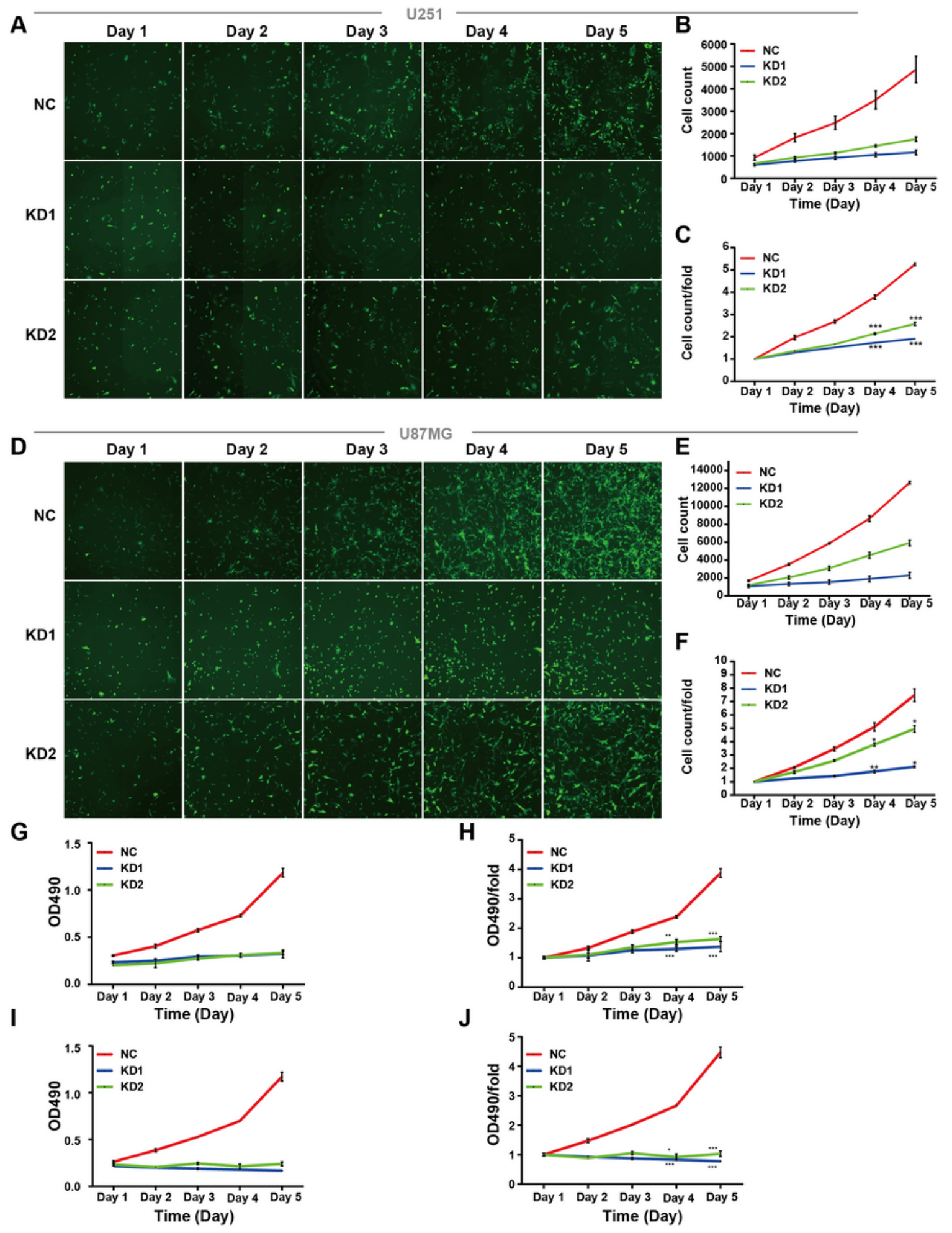

\section{Figure 3}

Knockdown of OLFML2A inhibits cell growth and proliferation. a-c and d-e. Cell growth was measured by Celigo assay for five days in U251 and U87MG cells. g-h and i-j. Cell growth was measured by MTT assay for five days in U251 and U87MG cells. Data are represented as the mean $\pm S D$. ${ }^{*} P<0.05,{ }^{\star \star} P<0.01$, $\star \star \star P<0.001$. 

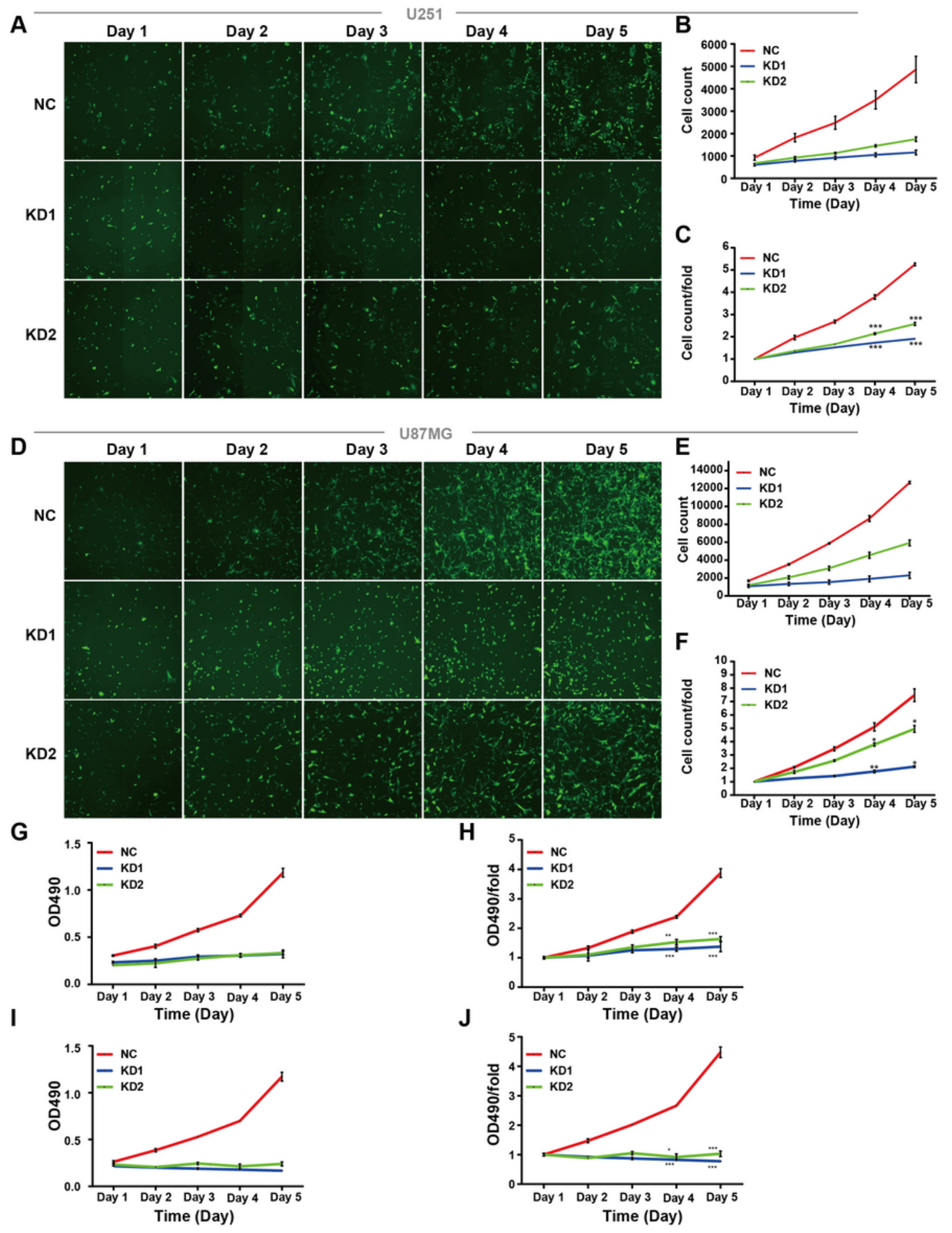

\section{Figure 3}

Knockdown of OLFML2A inhibits cell growth and proliferation. a-c and d-e. Cell growth was measured by Celigo assay for five days in U251 and U87MG cells. g-h and i-j. Cell growth was measured by MTT assay for five days in U251 and U87MG cells. Data are represented as the mean $\pm S D$. ${ }^{*} P<0.05,{ }^{\star \star} P<0.01$, $\star \star \star P<0.001$. 

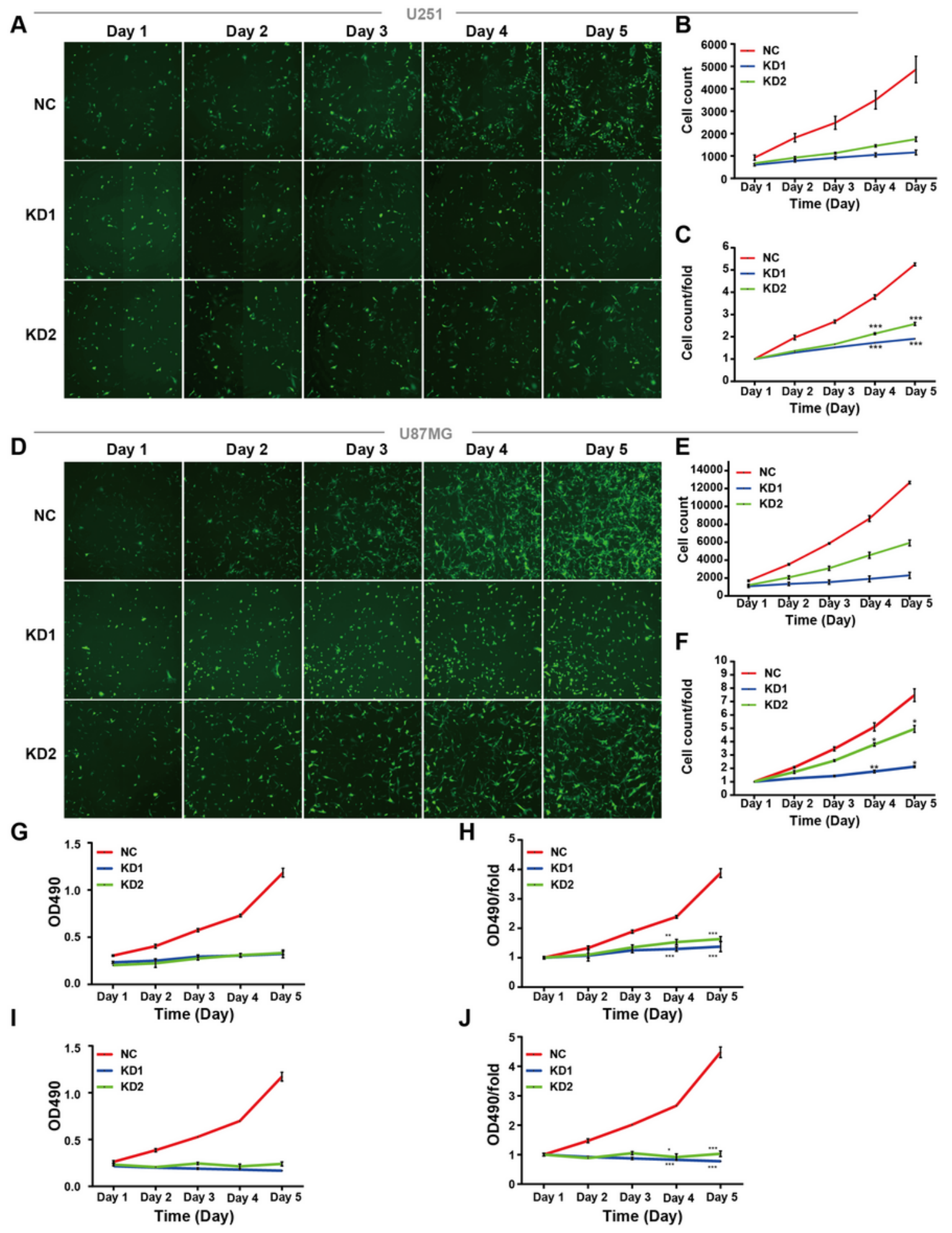

\section{Figure 3}

Knockdown of OLFML2A inhibits cell growth and proliferation. a-c and d-e. Cell growth was measured by Celigo assay for five days in U251 and U87MG cells. g-h and i-j. Cell growth was measured by MTT assay for five days in U251 and U87MG cells. Data are represented as the mean $\pm S D$. ${ }^{*} P<0.05,{ }^{\star \star} P<0.01$, $\star \star \star P<0.001$. 

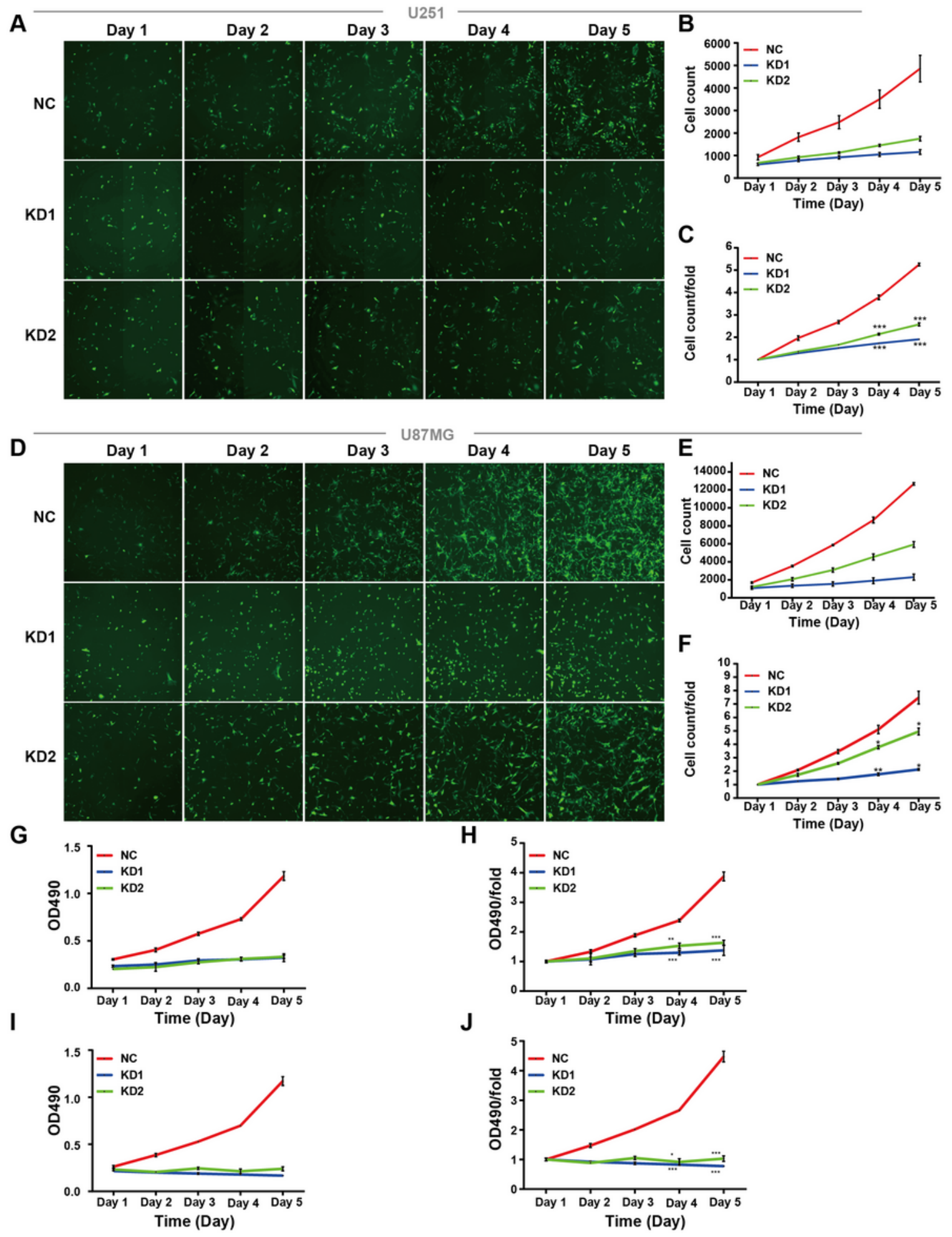

\section{Figure 3}

Knockdown of OLFML2A inhibits cell growth and proliferation. a-c and d-e. Cell growth was measured by Celigo assay for five days in U251 and U87MG cells. g-h and i-j. Cell growth was measured by MTT assay for five days in U251 and U87MG cells. Data are represented as the mean $\pm S D$. ${ }^{*} P<0.05,{ }^{\star \star} P<0.01$, $\star \star \star P<0.001$. 


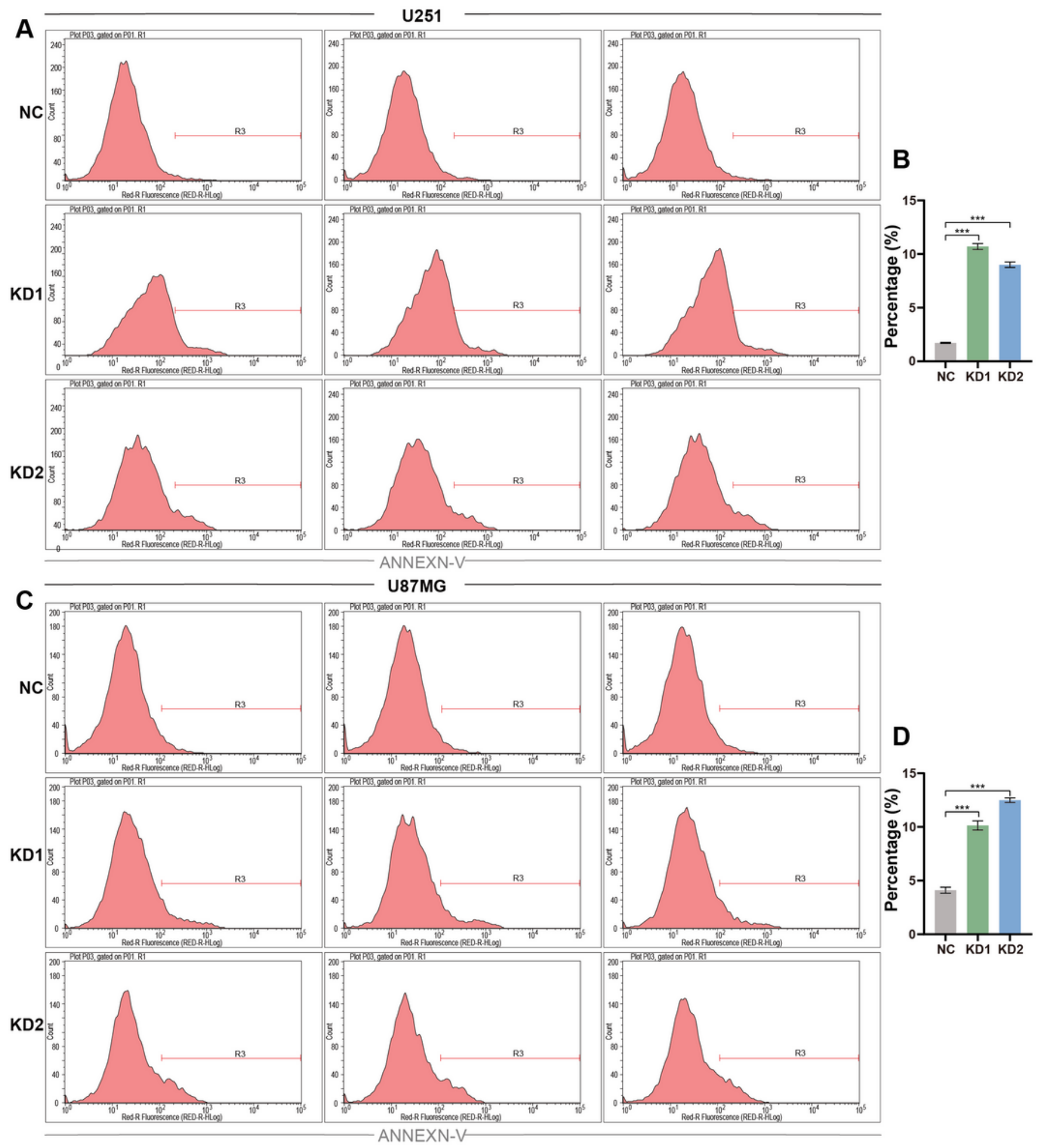

\section{Figure 4}

Suppression of OLFML2A promotes apoptosis of glioma cells. Apoptosis of U251 and U87MG cells was assessed using Annexin- $\mathrm{V}$ staining and analyzed by flow cytometry. The rate of apoptosis is represented as the mean $\pm \mathrm{SD}$. $* \star * P<0.01$. 


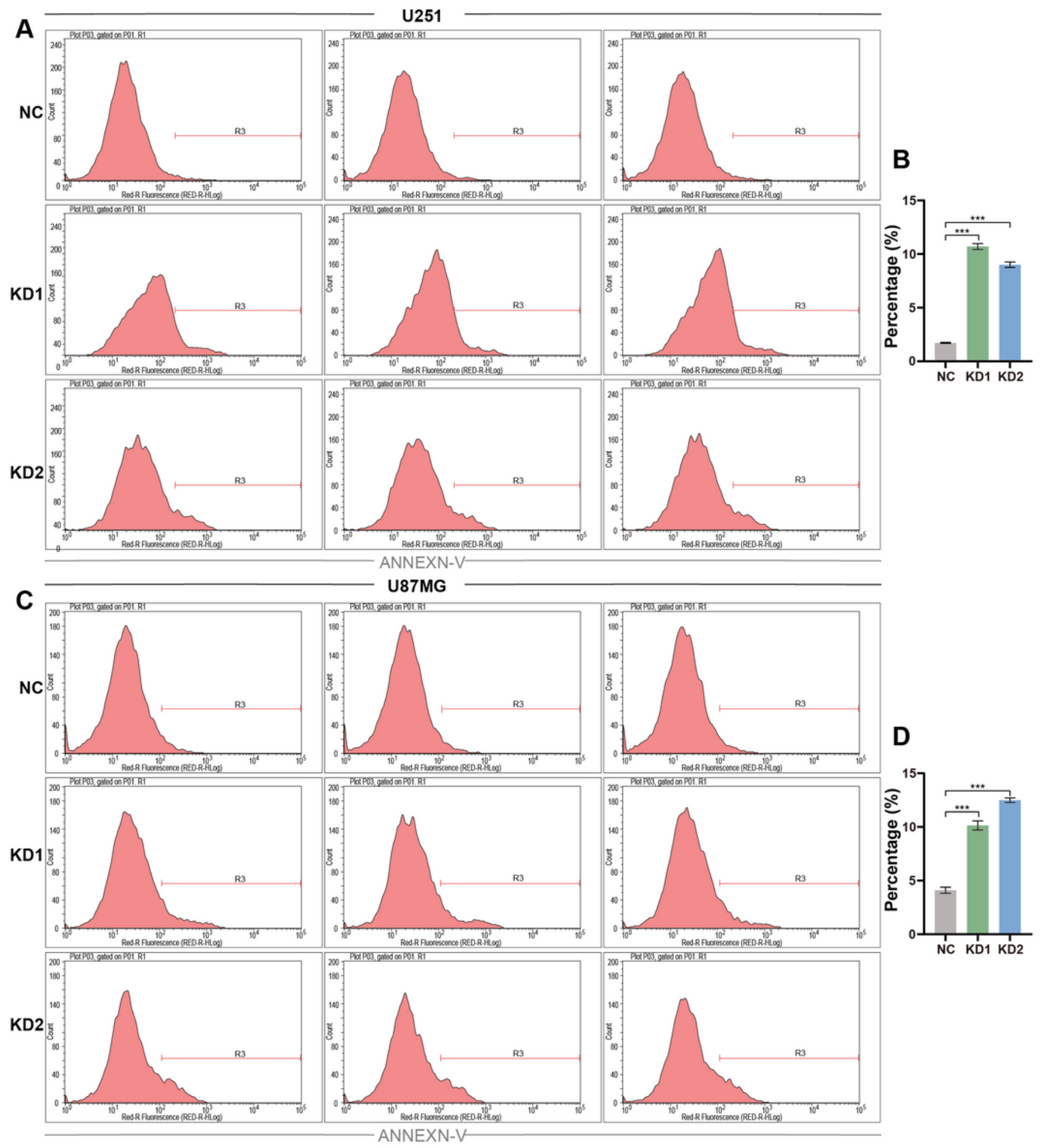

\section{Figure 4}

Suppression of OLFML2A promotes apoptosis of glioma cells. Apoptosis of U251 and U87MG cells was assessed using Annexin- $\mathrm{V}$ staining and analyzed by flow cytometry. The rate of apoptosis is represented as the mean $\pm \mathrm{SD}$. $* \star * P<0.01$. 


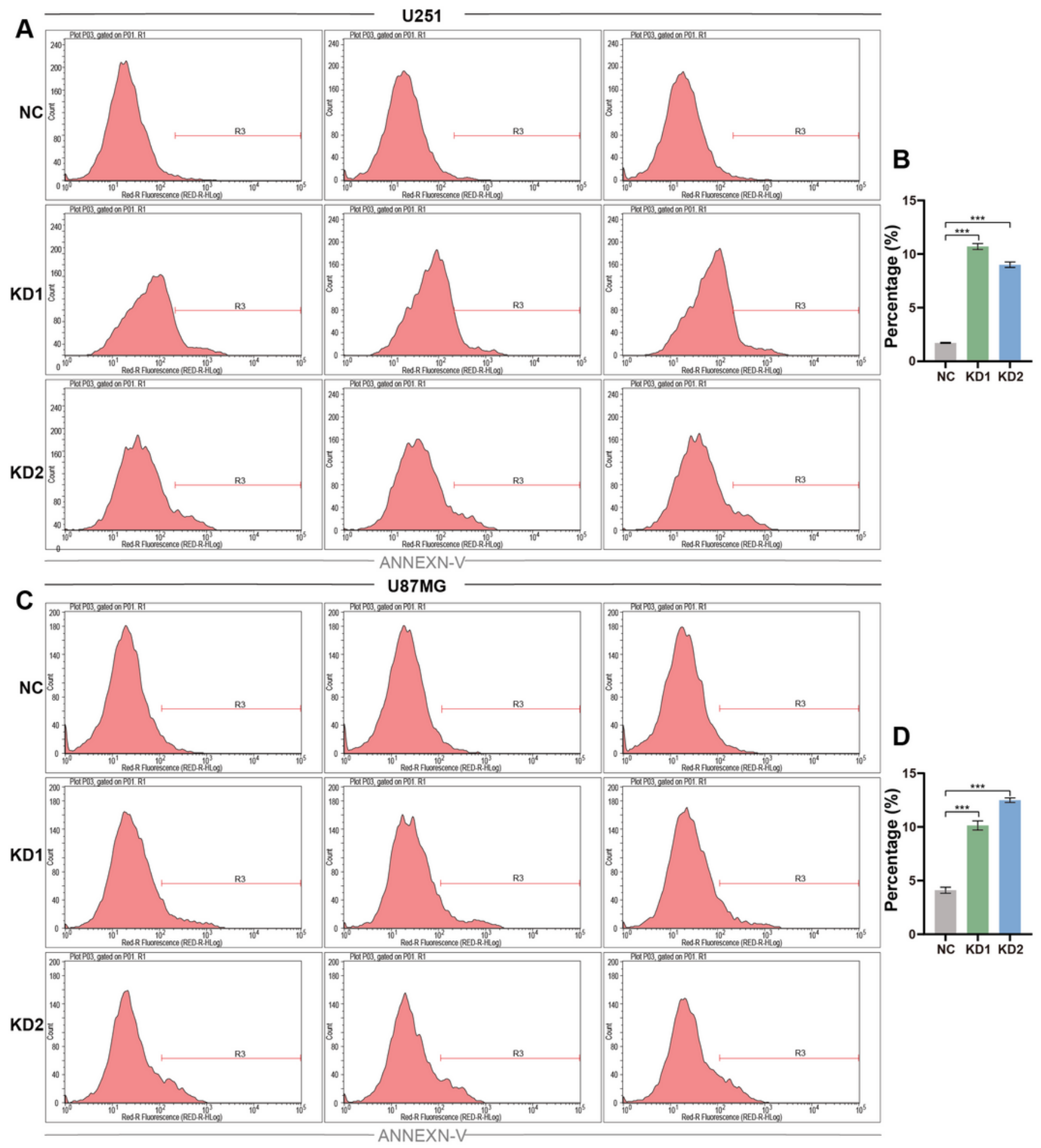

\section{Figure 4}

Suppression of OLFML2A promotes apoptosis of glioma cells. Apoptosis of U251 and U87MG cells was assessed using Annexin- $\mathrm{V}$ staining and analyzed by flow cytometry. The rate of apoptosis is represented as the mean $\pm \mathrm{SD}$. $* \star * P<0.01$. 


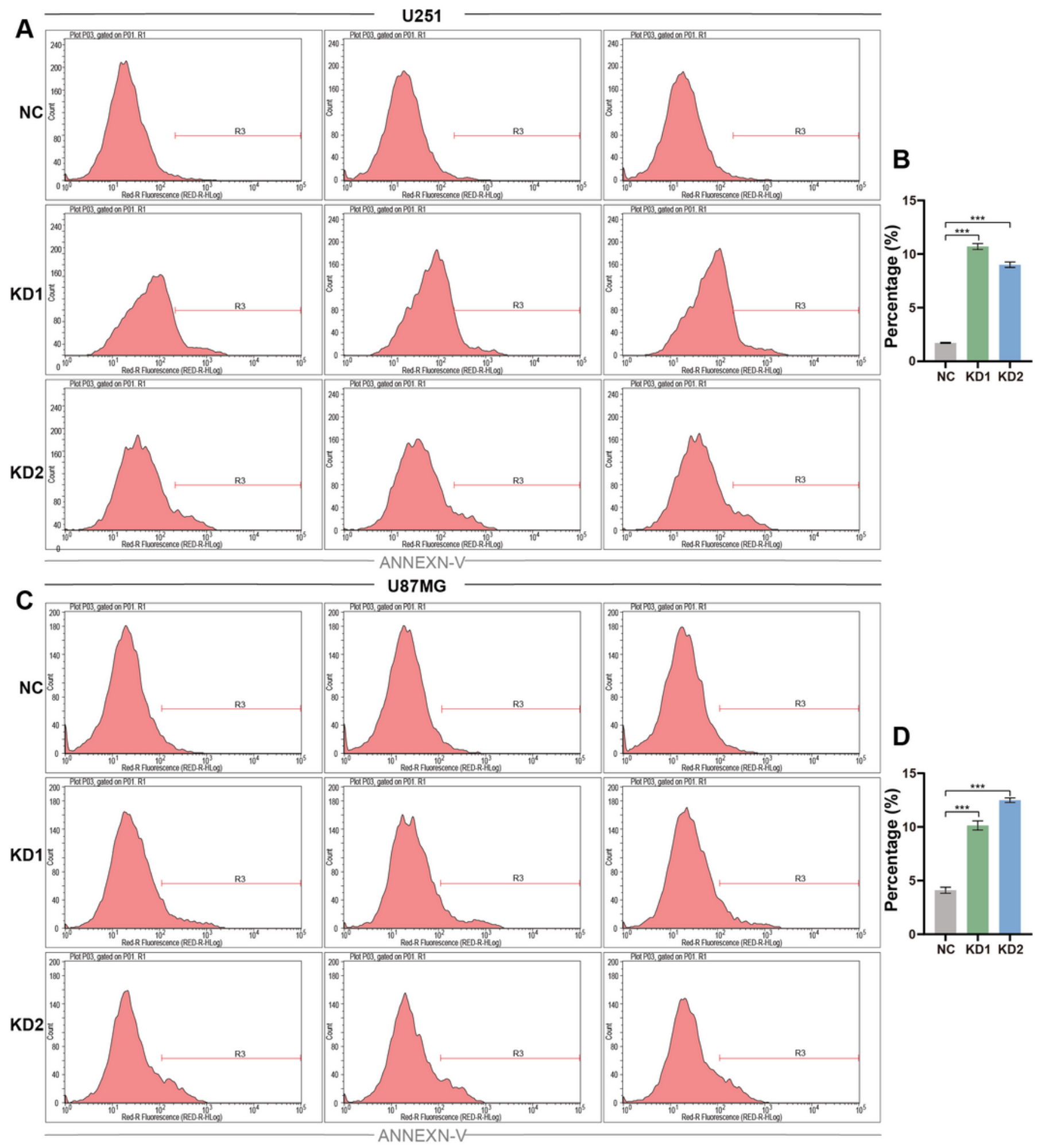

\section{Figure 4}

Suppression of OLFML2A promotes apoptosis of glioma cells. Apoptosis of U251 and U87MG cells was assessed using Annexin- $\mathrm{V}$ staining and analyzed by flow cytometry. The rate of apoptosis is represented as the mean $\pm \mathrm{SD}$. $* \star * P<0.01$. 
A

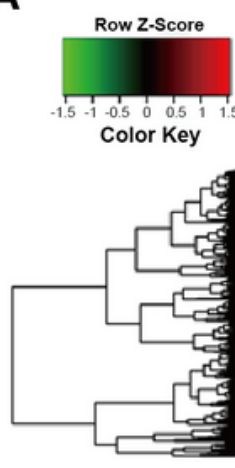

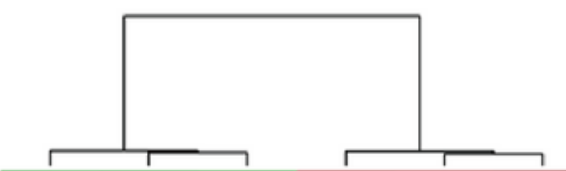

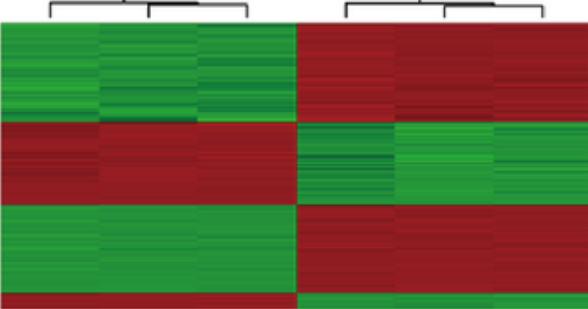

NC

KD

C

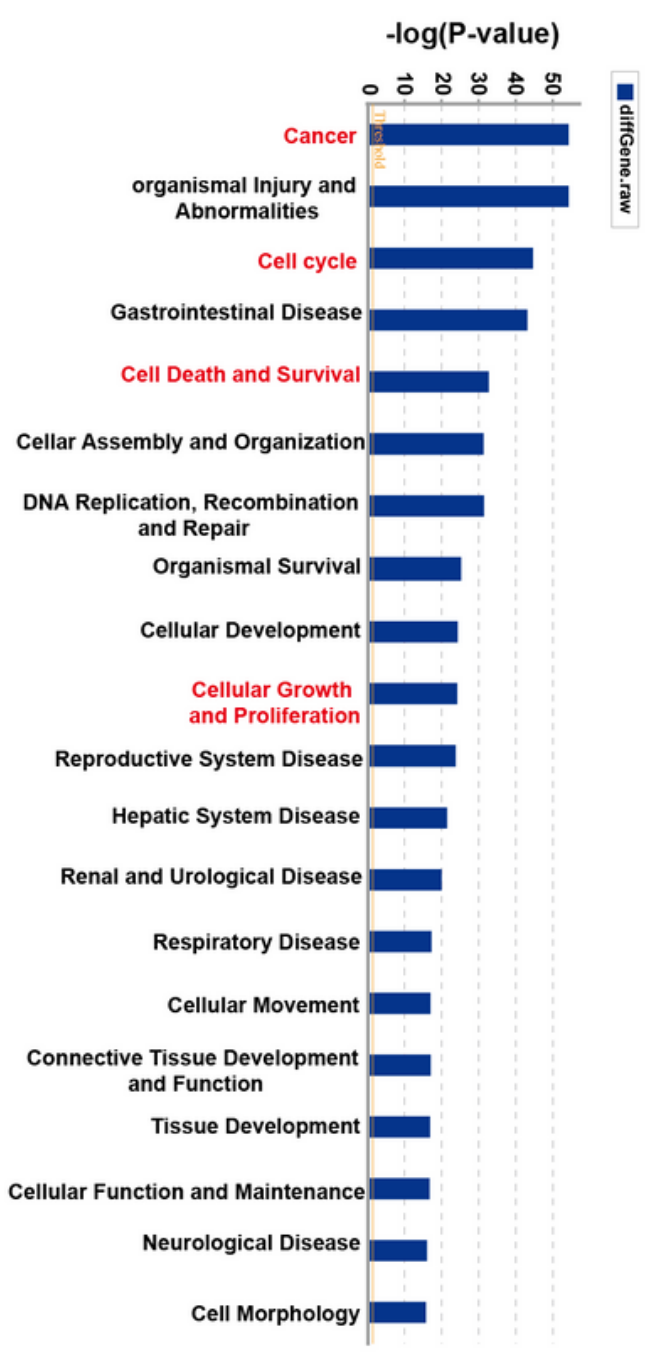

B

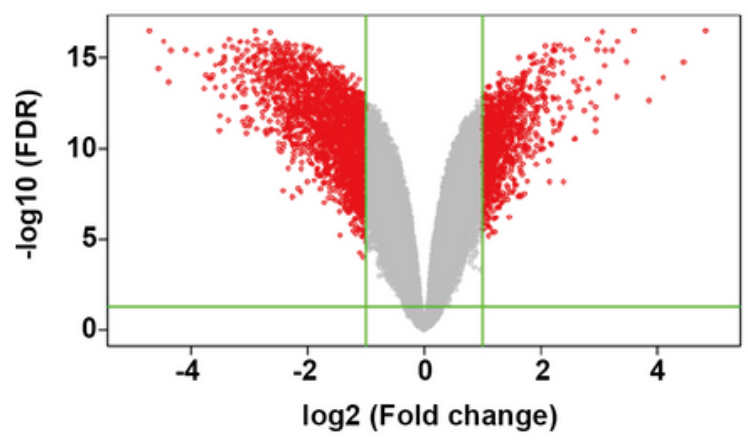

D

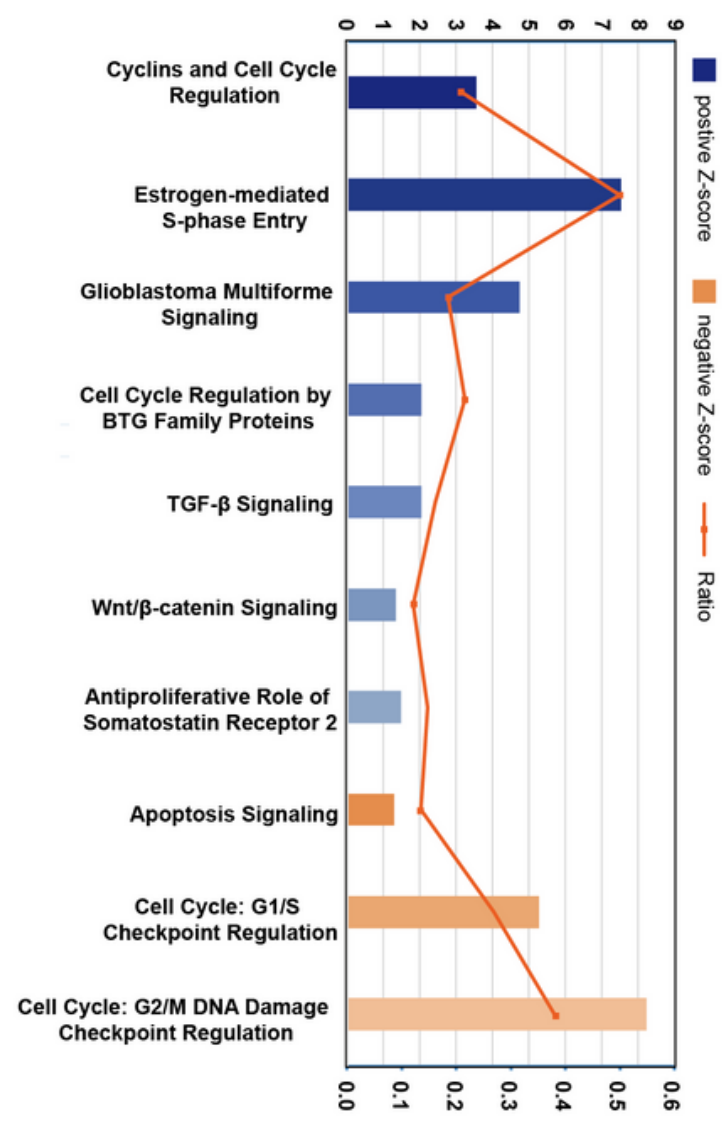

\section{Figure 5}

Widespread changes in gene expression in U87MG cells with OLFML2A knockdown by microarray. a. Heatmap representation of 1911 genes showing significant differential expression in the human malignant glioma cell line U87MG infected with lentivirus expressing either Scr-shRNA (NC) or OLFML2AshRNA (KD) under the criteria $\mathrm{P}<0.05$ and |fold change| $>2$. Genes and samples are listed in rows and columns, respectively. The color scale for the normalized expression data is shown at the bottom of the 
microarray heatmap (green represents downregulated genes, while red represents upregulated genes). b. Volcano plots. The significantly changed genes are marked in red. The chosen thresholds were a ffold changel $>2$ and a $p<0.05$. c. Disease and function analysis was performed to classify the enriched genes after OLFML2A silencing. d. Annotated classical pathway analysis indicated that multiple signaling pathways involved in cell proliferation were enriched after OLFML2A silencing. Blue represents suppressed signaling pathways, orange represents the activated signaling pathway, and the intensity of the color indicates the degree of activation or inhibition. (NC, cells infected with negative control lentivirus Scr-shRNA; KD, cells infected with OLFML2A-shRNA-1.) 
A

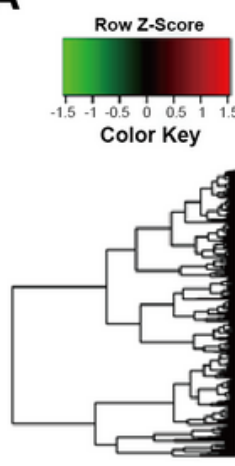

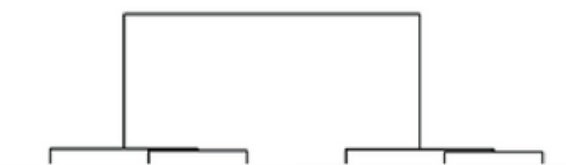

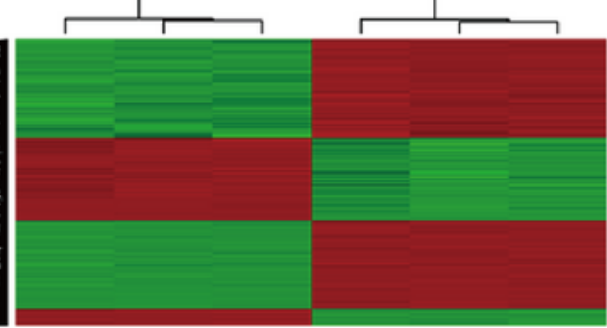

NC

KD

B

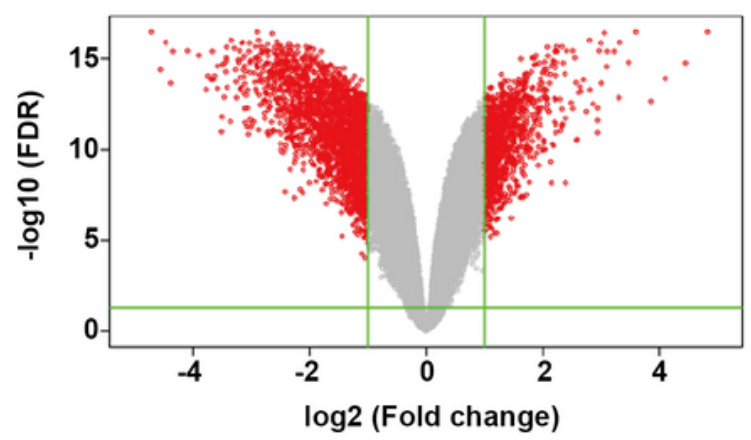

D

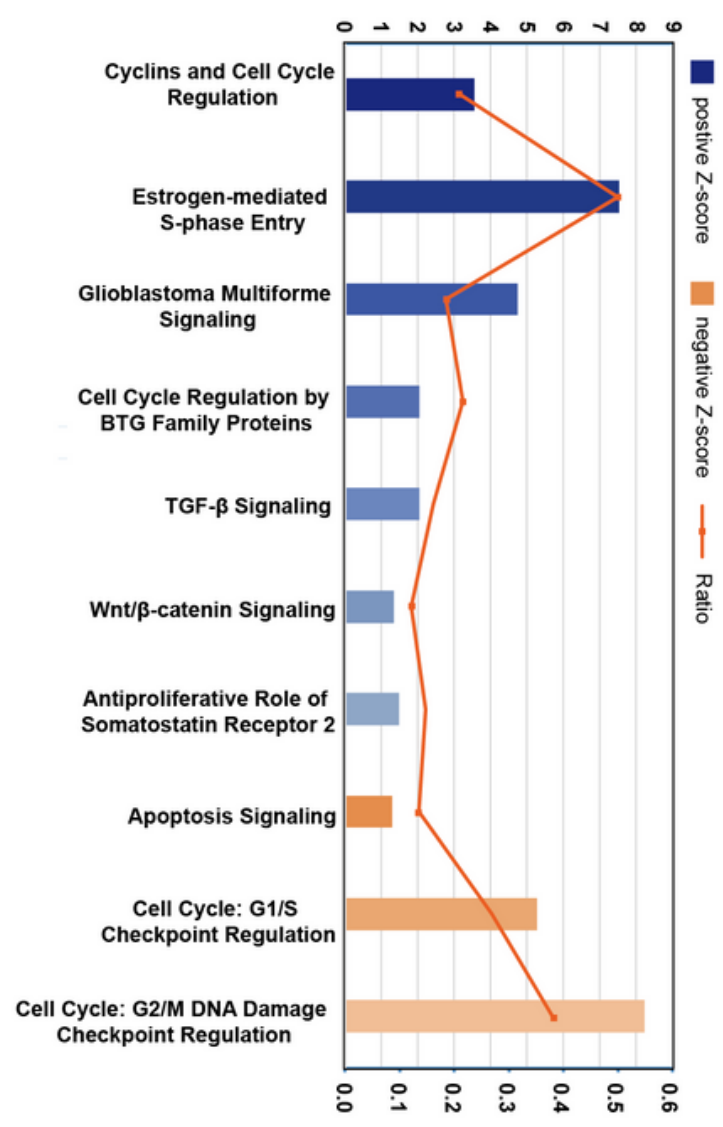

Cellular Function and Maintenance

-log(P-value)

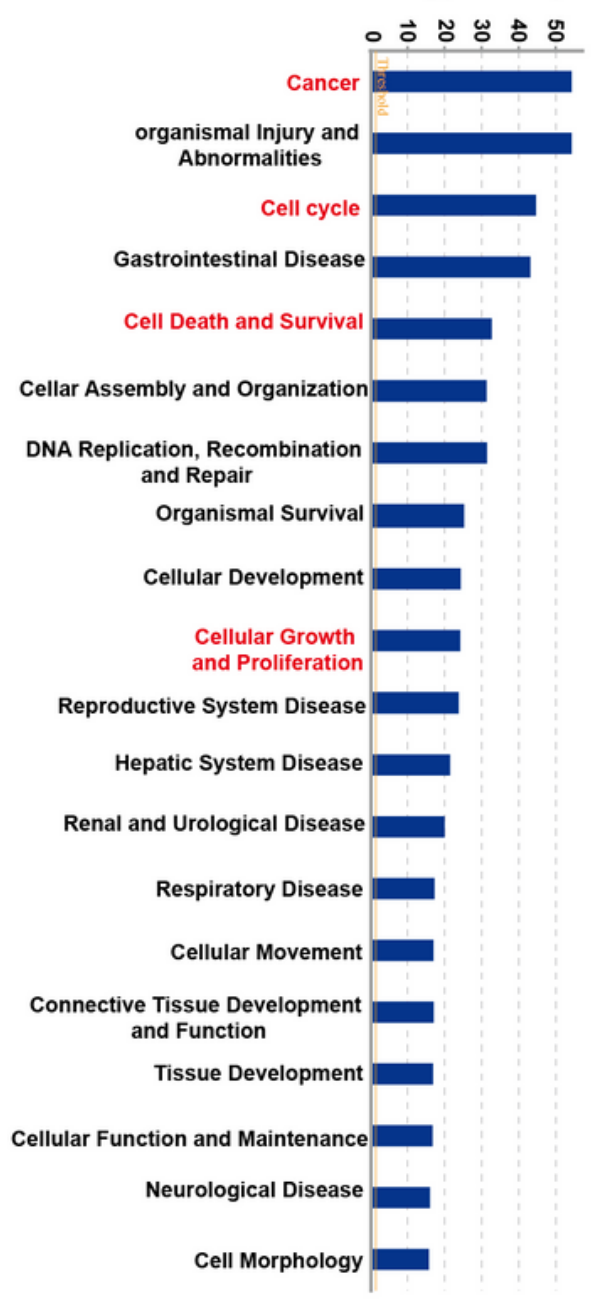

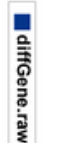

\section{Figure 5}

Widespread changes in gene expression in U87MG cells with OLFML2A knockdown by microarray. a. Heatmap representation of 1911 genes showing significant differential expression in the human malignant glioma cell line U87MG infected with lentivirus expressing either Scr-shRNA (NC) or OLFML2AshRNA (KD) under the criteria $\mathrm{P}<0.05$ and |fold change| $>2$. Genes and samples are listed in rows and columns, respectively. The color scale for the normalized expression data is shown at the bottom of the 
microarray heatmap (green represents downregulated genes, while red represents upregulated genes). b. Volcano plots. The significantly changed genes are marked in red. The chosen thresholds were a ffold changel $>2$ and a $p<0.05$. c. Disease and function analysis was performed to classify the enriched genes after OLFML2A silencing. d. Annotated classical pathway analysis indicated that multiple signaling pathways involved in cell proliferation were enriched after OLFML2A silencing. Blue represents suppressed signaling pathways, orange represents the activated signaling pathway, and the intensity of the color indicates the degree of activation or inhibition. (NC, cells infected with negative control lentivirus Scr-shRNA; KD, cells infected with OLFML2A-shRNA-1.) 
A

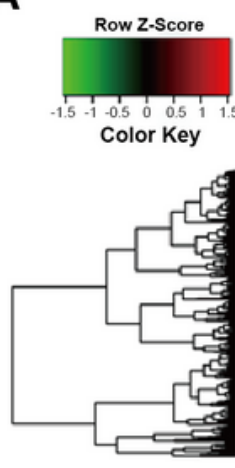

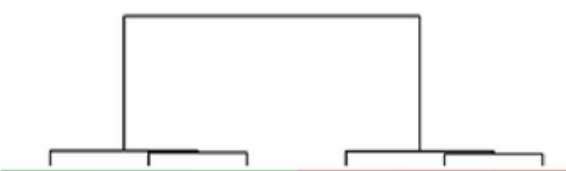

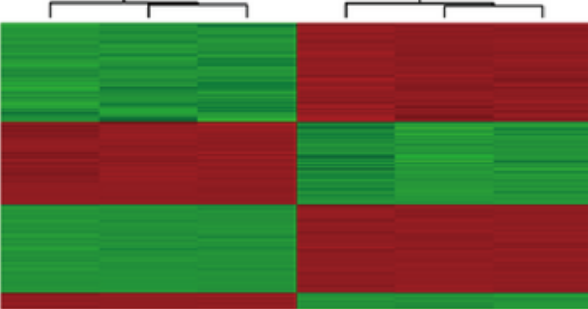

NC

KD

C

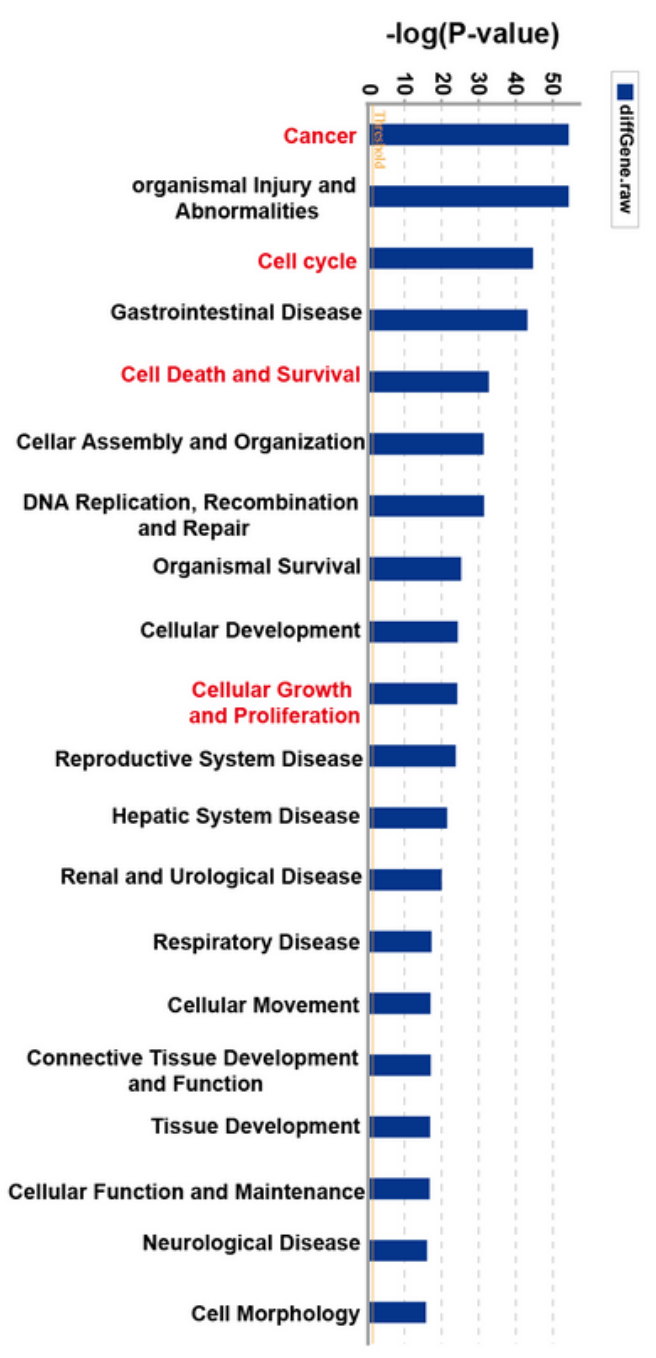

B

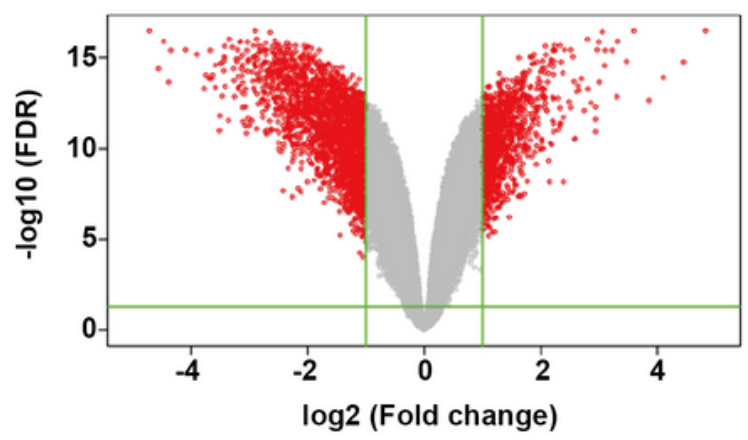

D

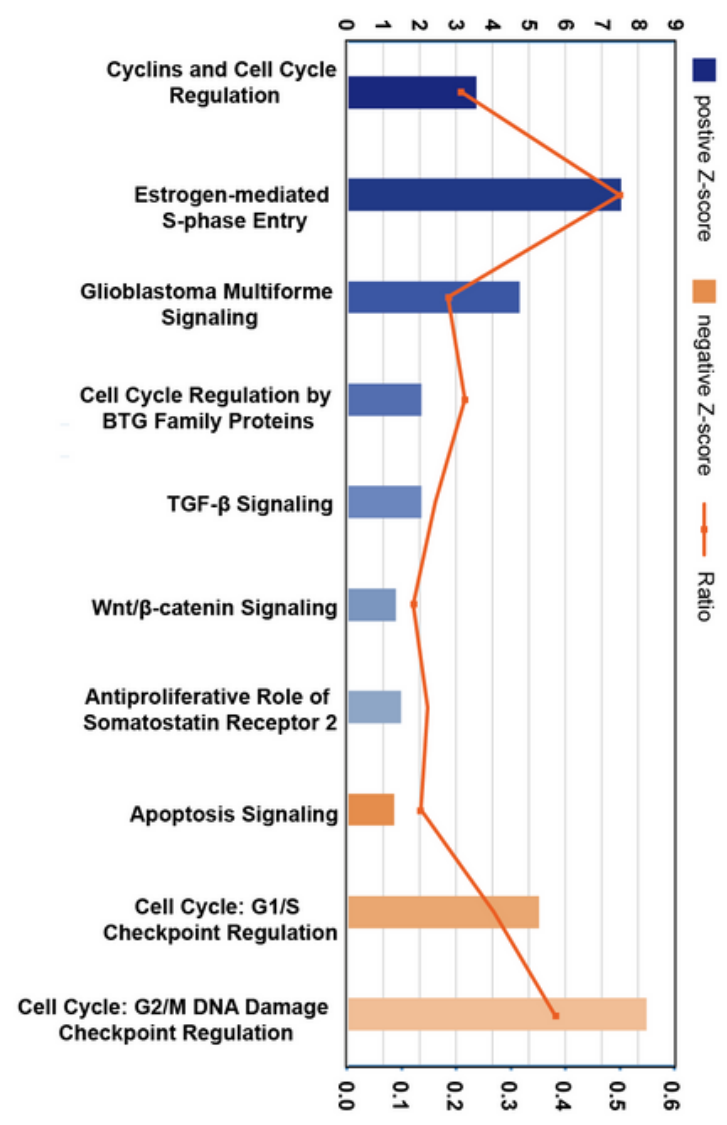

\section{Figure 5}

Widespread changes in gene expression in U87MG cells with OLFML2A knockdown by microarray. a. Heatmap representation of 1911 genes showing significant differential expression in the human malignant glioma cell line U87MG infected with lentivirus expressing either Scr-shRNA (NC) or OLFML2AshRNA (KD) under the criteria $\mathrm{P}<0.05$ and |fold change| $>2$. Genes and samples are listed in rows and columns, respectively. The color scale for the normalized expression data is shown at the bottom of the 
microarray heatmap (green represents downregulated genes, while red represents upregulated genes). b. Volcano plots. The significantly changed genes are marked in red. The chosen thresholds were a ffold changel $>2$ and a $p<0.05$. c. Disease and function analysis was performed to classify the enriched genes after OLFML2A silencing. d. Annotated classical pathway analysis indicated that multiple signaling pathways involved in cell proliferation were enriched after OLFML2A silencing. Blue represents suppressed signaling pathways, orange represents the activated signaling pathway, and the intensity of the color indicates the degree of activation or inhibition. (NC, cells infected with negative control lentivirus Scr-shRNA; KD, cells infected with OLFML2A-shRNA-1.) 
A

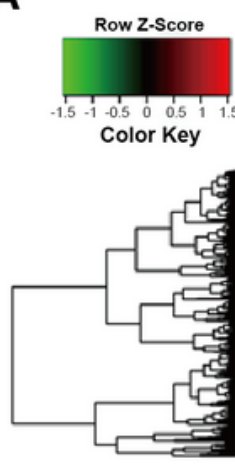

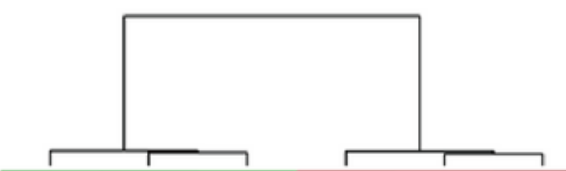

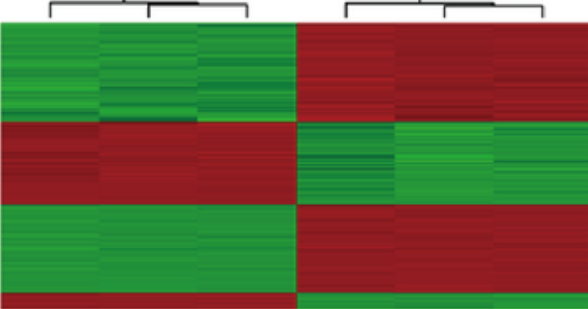

NC

KD

C

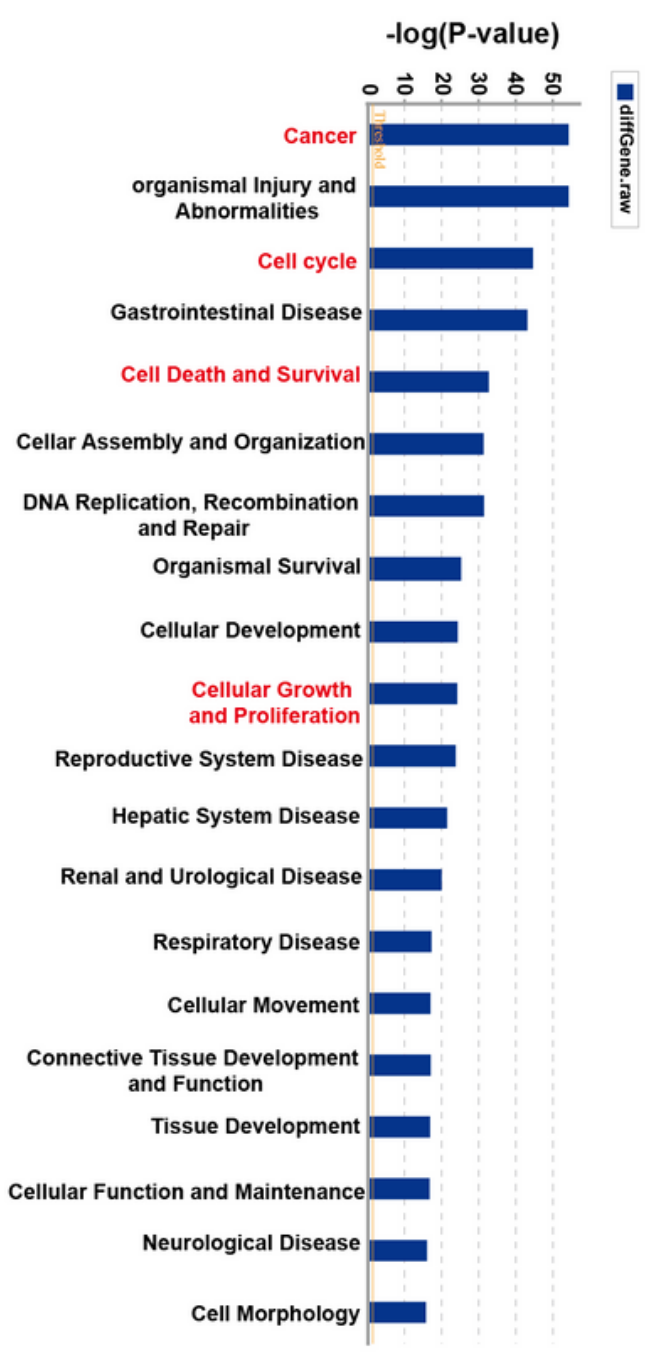

B

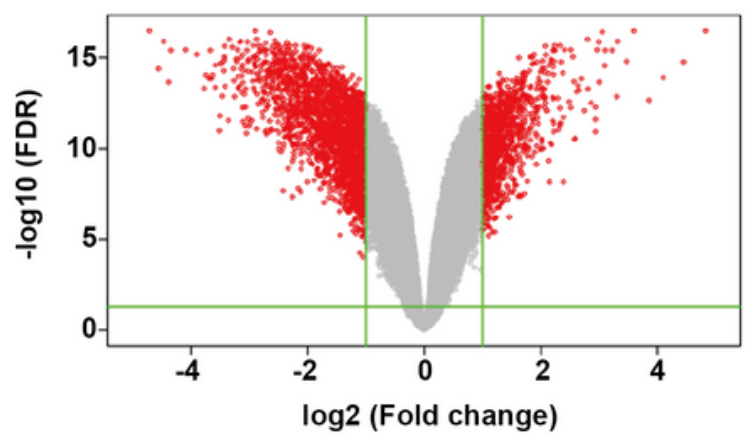

D

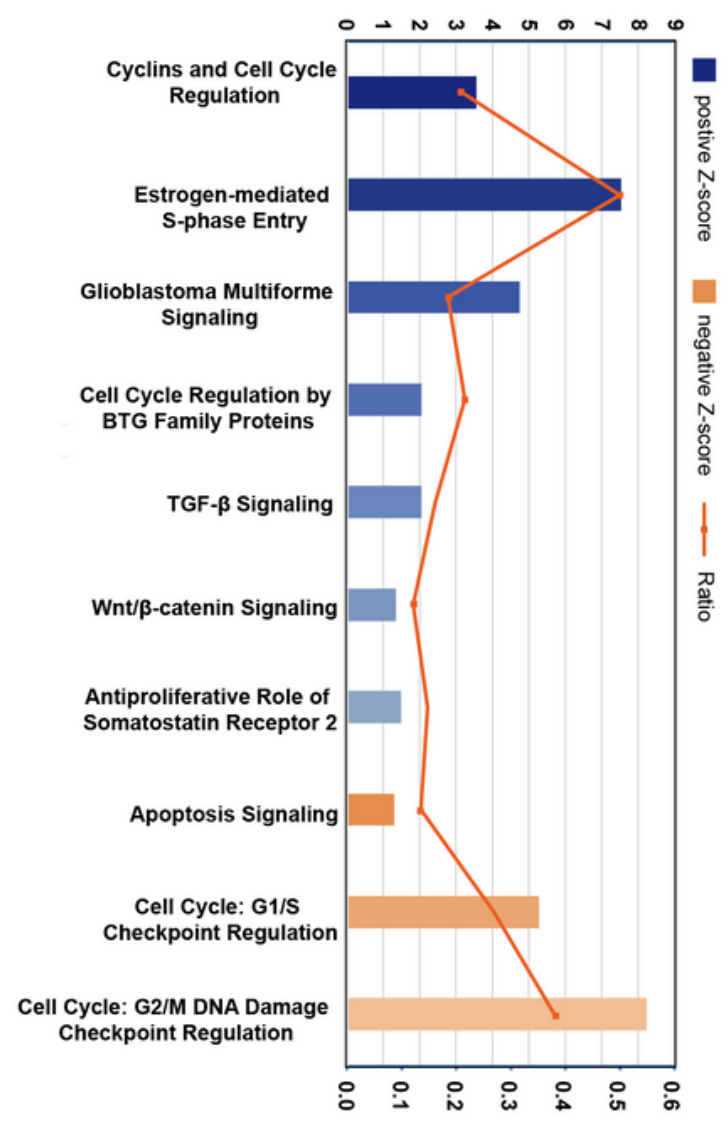

\section{Figure 5}

Widespread changes in gene expression in U87MG cells with OLFML2A knockdown by microarray. a. Heatmap representation of 1911 genes showing significant differential expression in the human malignant glioma cell line U87MG infected with lentivirus expressing either Scr-shRNA (NC) or OLFML2AshRNA (KD) under the criteria $\mathrm{P}<0.05$ and |fold change| $>2$. Genes and samples are listed in rows and columns, respectively. The color scale for the normalized expression data is shown at the bottom of the 
microarray heatmap (green represents downregulated genes, while red represents upregulated genes). b. Volcano plots. The significantly changed genes are marked in red. The chosen thresholds were a ffold changel $>2$ and a $p<0.05$. c. Disease and function analysis was performed to classify the enriched genes after OLFML2A silencing. d. Annotated classical pathway analysis indicated that multiple signaling pathways involved in cell proliferation were enriched after OLFML2A silencing. Blue represents suppressed signaling pathways, orange represents the activated signaling pathway, and the intensity of the color indicates the degree of activation or inhibition. (NC, cells infected with negative control lentivirus Scr-shRNA; KD, cells infected with OLFML2A-shRNA-1.) 
A

\begin{tabular}{|l|c|c|c|}
\hline & Fold change & P-value & Regulation \\
\hline SOX4 & 2.372679 & $1.12 \mathrm{E}-13$ & up \\
\hline WNT3 & -2.55006 & $1.39 \mathrm{E}-12$ & down \\
\hline FZD3 & 2.179912 & $5.07 \mathrm{E}-09$ & up \\
\hline LRP6 & 2.354673 & $1.84 \mathrm{E}-10$ & up \\
\hline MDM2 & 2.532865 & $1.51 \mathrm{E}-11$ & up \\
\hline ACVR2B & 2.270815 & $4.62 \mathrm{E}-09$ & up \\
\hline RARG & 2.011163 & $1.6 \mathrm{E}-12$ & up \\
\hline TGFBR2 & 2.426505 & $2.75 \mathrm{E}-16$ & up \\
\hline MYC & -5.51821 & $1.64 \mathrm{E}-16$ & down \\
\hline CSNK2A2 & -2.25322 & $3.3 \mathrm{E}-13$ & down \\
\hline PPP2R2B & -3.25051 & $5.72 \mathrm{E}-11$ & down \\
\hline MAP3K7 & -2.4107 & $1.84 \mathrm{E}-12$ & down \\
\hline CD44 & -2.15904 & $1.11 \mathrm{E}-15$ & down \\
\hline AKT3 & -2.33262 & $4.99 \mathrm{E}-10$ & down \\
\hline DVL3 & 2.00553 & $4.35 \mathrm{E}-12$ & up \\
\hline LEF1 & -2.17595 & $4.32 \mathrm{E}-08$ & down \\
\hline BTRC & 2.498081 & $2.83 \mathrm{E}-12$ & up \\
\hline ACVR1C & 4.926808 & $5.14 \mathrm{E}-13$ & up \\
\hline LRP1 & -0.34708 & $1.03 \mathrm{E}-13$ & up \\
\hline WNT5B & -0.40074 & $2.73 \mathrm{E}-12$ & down \\
\hline WNT5A & -0.4544 & $2.28 \mathrm{E}-11$ & down \\
\hline
\end{tabular}

B

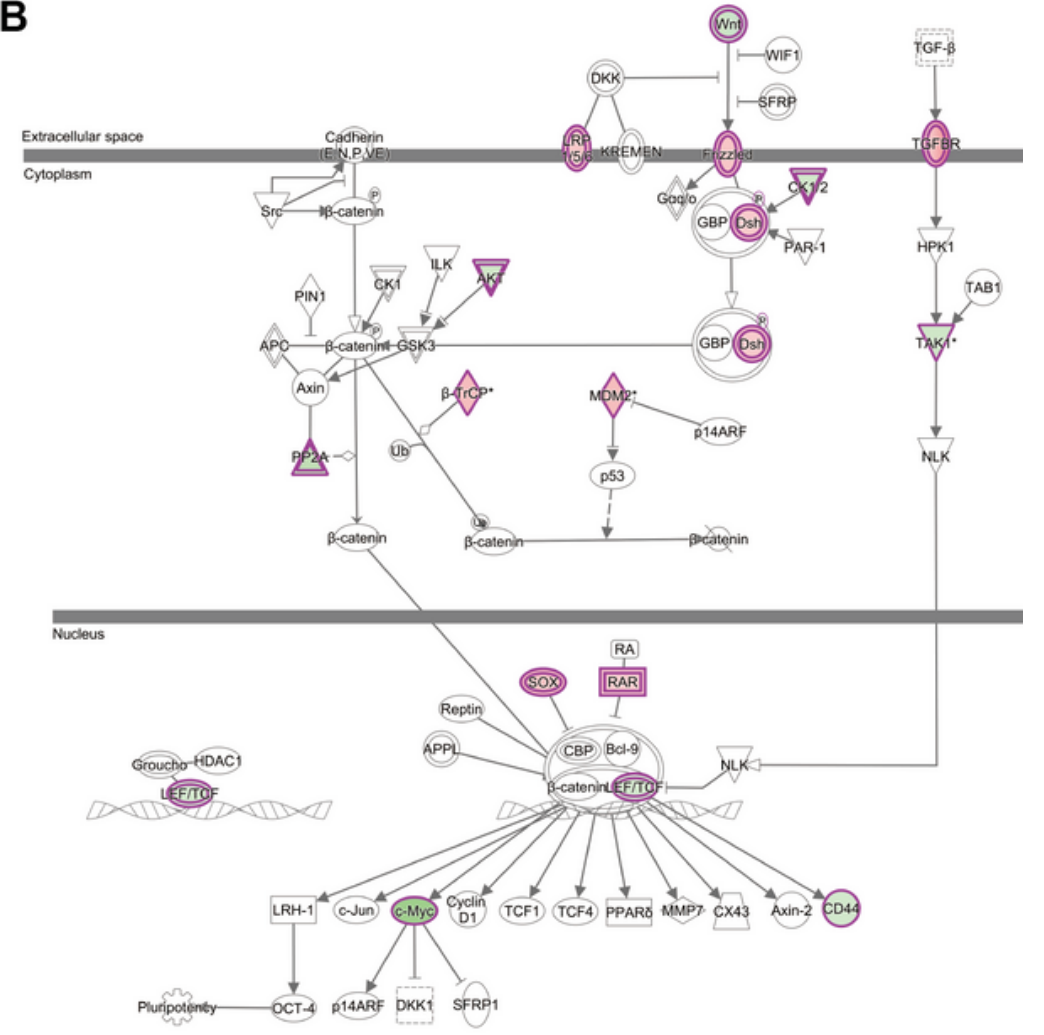

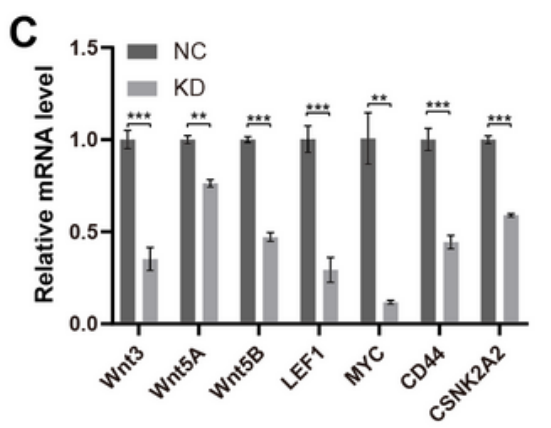

D

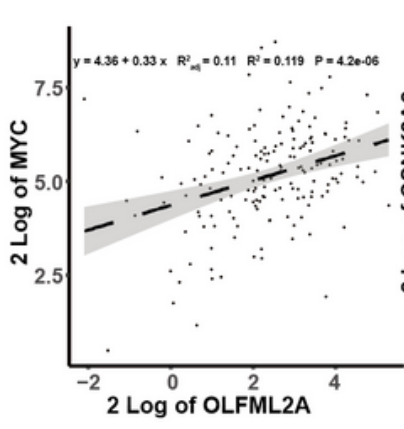

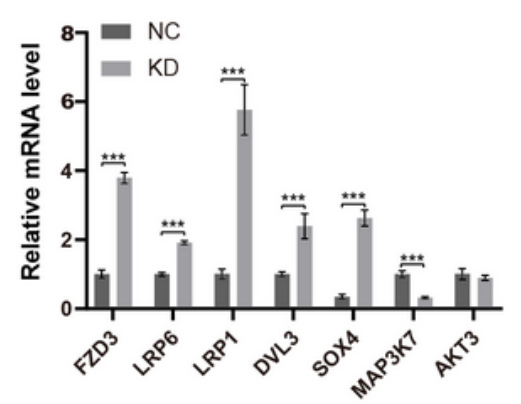

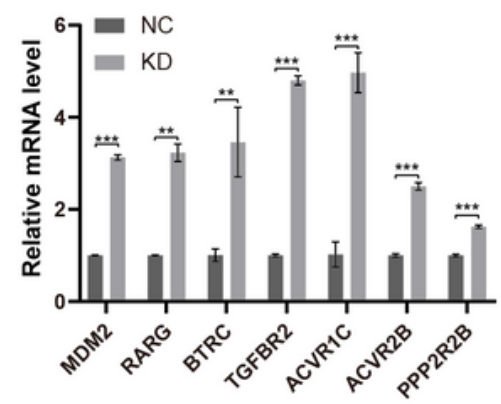

E
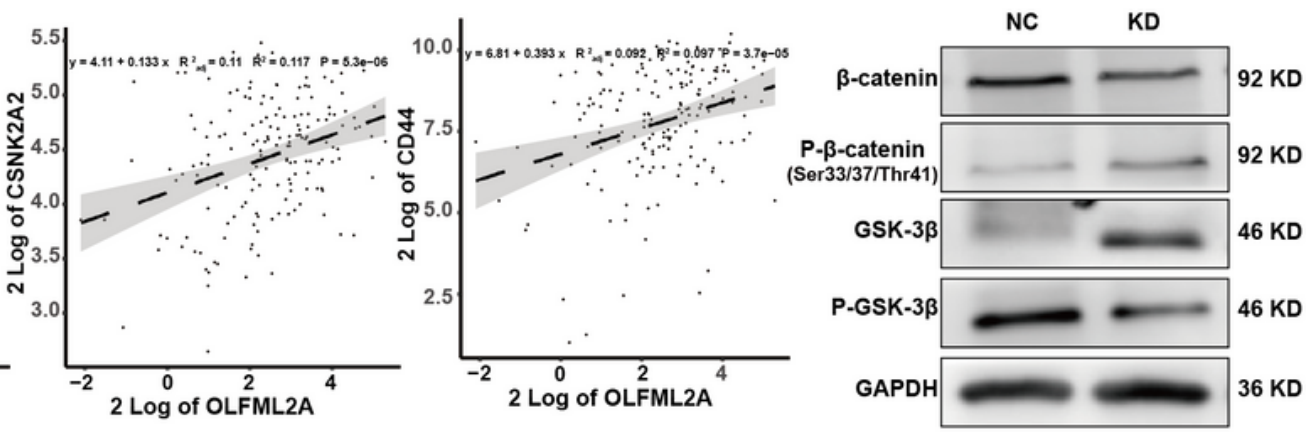

\section{Figure 6}

OLFML2A knockdown suppresses the Wnt/ $\beta$-catenin pathway in glioma cells. a. The fold change, $\mathrm{P}$ values and regulatory effect of the molecules associated with the Wnt/ $\beta$-catenin signaling pathway relative to OLFML2A knockdown are collated in the table. b. The Wnt/ $\beta$-catenin signaling pathway was mapped by IPA, and the 21 molecules are included in the table (a). Green: downregulated. Red: upregulated. c. The expression of the 21 molecules was verified by quantitative RT-PCR in U87MG cells. 
$\star \star P<0.01,{ }^{\star} * * P<0.001$. d. The correlation of OLFML2A with MYC, CSNk2A2 and CD44 from a TCGA dataset $(n=169)$. e. The protein content of $\beta$-catenin, $p 33 / 37 / 41-\beta$-catenin, GSK-3 $\beta$, and P-GSK-3 $\beta$ was assessed by western blotting in U87MG cells. (NC, cells infected with negative control lentivirus expressing Scr-shRNA; KD, cells infected with OLFML2A-shRNA-1-expressing lentivirus.)

A

\begin{tabular}{|l|c|c|c|}
\hline & Fold change & P-value & Regulation \\
\hline SOX4 & 2.372679 & $1.12 \mathrm{E}-13$ & up \\
\hline WNT3 & -2.55006 & $1.39 \mathrm{E}-12$ & down \\
\hline FZD3 & 2.179912 & $5.07 \mathrm{E}-09$ & up \\
\hline LRP6 & 2.354673 & $1.84 \mathrm{E}-10$ & up \\
\hline MDM2 & 2.532865 & $1.51 \mathrm{E}-11$ & up \\
\hline ACVR2B & 2.270815 & $4.62 \mathrm{E}-09$ & up \\
\hline RARG & 2.011163 & $1.6 \mathrm{E}-12$ & up \\
\hline TGFBR2 & 2.426505 & $2.75 \mathrm{E}-16$ & up \\
\hline MYC & -5.51821 & $1.64 \mathrm{E}-16$ & down \\
\hline CSNK2A2 & -2.25322 & $3.3 \mathrm{E}-13$ & down \\
\hline PPP2R2B & -3.25051 & $5.72 \mathrm{E}-11$ & down \\
\hline MAP3K7 & -2.4107 & $1.84 \mathrm{E}-12$ & down \\
\hline CD44 & -2.15904 & $1.11 \mathrm{E}-15$ & down \\
\hline AKT3 & -2.33262 & $4.99 \mathrm{E}-10$ & down \\
\hline DVL3 & 2.00553 & $4.35 \mathrm{E}-12$ & up \\
\hline LEF1 & -2.17595 & $4.32 \mathrm{E}-08$ & down \\
\hline BTRC & 2.498081 & $2.83 \mathrm{E}-12$ & up \\
\hline ACVR1C & 4.926808 & $5.14 \mathrm{E}-13$ & up \\
\hline LRP1 & -0.34708 & $1.03 \mathrm{E}-13$ & up \\
\hline WNT5B & -0.40074 & $2.73 \mathrm{E}-12$ & down \\
\hline WNT5A & -0.4544 & $2.28 \mathrm{E}-11$ & down \\
\hline
\end{tabular}

B

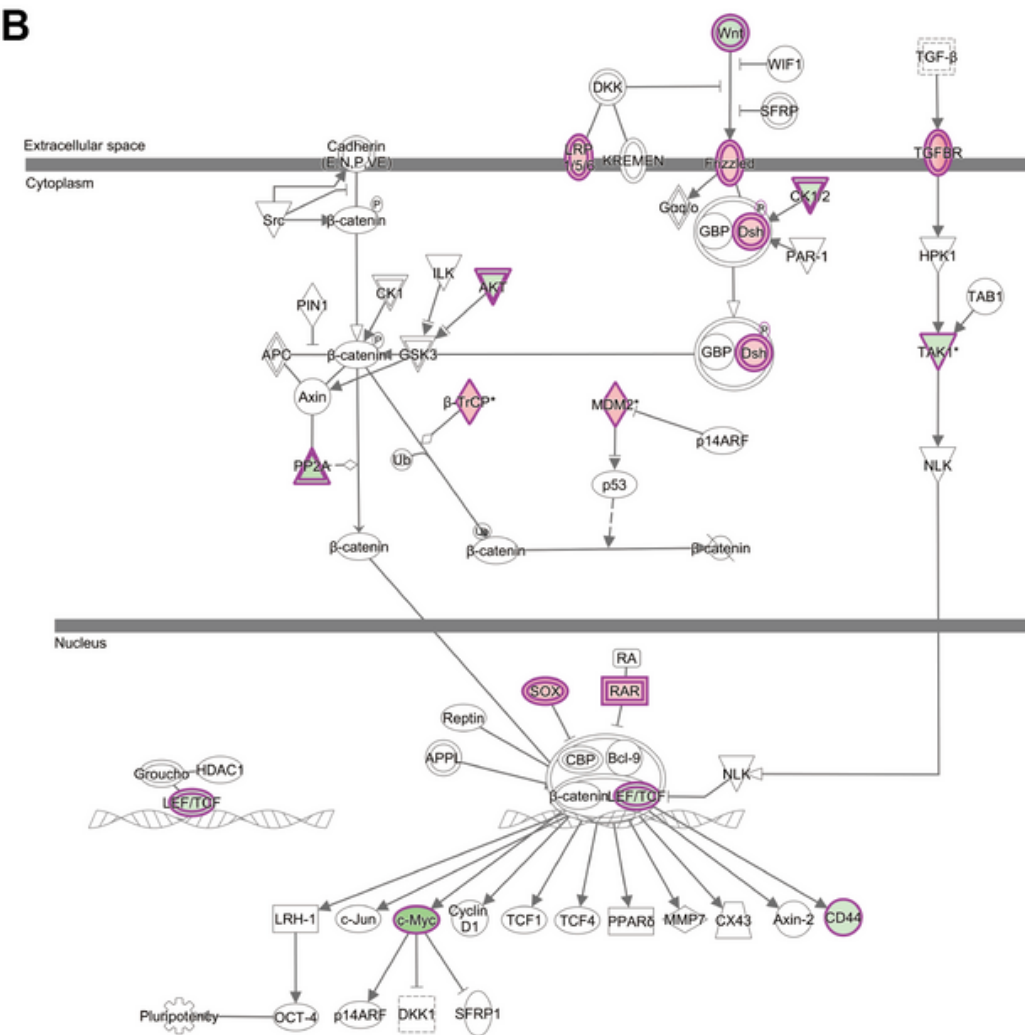

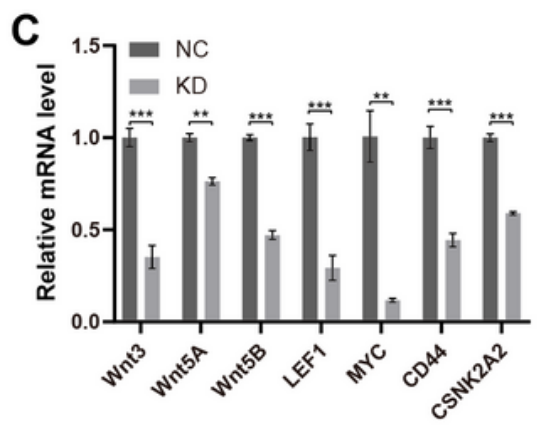

D

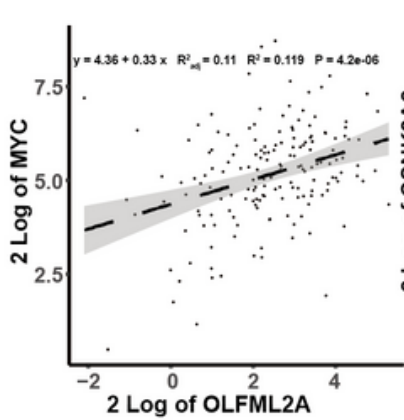

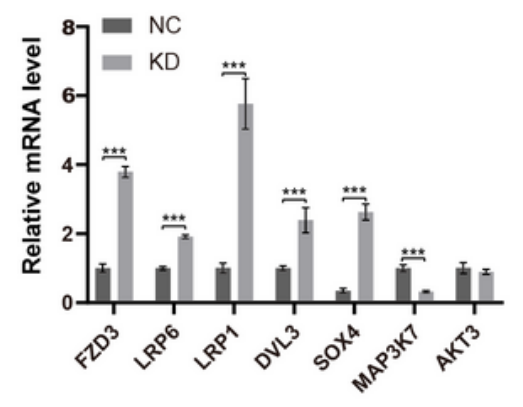

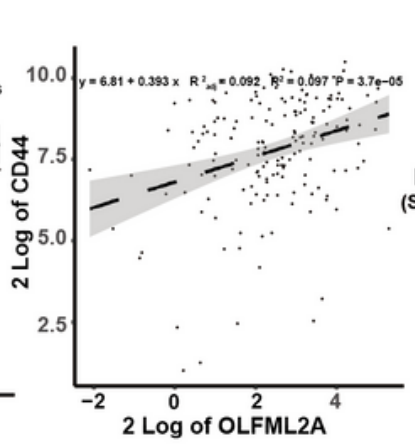

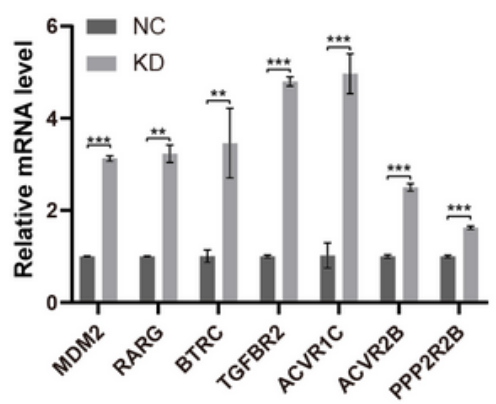

$\mathbf{E}$

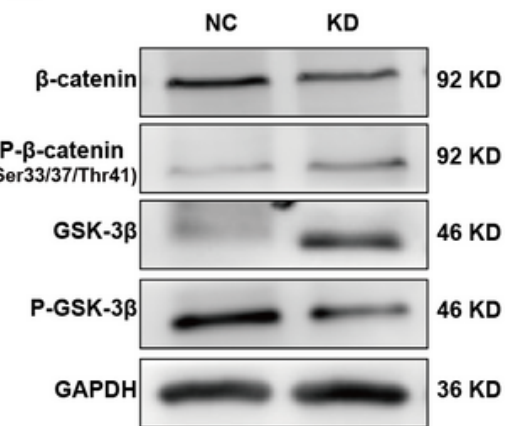

Figure 6 
OLFML2A knockdown suppresses the Wnt/ $\beta$-catenin pathway in glioma cells. a. The fold change, $\mathrm{P}$ values and regulatory effect of the molecules associated with the Wnt/ $\beta$-catenin signaling pathway relative to OLFML2A knockdown are collated in the table. $b$. The $W n t / \beta$-catenin signaling pathway was mapped by IPA, and the 21 molecules are included in the table (a). Green: downregulated. Red:

upregulated. c. The expression of the 21 molecules was verified by quantitative RT-PCR in U87MG cells. ${ }^{\star} \mathrm{P}<0.01,{ }^{\star \star \star} \mathrm{P}<0.001$. d. The correlation of OLFML2A with MYC, CSNk2A2 and CD44 from a TCGA dataset $(n=169)$. e. The protein content of $\beta$-catenin, $p 33 / 37 / 41-\beta$-catenin, GSK-3 $\beta$, and P-GSK-3 $\beta$ was assessed by western blotting in U87MG cells. (NC, cells infected with negative control lentivirus expressing Scr-shRNA; KD, cells infected with OLFML2A-shRNA-1-expressing lentivirus.) 
A

\begin{tabular}{|l|c|c|c|}
\hline & Fold change & P-value & Regulation \\
\hline SOX4 & 2.372679 & $1.12 \mathrm{E}-13$ & up \\
\hline WNT3 & -2.55006 & $1.39 \mathrm{E}-12$ & down \\
\hline FZD3 & 2.179912 & $5.07 \mathrm{E}-09$ & up \\
\hline LRP6 & 2.354673 & $1.84 \mathrm{E}-10$ & up \\
\hline MDM2 & 2.532865 & $1.51 \mathrm{E}-11$ & up \\
\hline ACVR2B & 2.270815 & $4.62 \mathrm{E}-09$ & up \\
\hline RARG & 2.011163 & $1.6 \mathrm{E}-12$ & up \\
\hline TGFBR2 & 2.426505 & $2.75 \mathrm{E}-16$ & up \\
\hline MYC & -5.51821 & $1.64 \mathrm{E}-16$ & down \\
\hline CSNK2A2 & -2.25322 & $3.3 \mathrm{E}-13$ & down \\
\hline PPP2R2B & -3.25051 & $5.72 \mathrm{E}-11$ & down \\
\hline MAP3K7 & -2.4107 & $1.84 \mathrm{E}-12$ & down \\
\hline CD44 & -2.15904 & $1.11 \mathrm{E}-15$ & down \\
\hline AKT3 & -2.33262 & $4.99 \mathrm{E}-10$ & down \\
\hline DVL3 & 2.00553 & $4.35 \mathrm{E}-12$ & up \\
\hline LEF1 & -2.17595 & $4.32 \mathrm{E}-08$ & down \\
\hline BTRC & 2.498081 & $2.83 \mathrm{E}-12$ & up \\
\hline ACVR1C & 4.926808 & $5.14 \mathrm{E}-13$ & up \\
\hline LRP1 & -0.34708 & $1.03 \mathrm{E}-13$ & up \\
\hline WNT5B & -0.40074 & $2.73 \mathrm{E}-12$ & down \\
\hline WNT5A & -0.4544 & $2.28 \mathrm{E}-11$ & down \\
\hline
\end{tabular}

B

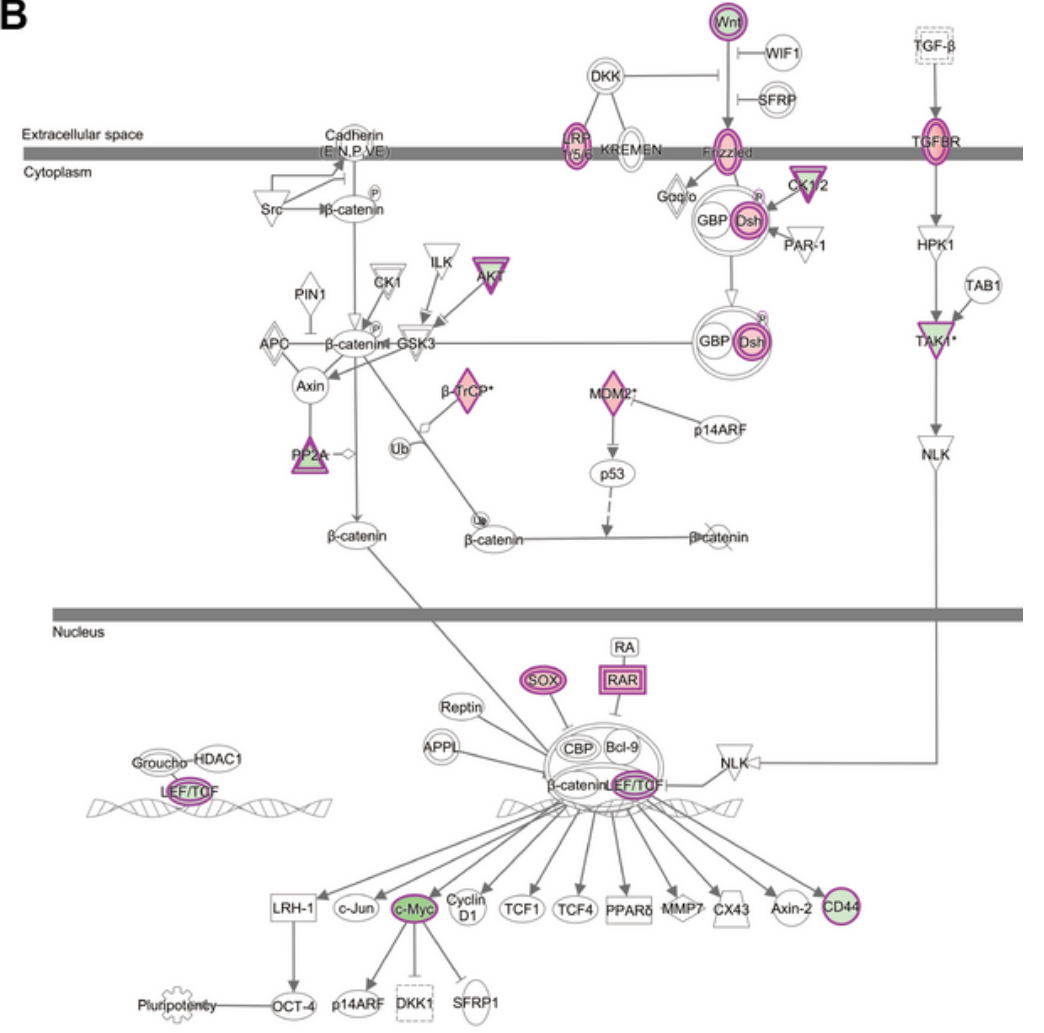

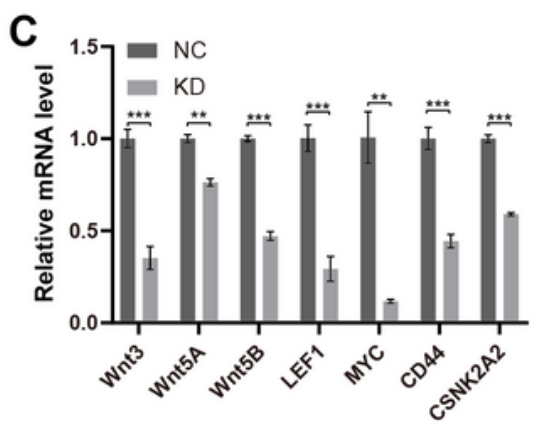

D

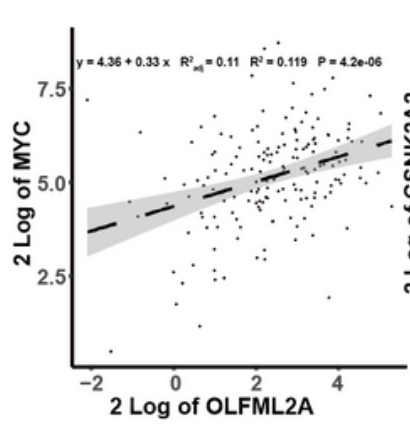

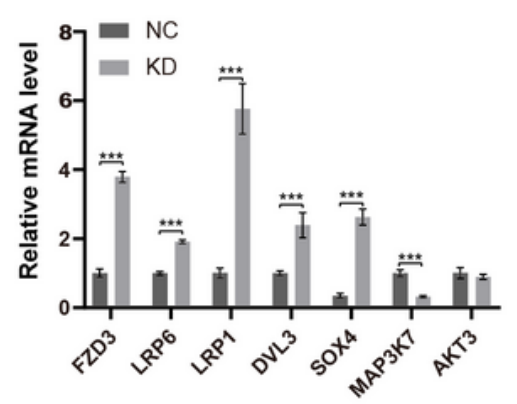

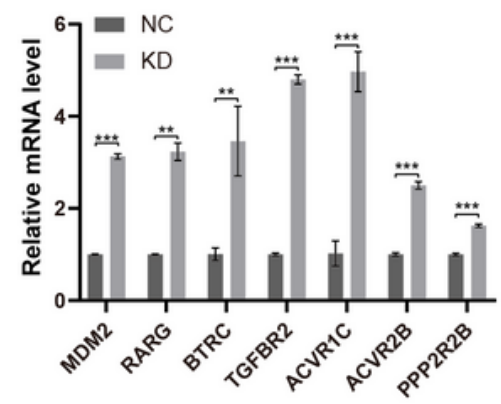

E
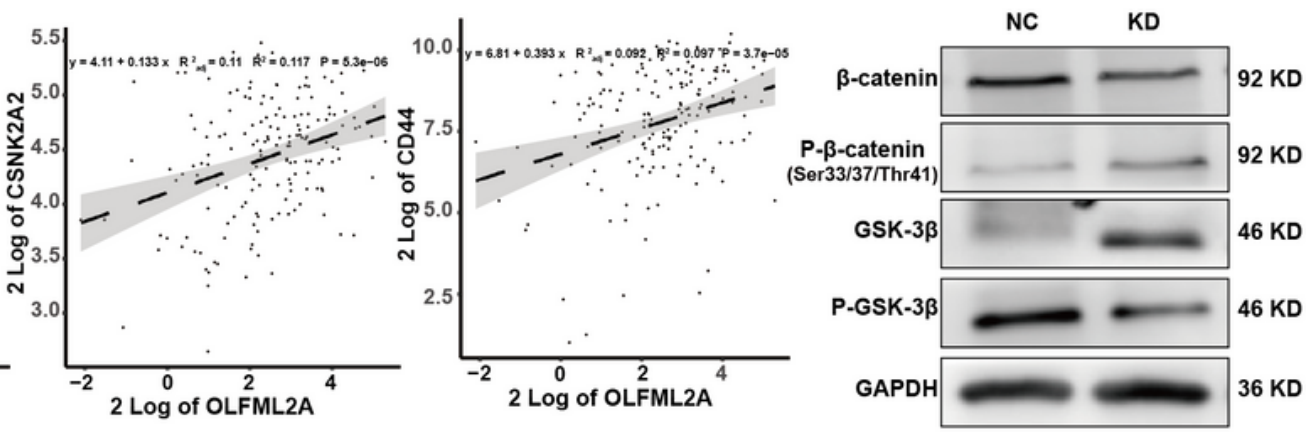

\section{Figure 6}

OLFML2A knockdown suppresses the Wnt/ $\beta$-catenin pathway in glioma cells. a. The fold change, $\mathrm{P}$ values and regulatory effect of the molecules associated with the Wnt/ $\beta$-catenin signaling pathway relative to OLFML2A knockdown are collated in the table. b. The Wnt/ $\beta$-catenin signaling pathway was mapped by IPA, and the 21 molecules are included in the table (a). Green: downregulated. Red: upregulated. c. The expression of the 21 molecules was verified by quantitative RT-PCR in U87MG cells. 
$\star \star P<0.01,{ }^{\star} * * P<0.001$. d. The correlation of OLFML2A with MYC, CSNk2A2 and CD44 from a TCGA dataset $(n=169)$. e. The protein content of $\beta$-catenin, $p 33 / 37 / 41-\beta$-catenin, GSK-3 $\beta$, and P-GSK-3 $\beta$ was assessed by western blotting in U87MG cells. (NC, cells infected with negative control lentivirus expressing Scr-shRNA; KD, cells infected with OLFML2A-shRNA-1-expressing lentivirus.)

A

\begin{tabular}{|l|c|c|c|}
\hline & Fold change & P-value & Regulation \\
\hline SOX4 & 2.372679 & $1.12 \mathrm{E}-13$ & up \\
\hline WNT3 & -2.55006 & $1.39 \mathrm{E}-12$ & down \\
\hline FZD3 & 2.179912 & $5.07 \mathrm{E}-09$ & up \\
\hline LRP6 & 2.354673 & $1.84 \mathrm{E}-10$ & up \\
\hline MDM2 & 2.532865 & $1.51 \mathrm{E}-11$ & up \\
\hline ACVR2B & 2.270815 & $4.62 \mathrm{E}-09$ & up \\
\hline RARG & 2.011163 & $1.6 \mathrm{E}-12$ & up \\
\hline TGFBR2 & 2.426505 & $2.75 \mathrm{E}-16$ & up \\
\hline MYC & -5.51821 & $1.64 \mathrm{E}-16$ & down \\
\hline CSNK2A2 & -2.25322 & $3.3 \mathrm{E}-13$ & down \\
\hline PPP2R2B & -3.25051 & $5.72 \mathrm{E}-11$ & down \\
\hline MAP3K7 & -2.4107 & $1.84 \mathrm{E}-12$ & down \\
\hline CD44 & -2.15904 & $1.11 \mathrm{E}-15$ & down \\
\hline AKT3 & -2.33262 & $4.99 \mathrm{E}-10$ & down \\
\hline DVL3 & 2.00553 & $4.35 \mathrm{E}-12$ & up \\
\hline LEF1 & -2.17595 & $4.32 \mathrm{E}-08$ & down \\
\hline BTRC & 2.498081 & $2.83 \mathrm{E}-12$ & up \\
\hline ACVR1C & 4.926808 & $5.14 \mathrm{E}-13$ & up \\
\hline LRP1 & -0.34708 & $1.03 \mathrm{E}-13$ & up \\
\hline WNT5B & -0.40074 & $2.73 \mathrm{E}-12$ & down \\
\hline WNT5A & -0.4544 & $2.28 \mathrm{E}-11$ & down \\
\hline
\end{tabular}

B

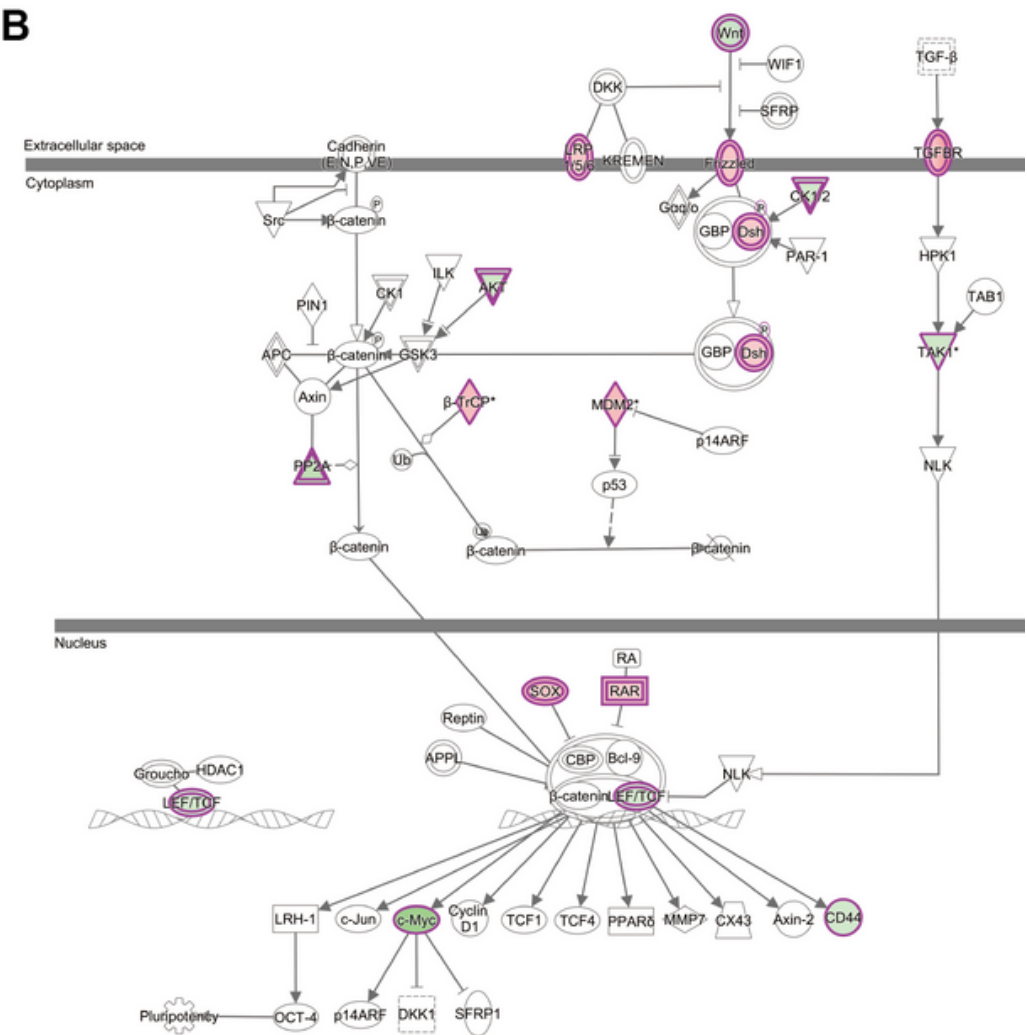

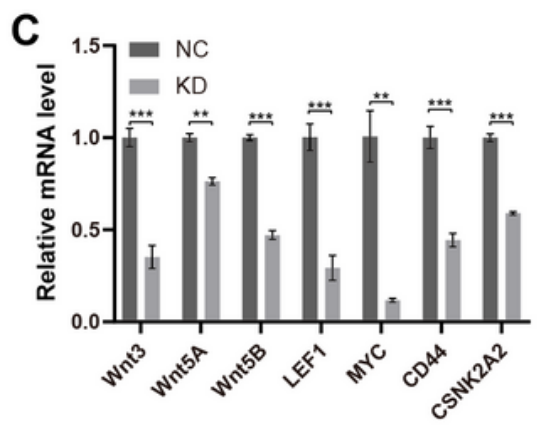

D

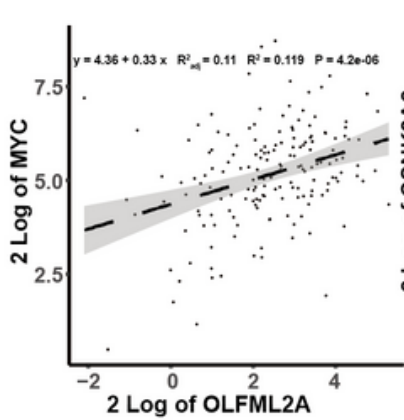

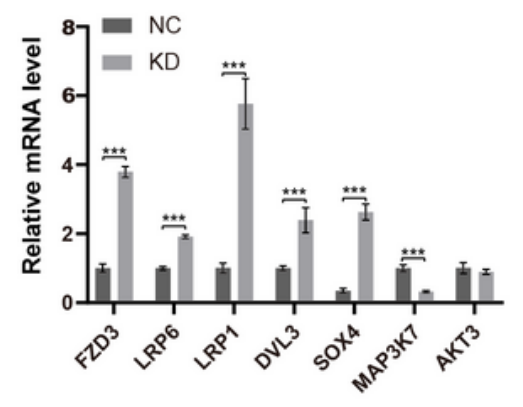

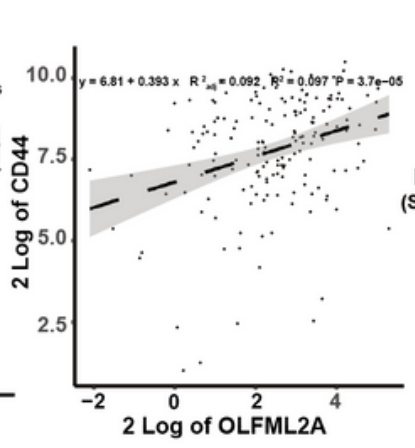

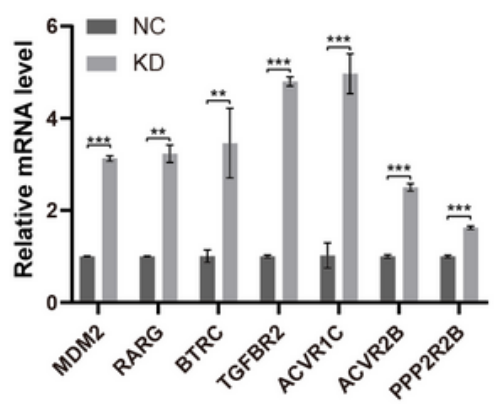

$\mathbf{E}$

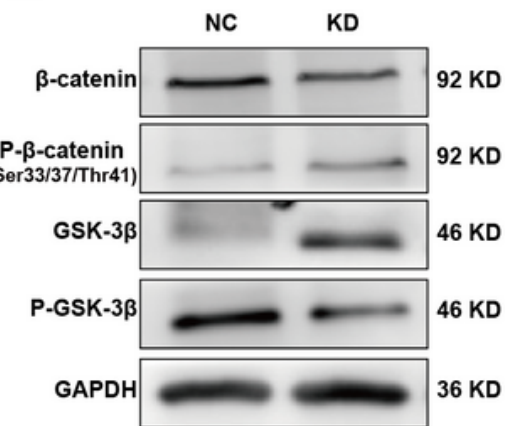

Figure 6 
OLFML2A knockdown suppresses the Wnt/ $\beta$-catenin pathway in glioma cells. a. The fold change, $\mathrm{P}$ values and regulatory effect of the molecules associated with the Wnt/ $\beta$-catenin signaling pathway relative to OLFML2A knockdown are collated in the table. $b$. The $W n t / \beta$-catenin signaling pathway was mapped by IPA, and the 21 molecules are included in the table (a). Green: downregulated. Red:

upregulated. c. The expression of the 21 molecules was verified by quantitative RT-PCR in U87MG cells. ${ }^{\star} \mathrm{P}<0.01,{ }^{\star \star \star} \mathrm{P}<0.001$. d. The correlation of OLFML2A with MYC, CSNk2A2 and CD44 from a TCGA dataset $(n=169)$. e. The protein content of $\beta$-catenin, $p 33 / 37 / 41-\beta$-catenin, GSK-3 $\beta$, and P-GSK-3 $\beta$ was assessed by western blotting in U87MG cells. (NC, cells infected with negative control lentivirus expressing Scr-shRNA; KD, cells infected with OLFML2A-shRNA-1-expressing lentivirus.) 
A

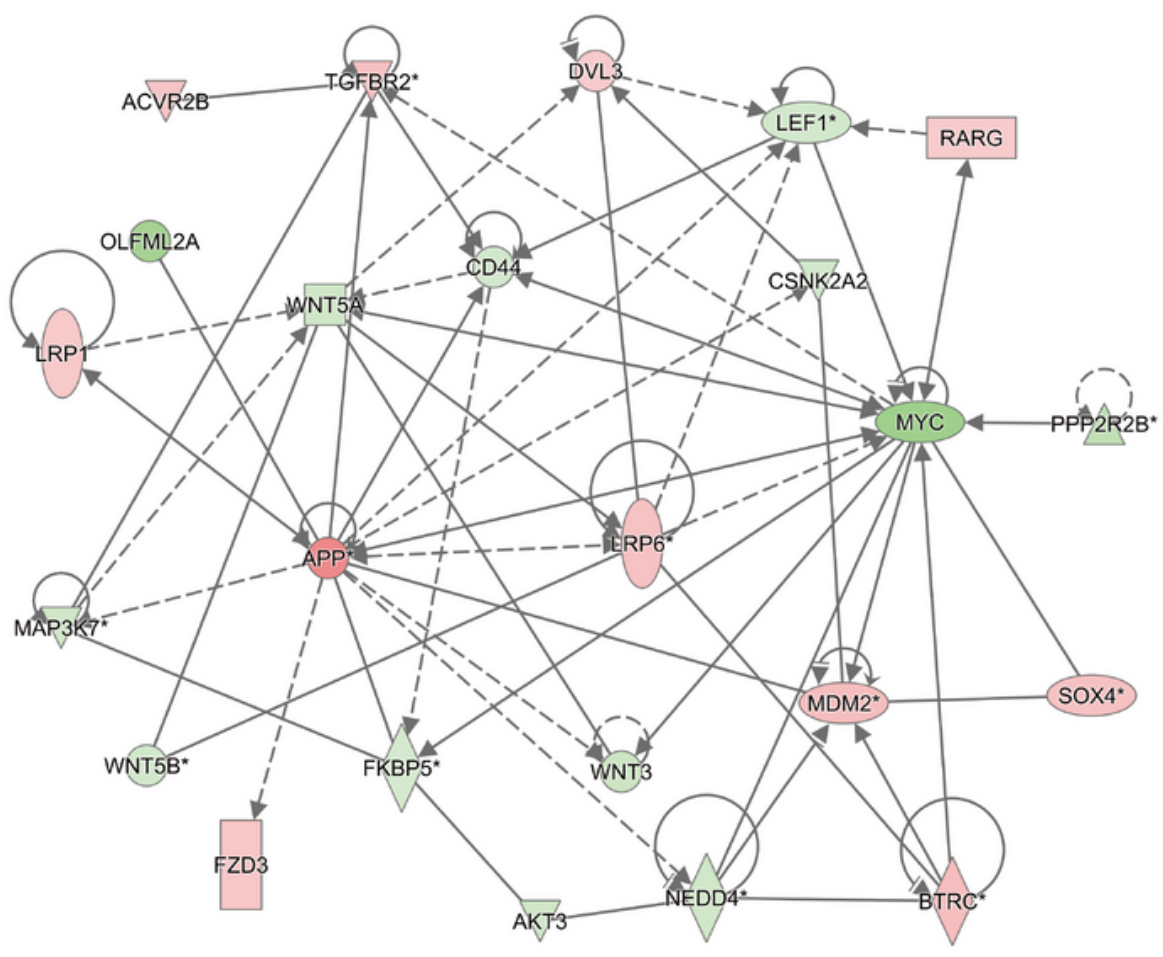

B

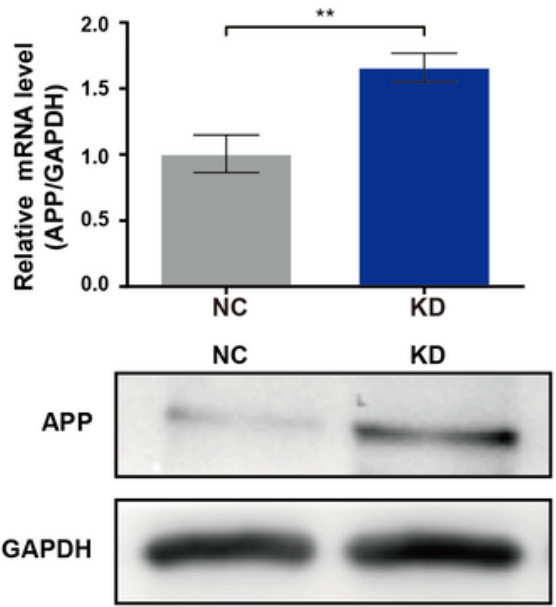

E

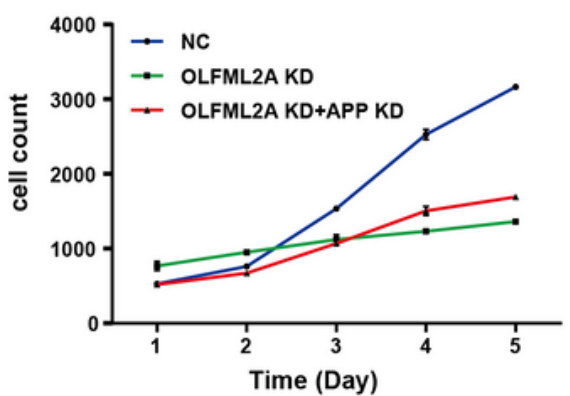

D
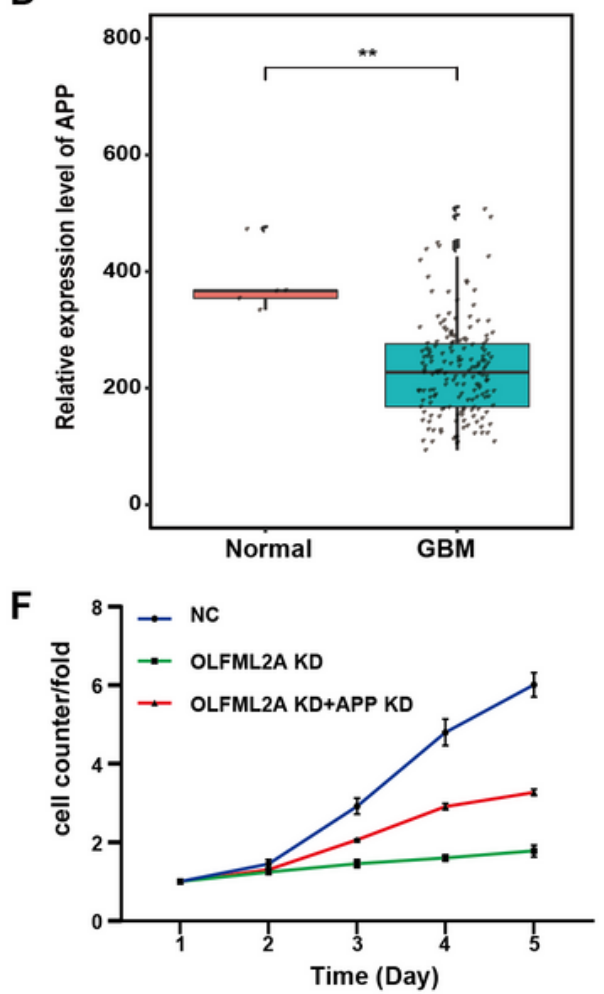

\section{Figure 7}

APP acts as an intermediate molecule to mediate the downstream regulatory effects of OLFML2A in glioma. a. Interaction network analysis by IPA. The interaction network analysis table shows the interactions among molecules in the datasets. b-c. The expression of APP was assessed by quantitative RT-PCR (b) and western blotting (c) in U87MG cells. (NC, cells infected with negative control lentivirus expressing Scr-shRNA; KD, cells infected with OLFML2A-shRNA-1-expressing lentivirus.) d. Expression 
profile of APP mRNA in primary GBM tissues $(n=169)$ and normal brain tissues $(n=5$; Mann-Whitney $U$ test; $\left.{ }^{*} P<0.01 ; T C G A\right)$. e. Cell growth was measured by Celigo assay for five days in U87MG cells. (NC, cells infected with negative control lentivirus expressing Scr-shRNA; OLFML2A KD, cells infected with OLFML2A-shRNA-1-expressing lentivirus; OLFML2A KD+APP KD, cells infected with OLFML2A-shRNA-1 and APP-shRNA lentiviruses.)

A

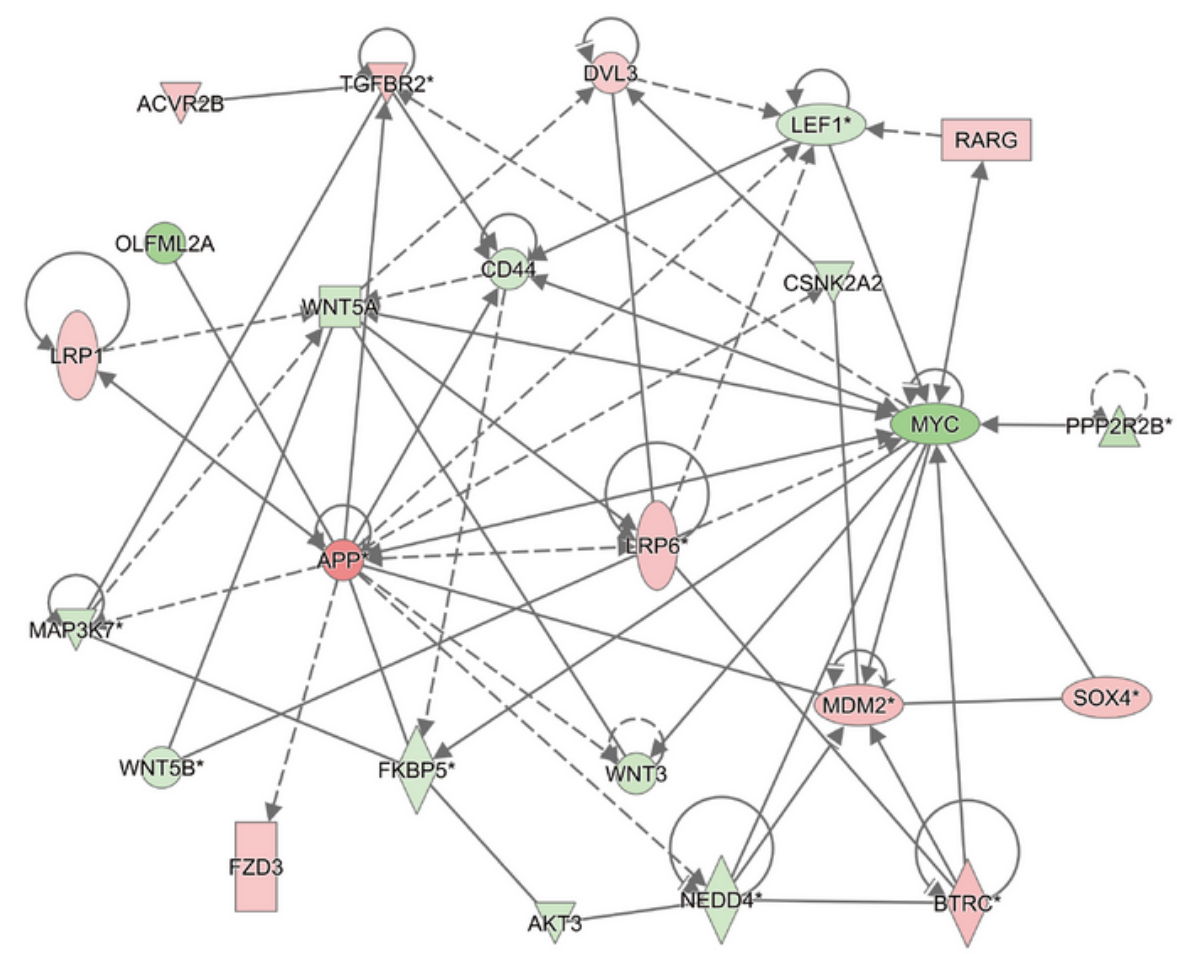

B

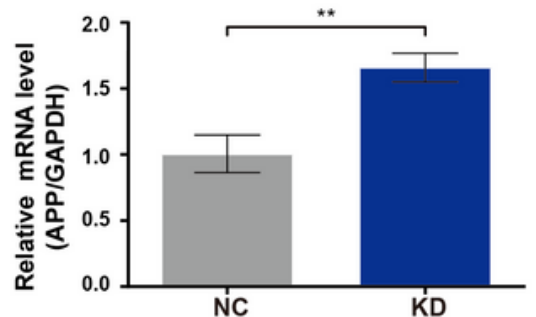

C

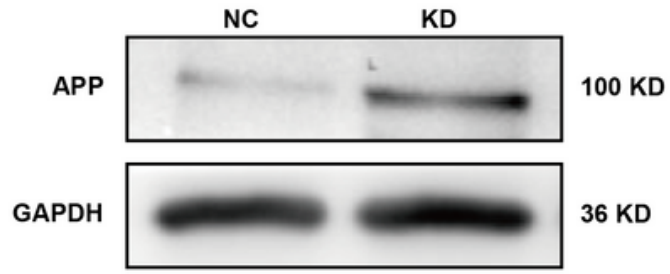

E

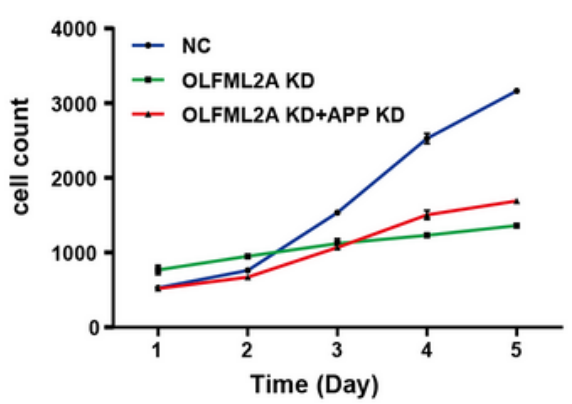

D

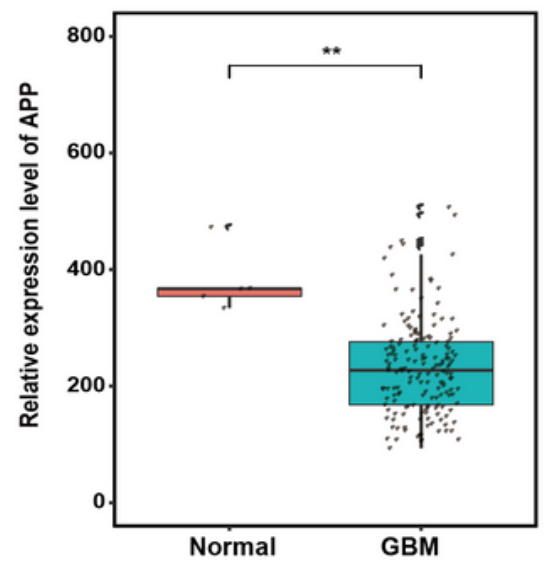

F

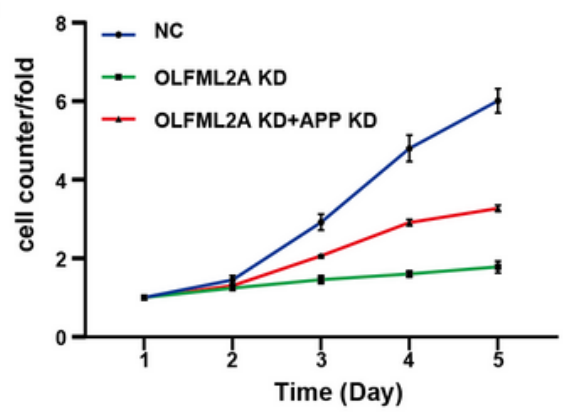

Figure 7 
APP acts as an intermediate molecule to mediate the downstream regulatory effects of OLFML2A in glioma. a. Interaction network analysis by IPA. The interaction network analysis table shows the interactions among molecules in the datasets. b-c. The expression of APP was assessed by quantitative RT-PCR (b) and western blotting (c) in U87MG cells. (NC, cells infected with negative control lentivirus expressing Scr-shRNA; KD, cells infected with OLFML2A-shRNA-1-expressing lentivirus.) d. Expression profile of APP mRNA in primary GBM tissues $(n=169)$ and normal brain tissues $(n=5$; Mann-Whitney $U$ test; ${ }^{*} \mathrm{P}<0.01 ; \mathrm{TCGA}$ ). e. Cell growth was measured by Celigo assay for five days in U87MG cells. (NC, cells infected with negative control lentivirus expressing Scr-shRNA; OLFML2A KD, cells infected with OLFML2A-shRNA-1-expressing lentivirus; OLFML2A KD+APP KD, cells infected with OLFML2A-shRNA-1 and APP-shRNA lentiviruses.) 
A

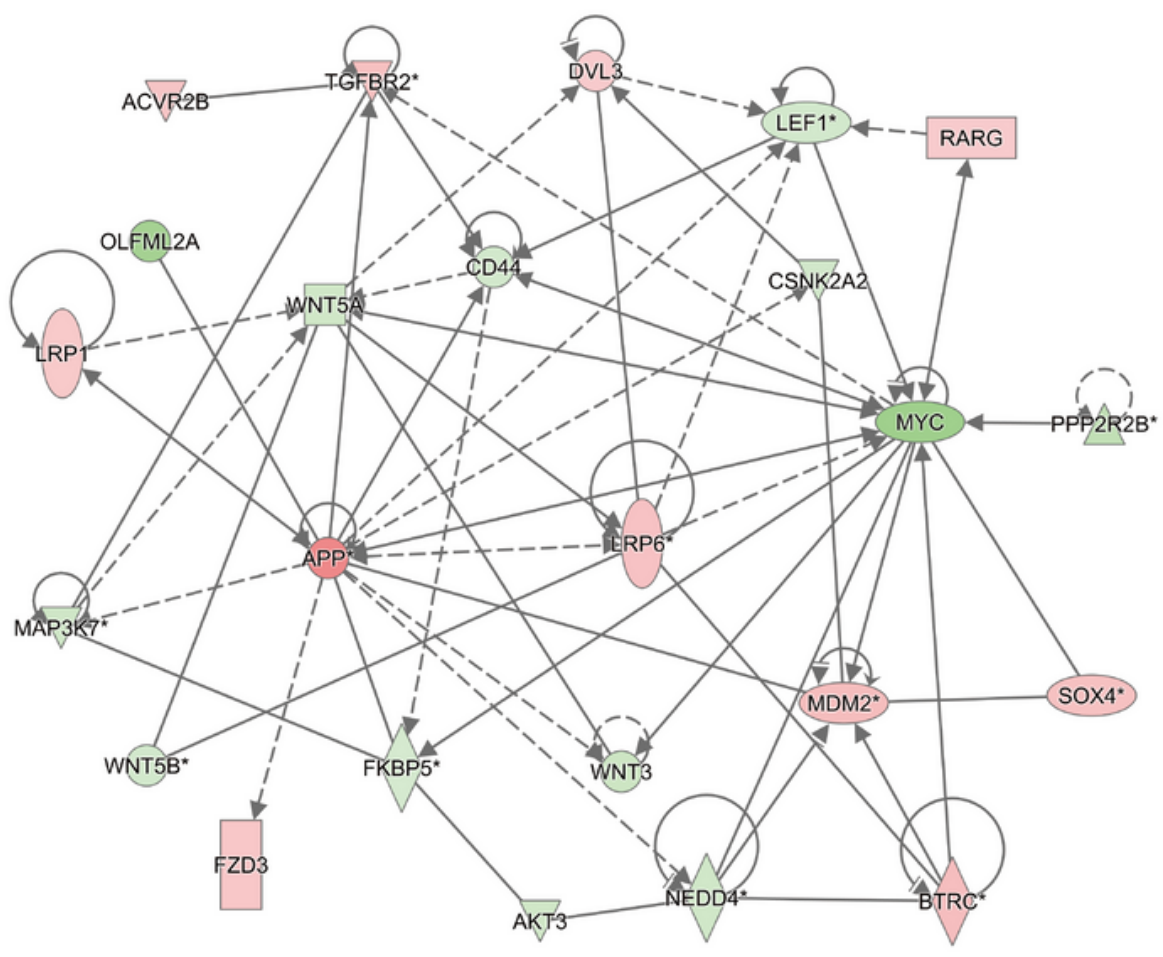

B

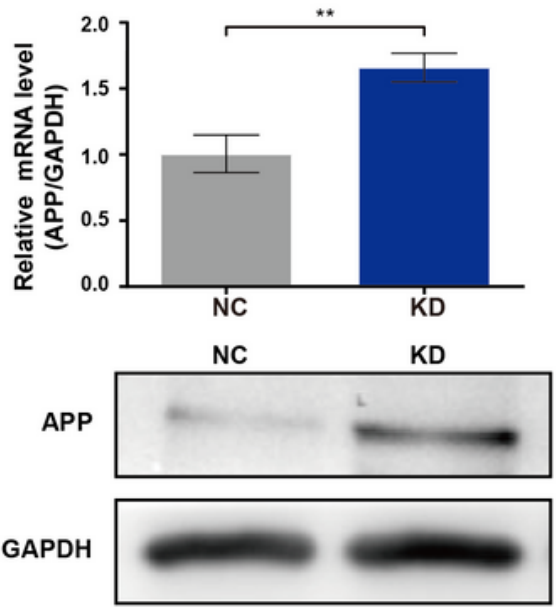

E

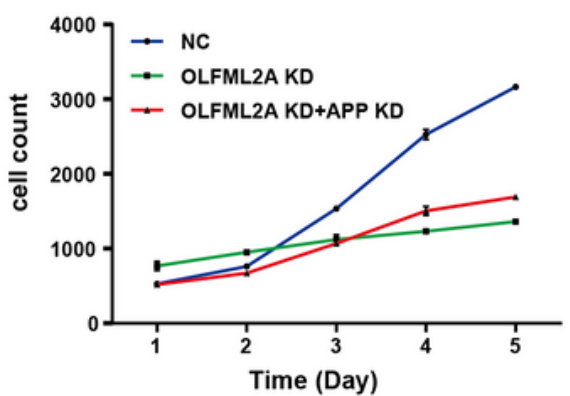

D
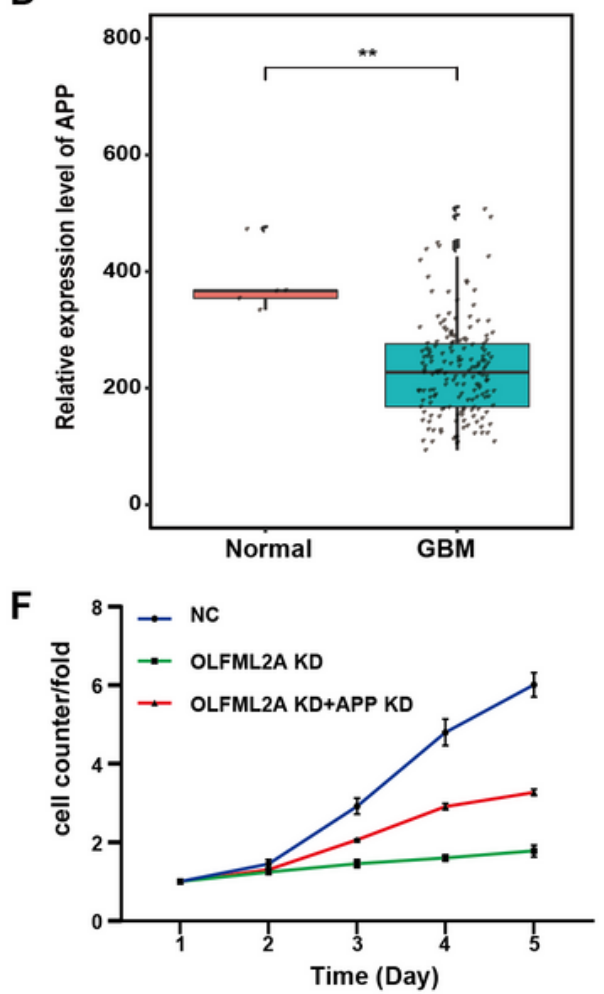

\section{Figure 7}

APP acts as an intermediate molecule to mediate the downstream regulatory effects of OLFML2A in glioma. a. Interaction network analysis by IPA. The interaction network analysis table shows the interactions among molecules in the datasets. b-c. The expression of APP was assessed by quantitative RT-PCR (b) and western blotting (c) in U87MG cells. (NC, cells infected with negative control lentivirus expressing Scr-shRNA; KD, cells infected with OLFML2A-shRNA-1-expressing lentivirus.) d. Expression 
profile of APP mRNA in primary GBM tissues $(n=169)$ and normal brain tissues $(n=5$; Mann-Whitney $U$ test; $\left.{ }^{*} P<0.01 ; T C G A\right)$. e. Cell growth was measured by Celigo assay for five days in U87MG cells. (NC, cells infected with negative control lentivirus expressing Scr-shRNA; OLFML2A KD, cells infected with OLFML2A-shRNA-1-expressing lentivirus; OLFML2A KD+APP KD, cells infected with OLFML2A-shRNA-1 and APP-shRNA lentiviruses.)

A

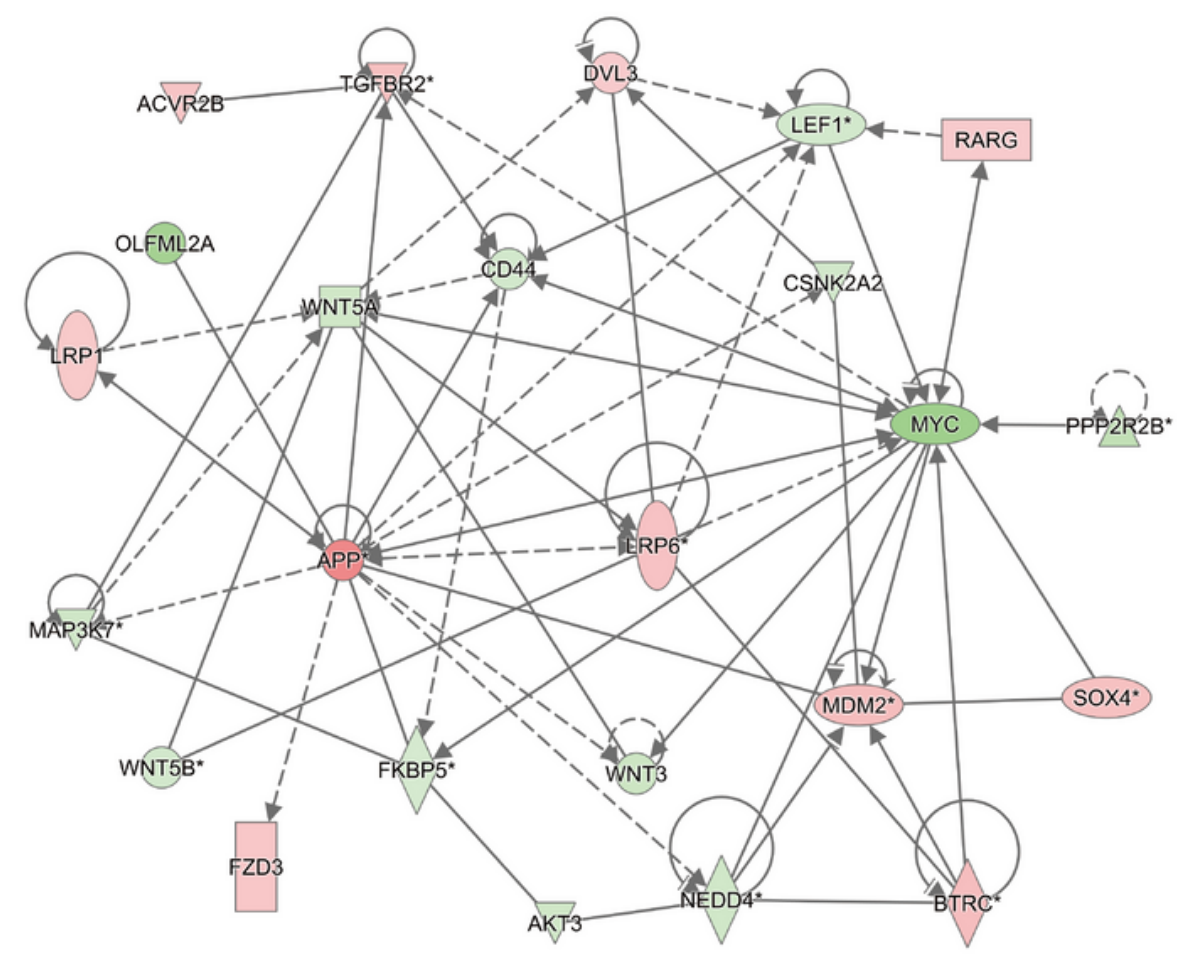

B

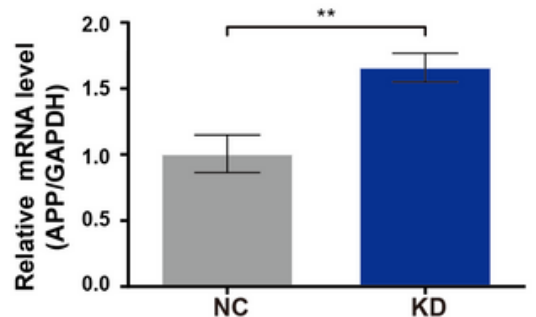

C

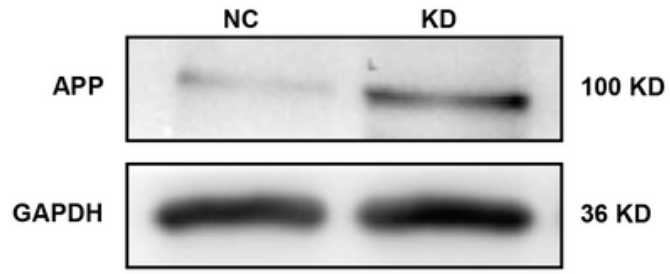

E

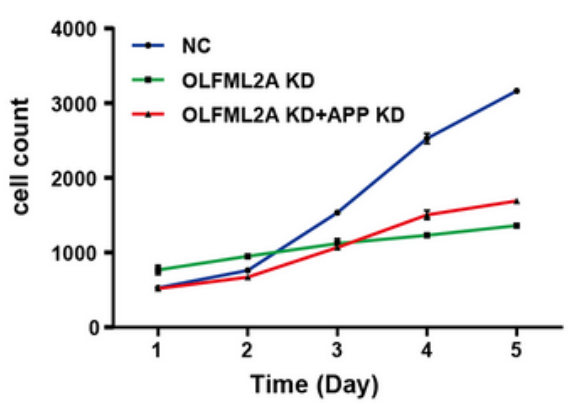

D
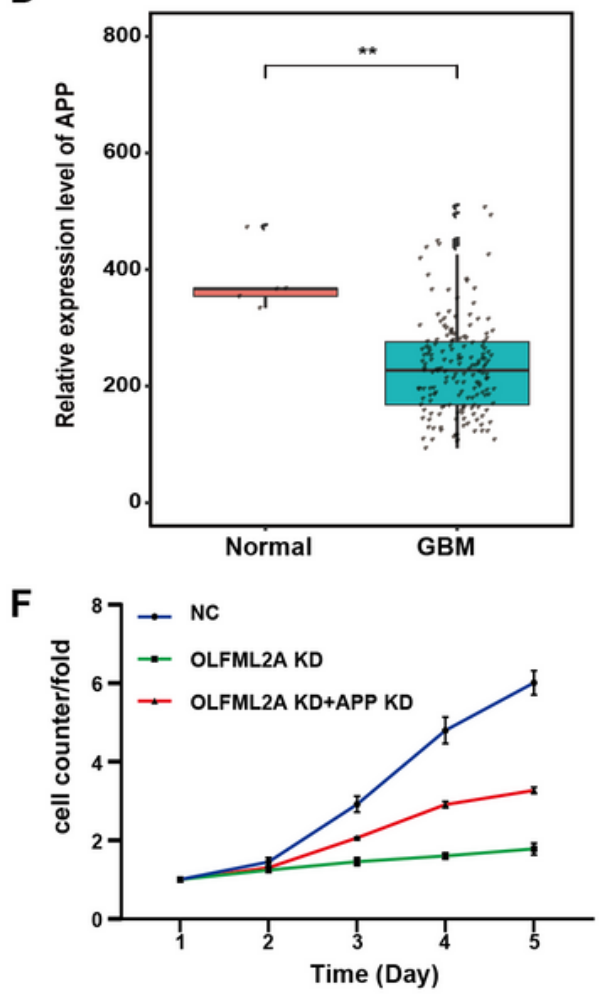

Figure 7 
APP acts as an intermediate molecule to mediate the downstream regulatory effects of OLFML2A in glioma. a. Interaction network analysis by IPA. The interaction network analysis table shows the interactions among molecules in the datasets. b-c. The expression of APP was assessed by quantitative RT-PCR (b) and western blotting (c) in U87MG cells. (NC, cells infected with negative control lentivirus expressing Scr-shRNA; KD, cells infected with OLFML2A-shRNA-1-expressing lentivirus.) d. Expression profile of APP mRNA in primary GBM tissues $(n=169)$ and normal brain tissues $(n=5$; Mann-Whitney $U$ test; ${ }^{*} \mathrm{P}<0.01 ; \mathrm{TCGA}$ ). e. Cell growth was measured by Celigo assay for five days in U87MG cells. (NC, cells infected with negative control lentivirus expressing Scr-shRNA; OLFML2A KD, cells infected with OLFML2A-shRNA-1-expressing lentivirus; OLFML2A KD+APP KD, cells infected with OLFML2A-shRNA-1 and APP-shRNA lentiviruses.) 


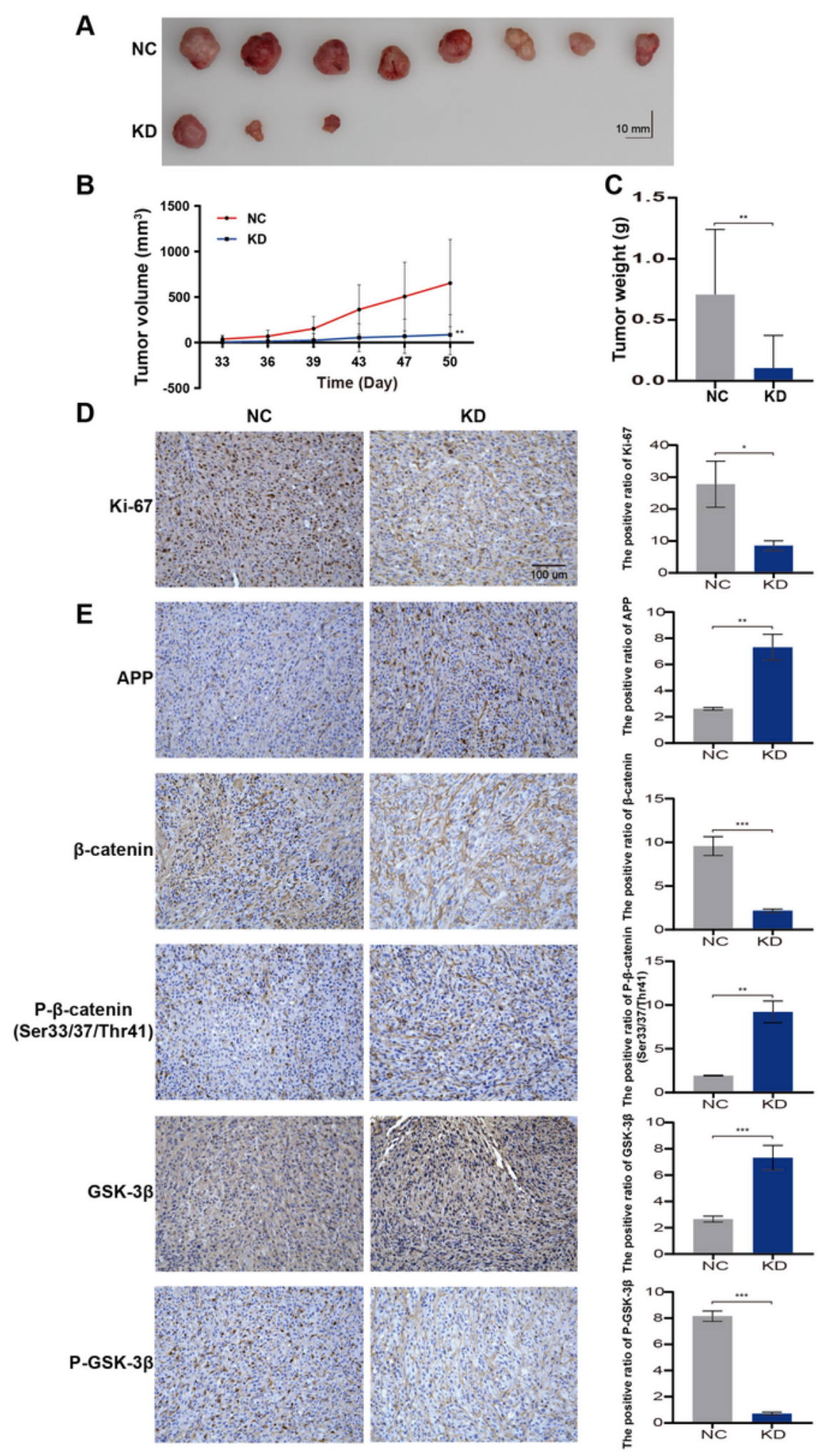

\section{Figure 8}

Downregulation of OLFML2A led to the repression of glioma cell proliferation and inhibition of the Wnt/ $\beta$ catenin signaling pathway in a xenograft implantation model. a-c. Subcutaneously transplanted gliomas were utilized to analyze the effect of OLFML2A on glioma in vivo, and tumor values were measured every 3-4 days. d. Representative IHC images of Ki67 expression in 2 groups of subcutaneous glioma tissues; 
scale bar $=100 \mu \mathrm{m}$. e. The expression of APP, p33/37/41- $\beta$-catenin, $\beta$-catenin, GSK-3 $\beta$ and P-GSK-3 $\beta$ in 2 groups of subcutaneous glioma tissues was detected by IHC. ${ }^{*} \mathrm{P}<0.05$, ** $\mathrm{P}<0.01$, ***P $<0.001$.

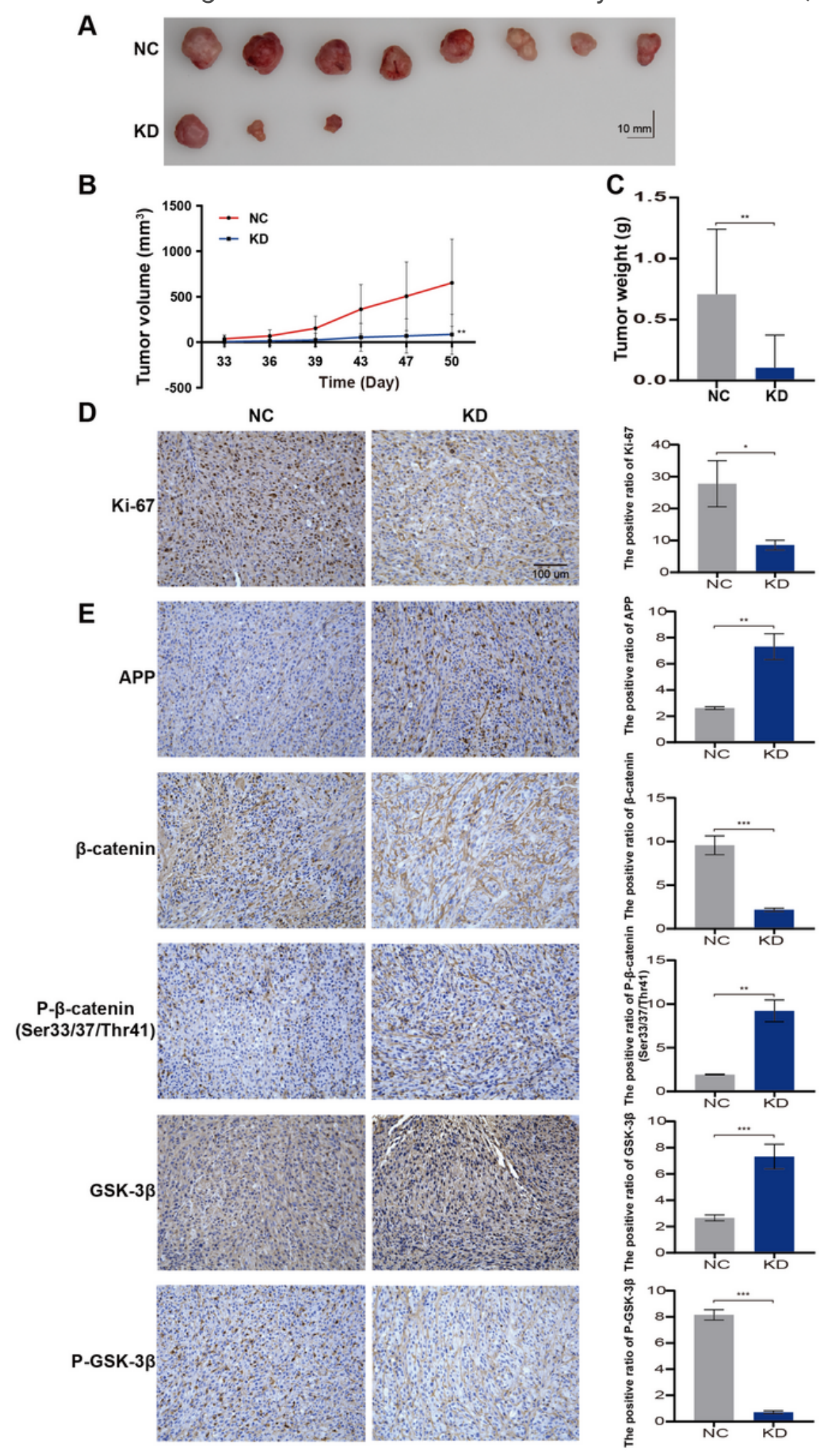

Figure 8

Downregulation of OLFML2A led to the repression of glioma cell proliferation and inhibition of the Wnt/ $\beta$ catenin signaling pathway in a xenograft implantation model. a-c. Subcutaneously transplanted gliomas were utilized to analyze the effect of OLFML2A on glioma in vivo, and tumor values were measured every 
3-4 days. d. Representative IHC images of Ki67 expression in 2 groups of subcutaneous glioma tissues; scale bar $=100 \mu \mathrm{m}$. e. The expression of APP, $p 33 / 37 / 41-\beta$-catenin, $\beta$-catenin, GSK-3 $\beta$ and P-GSK-3 $\beta$ in 2 groups of subcutaneous glioma tissues was detected by IHC. ${ }^{*} \mathrm{P}<0.05$, ${ }^{* *} \mathrm{P}<0.01$, ${ }^{* \star *} \mathrm{P}<0.001$.

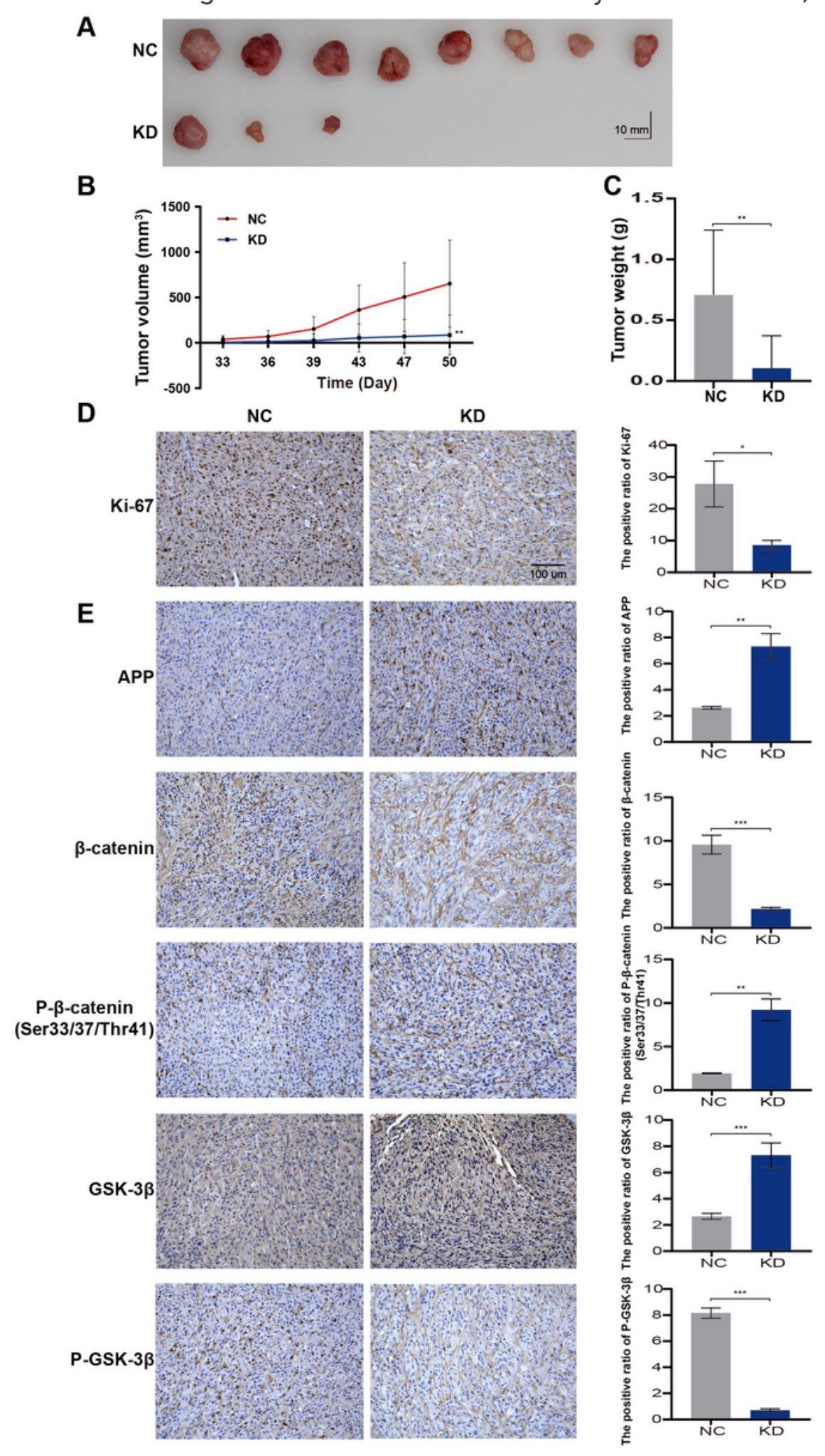

Figure 8

Downregulation of OLFML2A led to the repression of glioma cell proliferation and inhibition of the Wnt/ $\beta$ catenin signaling pathway in a xenograft implantation model. a-c. Subcutaneously transplanted gliomas 
were utilized to analyze the effect of OLFML2A on glioma in vivo, and tumor values were measured every 3-4 days. d. Representative IHC images of Ki67 expression in 2 groups of subcutaneous glioma tissues; scale bar $=100 \mu \mathrm{m}$. e. The expression of APP, p33/37/41- $\beta$-catenin, $\beta$-catenin, GSK-3 $\beta$ and P-GSK-3 $\beta$ in 2 groups of subcutaneous glioma tissues was detected by IHC. ${ }^{*} P<0.05$, ** $P<0.01$, ***P $<0.001$.

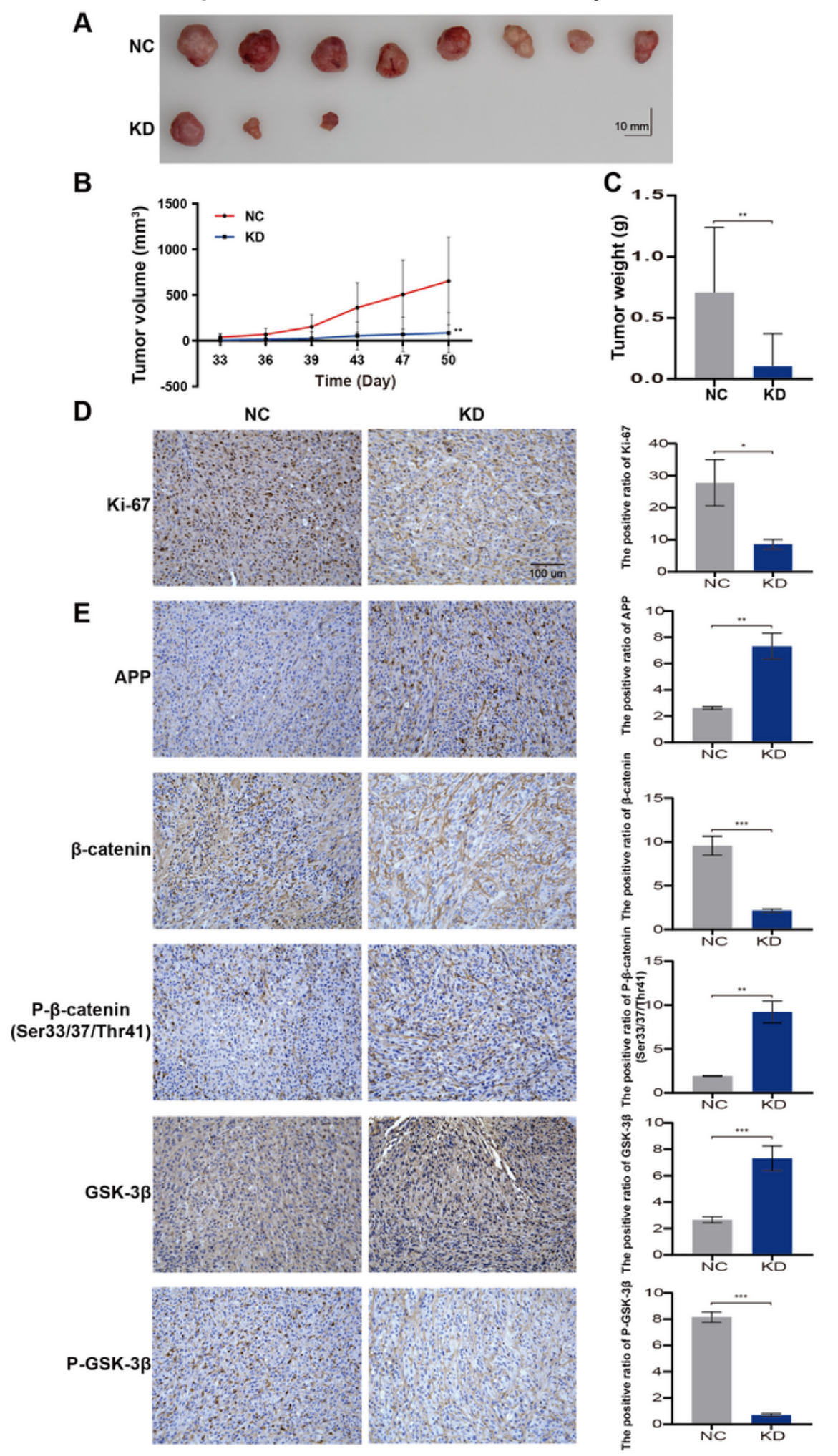

Figure 8 
Downregulation of OLFML2A led to the repression of glioma cell proliferation and inhibition of the Wnt/ $\beta$ catenin signaling pathway in a xenograft implantation model. a-c. Subcutaneously transplanted gliomas were utilized to analyze the effect of OLFML2A on glioma in vivo, and tumor values were measured every 3-4 days. d. Representative IHC images of Ki67 expression in 2 groups of subcutaneous glioma tissues; scale bar $=100 \mu \mathrm{m}$. e. The expression of APP, p33/37/41- $\beta$-catenin, $\beta$-catenin, GSK-3 $\beta$ and P-GSK-3 $\beta$ in 2 groups of subcutaneous glioma tissues was detected by IHC. ${ }^{*} P<0.05$, $* * P<0.01$, $* * * P<0.001$.

A

NC

KD
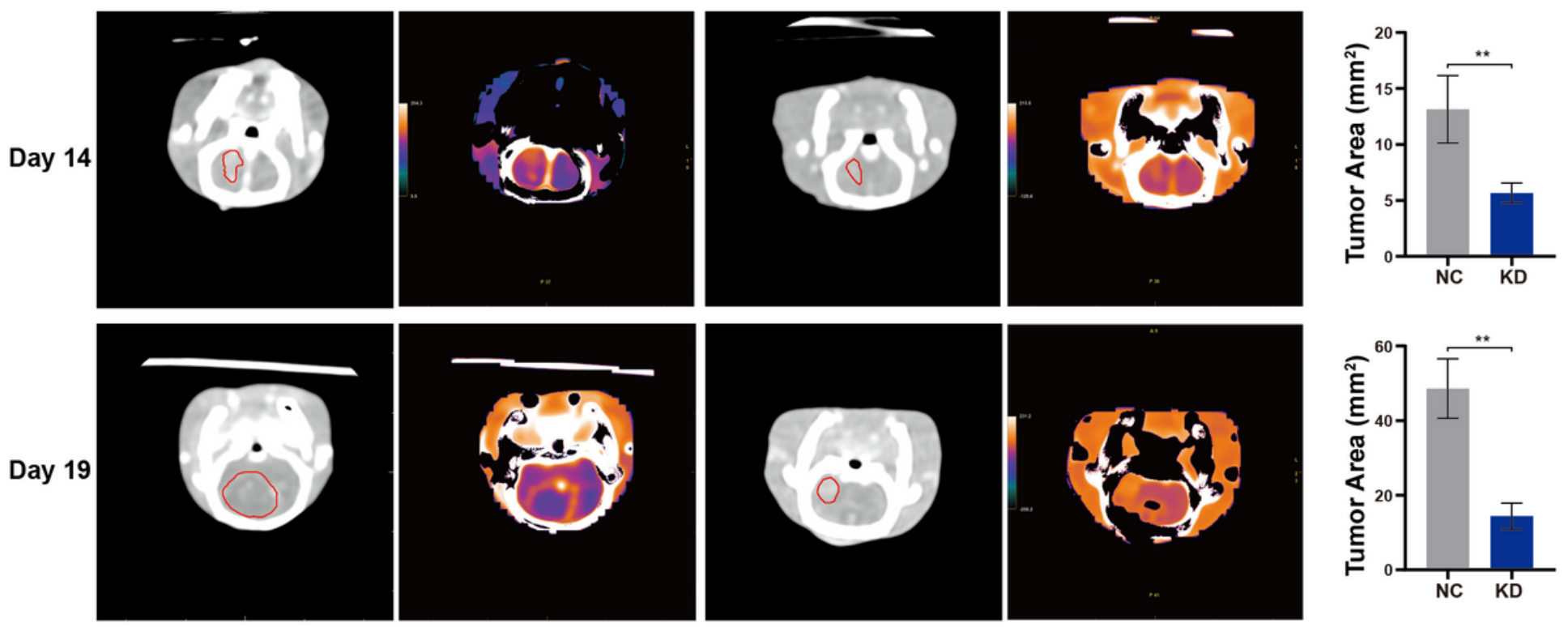

B

NC

KD

NC
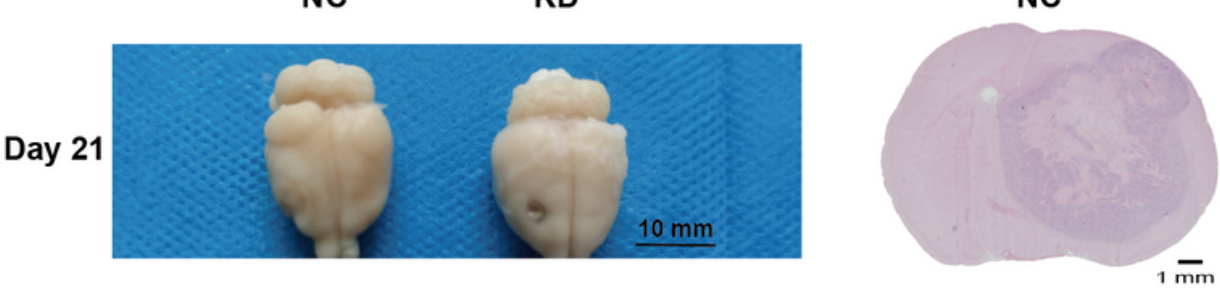

KD
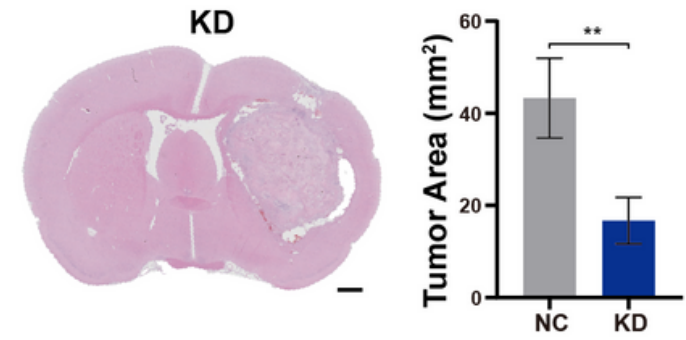

C

NC

KD
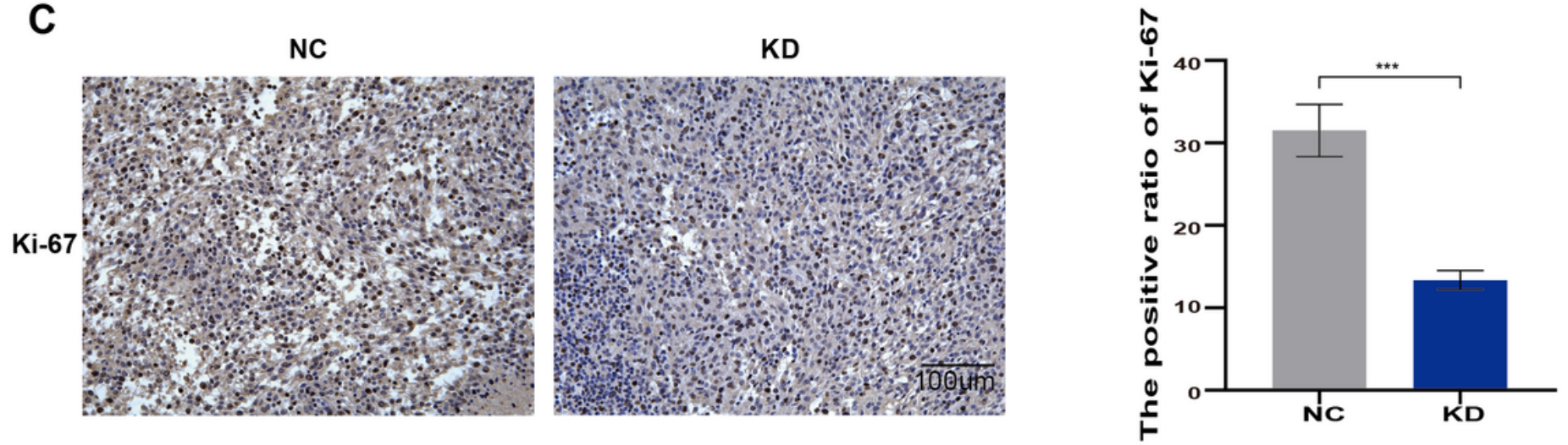

Figure 9 
Knockdown of OLFML2A inhibits cell growth and proliferation in an orthotropic model. a. Intracranial xenografts of gliomas were established with $\mathrm{C} 6$ cells after downregulation of OLFML2A, and representative spectral computed tomography images showed the tumor size at 14 days and 19 days after transplantation in each group. b. Representative gross image of glioma after dissection from mice in each group at 21 days. c. IHC staining of $\mathrm{Ki}-67$ showed the proliferation state of transplanted glioma. Scale bar $=100 \mu \mathrm{m} .{ }^{* * \mathrm{P}}<0.01 \mathbb{1}^{*} * * \mathrm{P}<0.001$.

A

NC

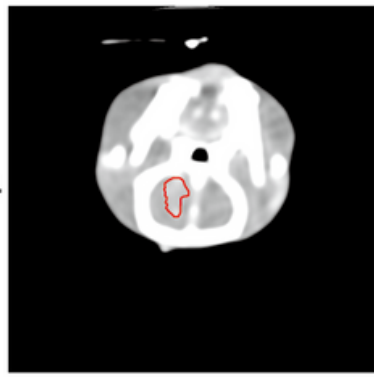

Day 14

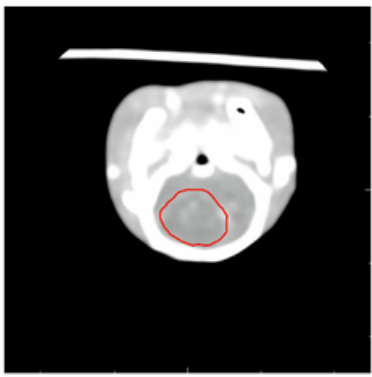

B

NC

KD

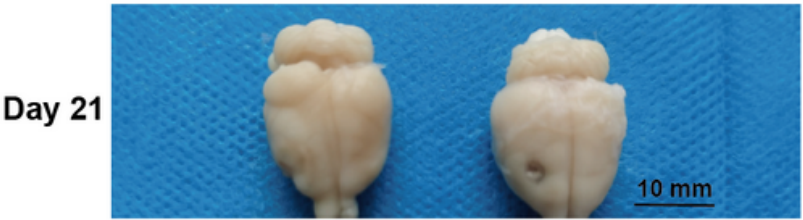

C

NC
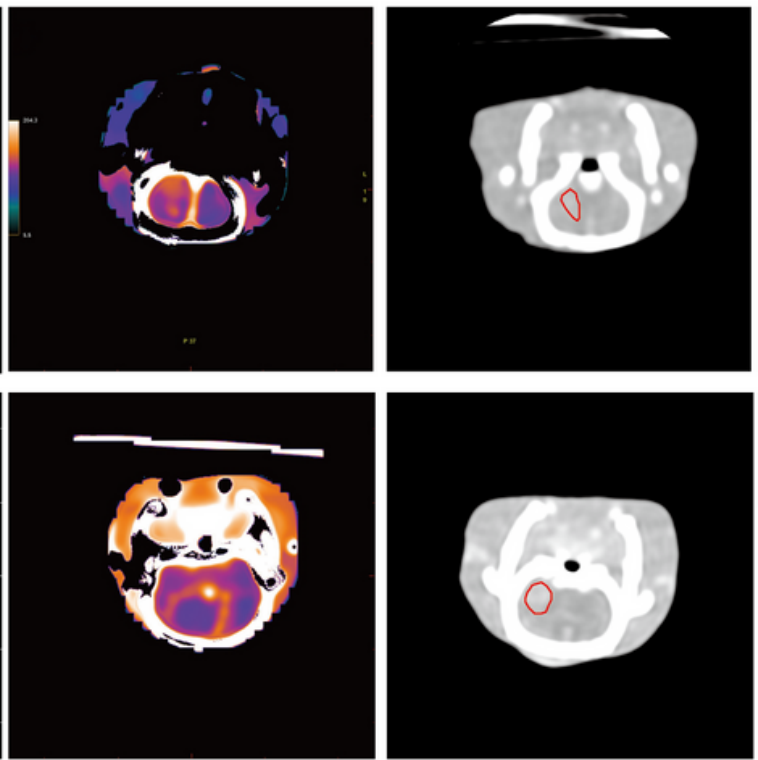

NC

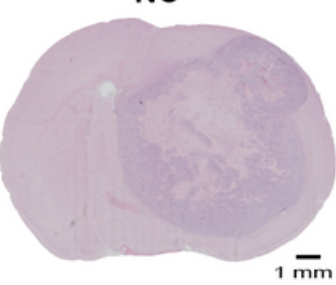

KD

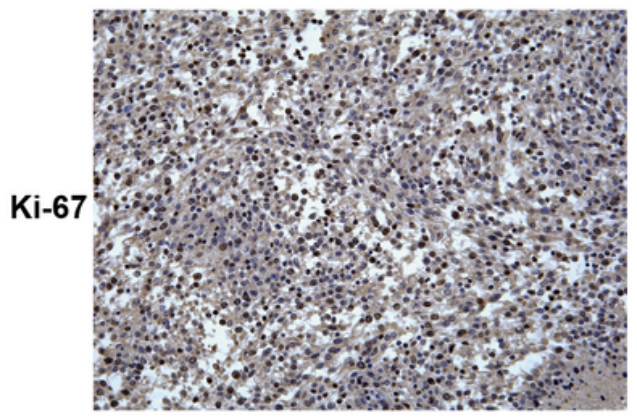

KD
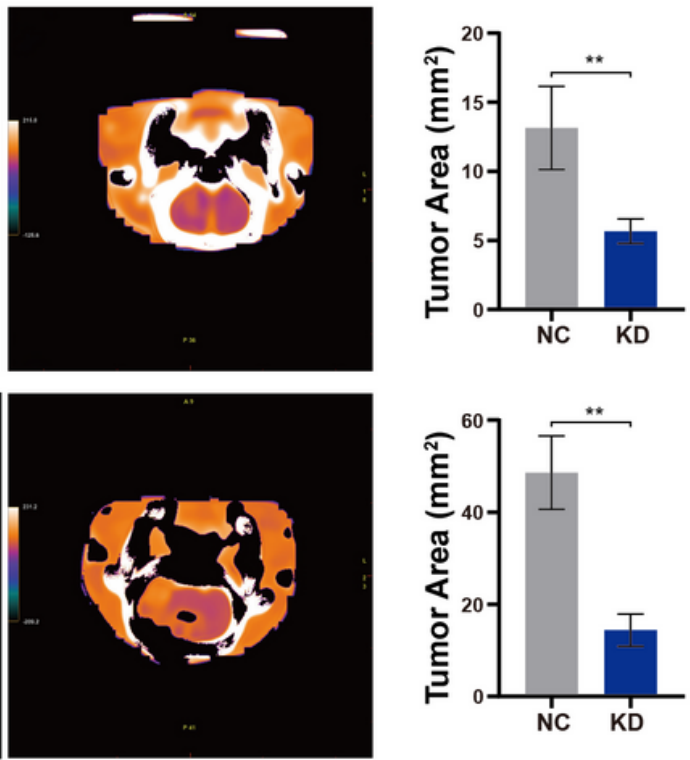

KD
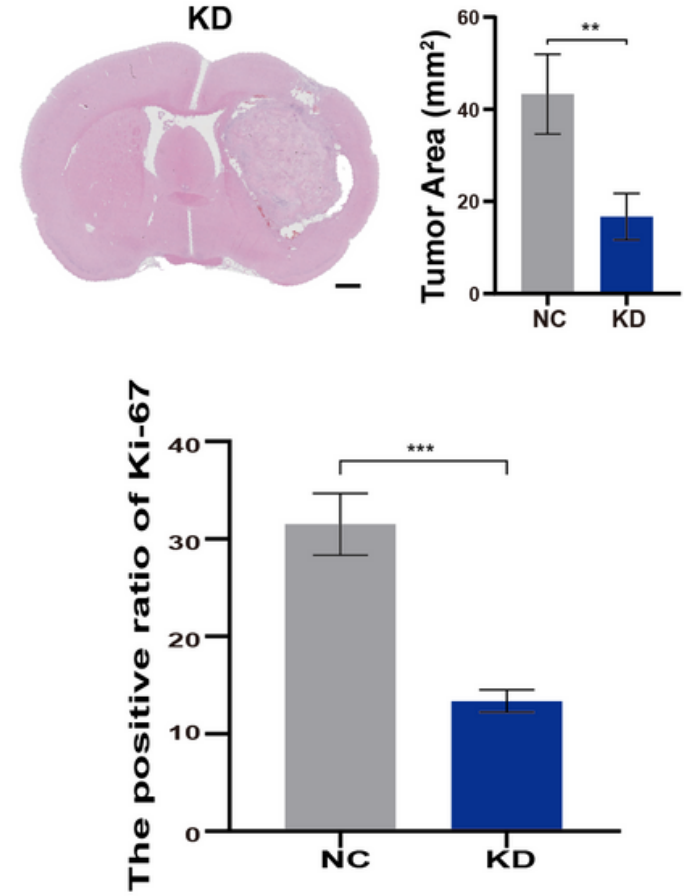

Figure 9 
Knockdown of OLFML2A inhibits cell growth and proliferation in an orthotropic model. a. Intracranial xenografts of gliomas were established with $\mathrm{C} 6$ cells after downregulation of OLFML2A, and representative spectral computed tomography images showed the tumor size at 14 days and 19 days after transplantation in each group. b. Representative gross image of glioma after dissection from mice in each group at 21 days. c. IHC staining of $\mathrm{Ki}-67$ showed the proliferation state of transplanted glioma. Scale bar $=100 \mu \mathrm{m} .{ }^{* * \mathrm{P}}<0.01 \mathbb{1}^{*} * * \mathrm{P}<0.001$.

A

NC

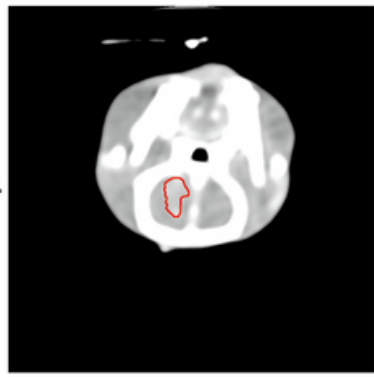

Day 14

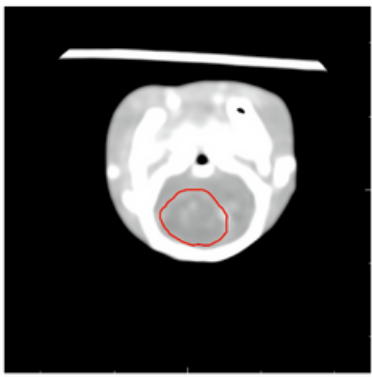

B

NC

KD

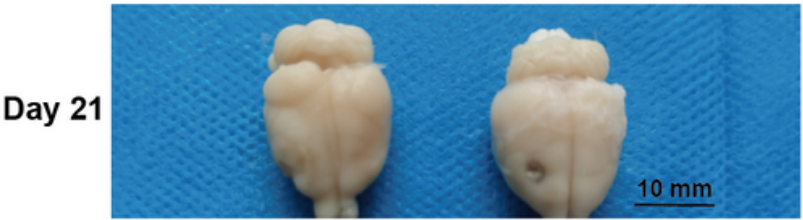

C

NC
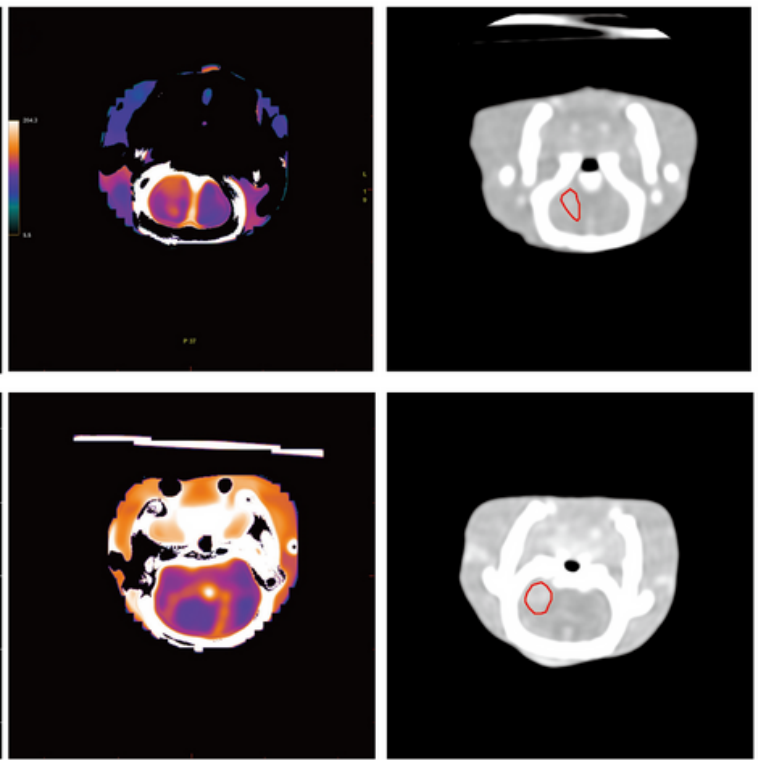

NC

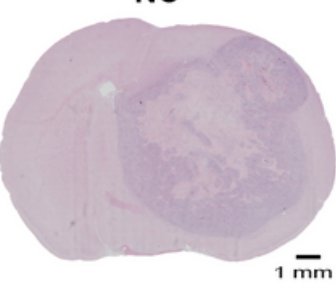

KD

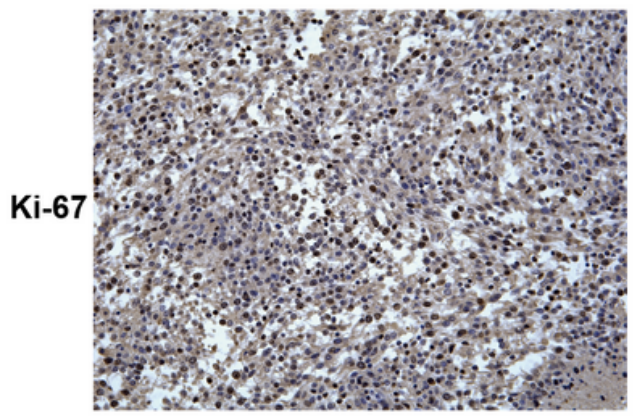

KD
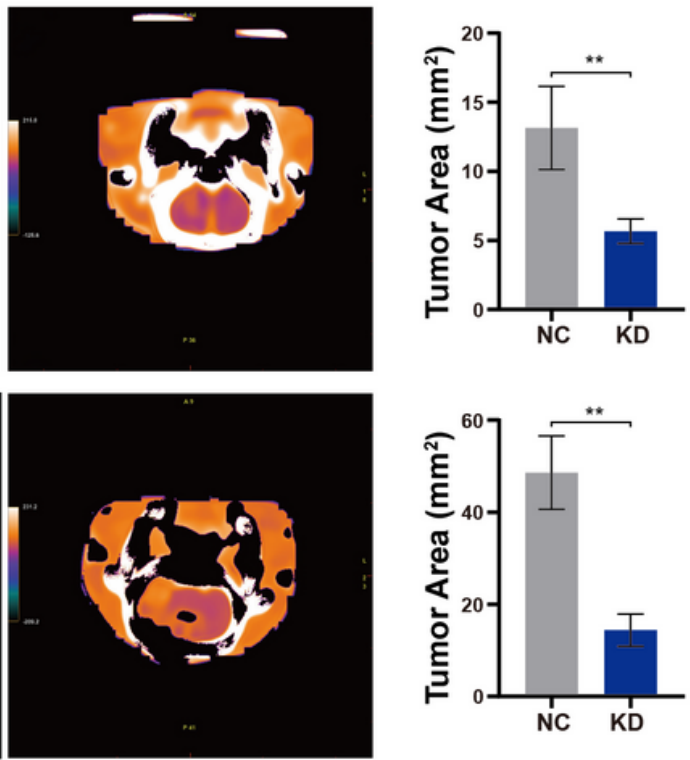

KD
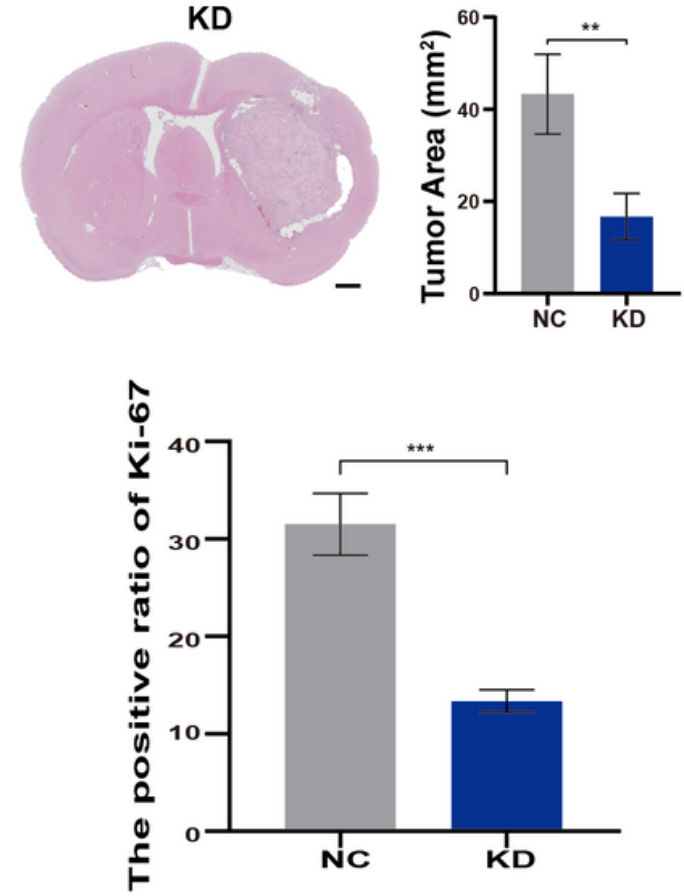

Figure 9 
Knockdown of OLFML2A inhibits cell growth and proliferation in an orthotropic model. a. Intracranial xenografts of gliomas were established with $\mathrm{C} 6$ cells after downregulation of OLFML2A, and representative spectral computed tomography images showed the tumor size at 14 days and 19 days after transplantation in each group. b. Representative gross image of glioma after dissection from mice in each group at 21 days. c. IHC staining of $\mathrm{Ki}-67$ showed the proliferation state of transplanted glioma. Scale bar $=100 \mu \mathrm{m} .{ }^{* * \mathrm{P}}<0.01 \mathbb{1}^{*} * * \mathrm{P}<0.001$.

A

NC

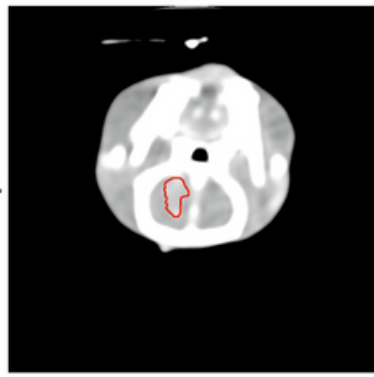

Day 14

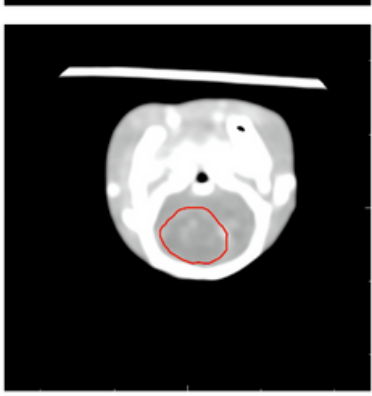

B

NC

KD

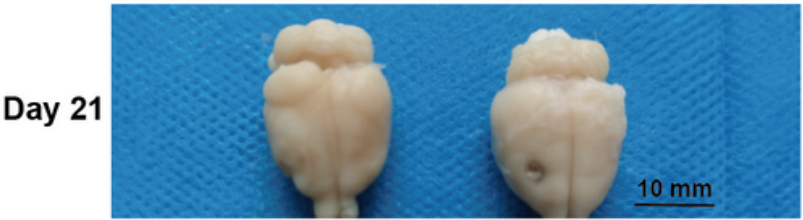

C

NC
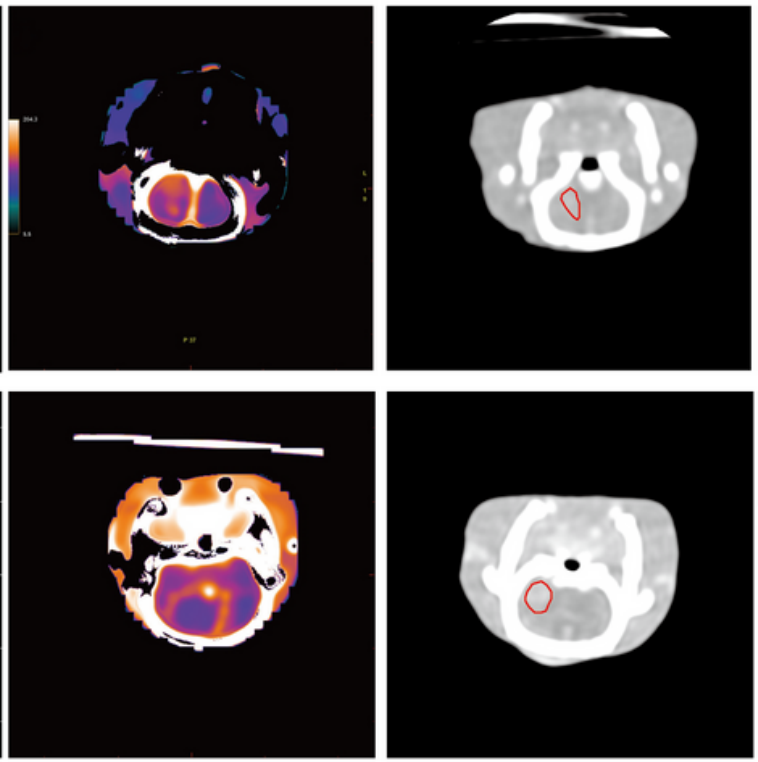

NC

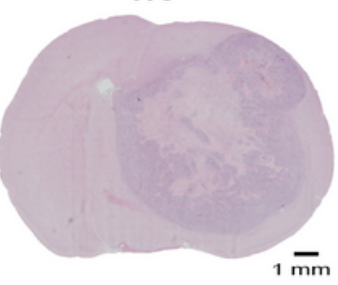

KD

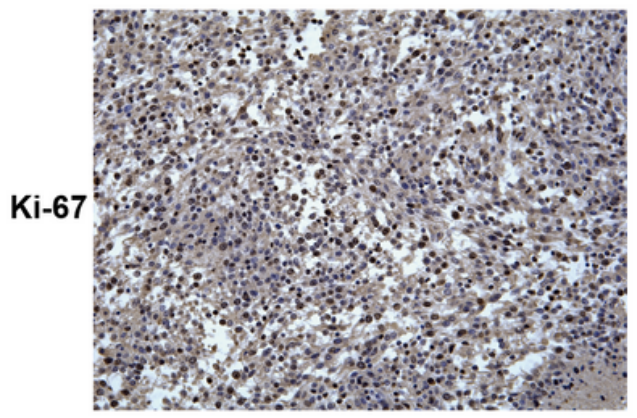

KD
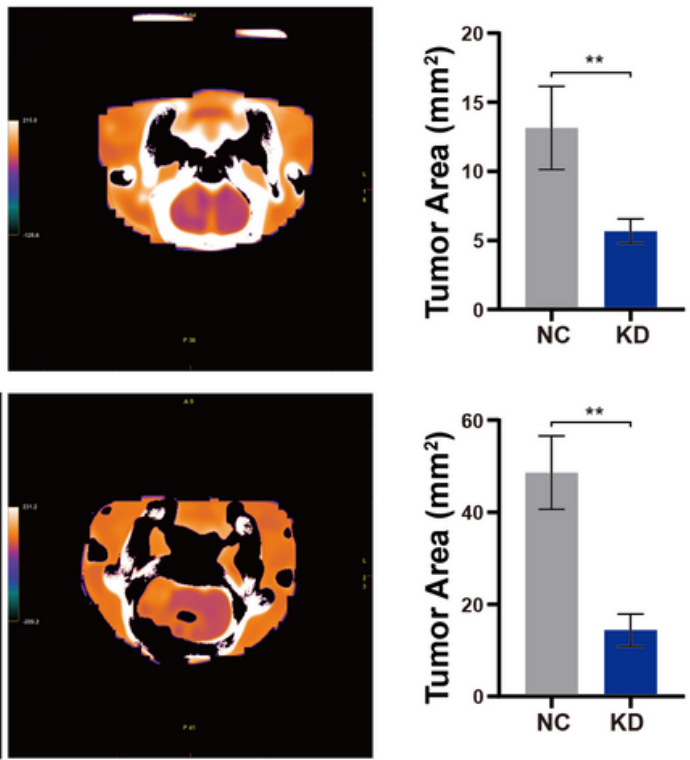

KD
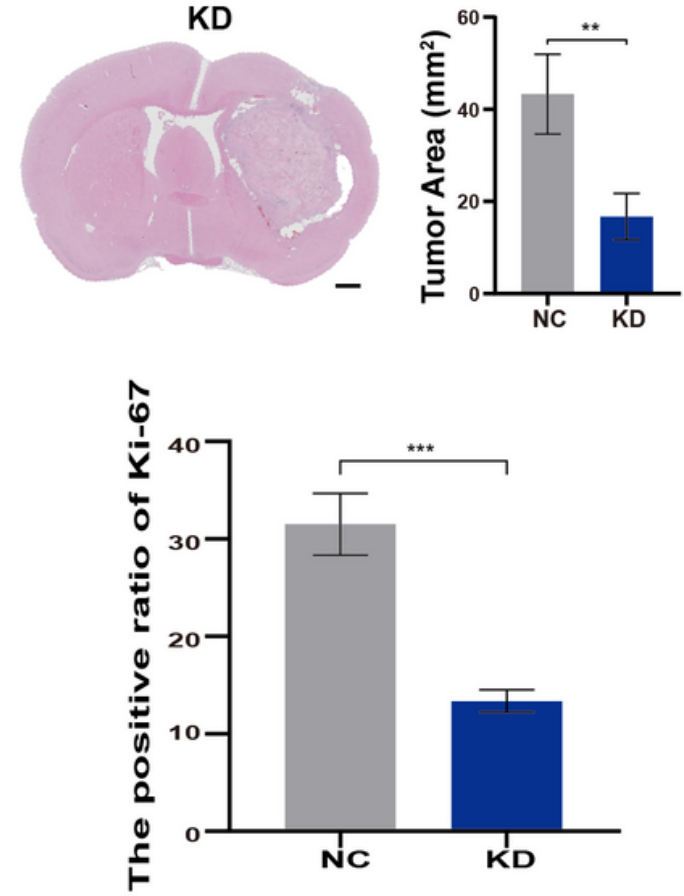

Figure 9 
Knockdown of OLFML2A inhibits cell growth and proliferation in an orthotropic model. a. Intracranial xenografts of gliomas were established with $\mathrm{C} 6$ cells after downregulation of OLFML2A, and representative spectral computed tomography images showed the tumor size at 14 days and 19 days after transplantation in each group. b. Representative gross image of glioma after dissection from mice in each group at 21 days. c. IHC staining of $\mathrm{Ki}-67$ showed the proliferation state of transplanted glioma. Scale bar $=100 \mu \mathrm{m} .{ }^{*} \mathrm{P}<0.01 \mathbb{1}^{\star * * *} \mathrm{P}<0.001$.

\section{Supplementary Files}

This is a list of supplementary files associated with this preprint. Click to download.

- SupplementaryDocument1DiffGene.xlsx

- SupplementaryDocument1DiffGene.xlsx

- SupplementaryDocument1DiffGene.xIsx

- SupplementaryDocument1DiffGene.xlsx

- SupplementaryDocument2Heatmap.pdf

- SupplementaryDocument2Heatmap.pdf

- SupplementaryDocument2Heatmap.pdf

- SupplementaryDocument2Heatmap.pdf

- SupplementaryDocument3CanonicalPathways.xlsx.xlsx

- SupplementaryDocument3CanonicalPathways.xlsx.xlsx

- SupplementaryDocument3CanonicalPathways.xlsx.xlsx

- SupplementaryDocument3CanonicalPathways.xIsx.xIsx 